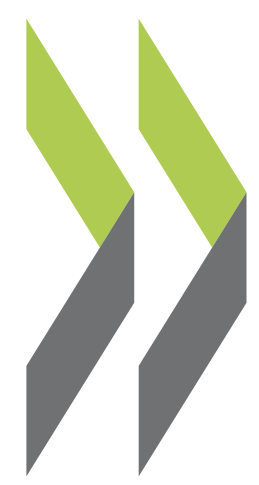

OECD Economics Department Working Papers No. 1384

A revised approach to trend employment projections in long-term scenarios

Maria Chiara Cavalleri, Yvan Guillemette 
Organisation de Coopération et de Développement Économiques

Organisation for Economic Co-operation and Development

16-May-2017

ECONOMICS DEPARTMENT

English - Or. English

\section{A REVISED APPROACH TO TREND EMPLOYMENT PROJECTIONS IN LONG-TERM SCENARIOS}

ECONOMICS DEPARMENT WORKING PAPERS No. 1384

By Maria Chiara Cavalleri and Yvan Guillemette

OECD Working Papers should not be reported as representing the official views of the OECD or of its member countries. The opinions expressed and arguments employed are those of the author(s).

Authorised for publication by Christian Kastrop, Director, Policy Studies Branch, Economics Department.

All Economics Department Working Papers are available at www.oecd.org/eco/workingpapers

JT03414224

Complete document available on OLIS in its original format

This document, as well as any data and map included herein, are without prejudice to the status of or sovereignty over any territory, to the delimitation of international frontiers and boundaries and to the name of any territory, city or area. 
OECD Working Papers should not be reported as representing the official views of the OECD or of its member countries. The opinions expressed and arguments employed are those of the author(s).

Working Papers describe preliminary results or research in progress by the author(s) and are published to stimulate discussion on a broad range of issues on which the OECD works.

Comments on Working Papers are welcomed, and may be sent to OECD Economics Department, 2 rue André Pascal, 75775 Paris Cedex 16, France, or by e-mail to eco.contact@oecd.org.

All Economics Department Working Papers are available at www.oecd.org/eco/workingpapers.

This document and any map included herein are without prejudice to the status of or sovereignty over any territory, to the delimitation of international frontiers and boundaries and to the name of any territory, city or area.

The statistical data for Israel are supplied by and under the responsibility of the relevant Israeli authorities. The use of such data by the OECD is without prejudice to the status of the Golan Heights, East Jerusalem and Israeli settlements in the West Bank under the terms of international law.

\section{(C) OECD (2017)}

You can copy, download or print OECD content for your own use, and you can include excerpts from OECD publications, databases and multimedia products in your own documents, presentations, blogs, websites and teaching materials, provided that suitable acknowledgment of OECD as source and copyright owner is given. All requests for commercial use and translation rights should be submitted to rights@oecd.org 
ECO/WKP(2017)16

\section{ABSTRACT/RÉSUMÉ \\ A revised approach to trend employment projections in long-term scenarios}

The paper describes revisions to the trend employment component of the production function underpinning long-term economic scenarios. Starting with historical age and sex-specific employment rates, a novel approach is developed to correct for cyclical effects using the country-level employment gap while allowing the different sex and age groups to exhibit different sensitivities to the economic cycle. From the resulting cyclically adjusted age/sex-specific employment rates, trend entry and exit rates into/out of employment are computed using the traditional cohort approach. The different employment propensities of existing cohorts are then used to project future employment rates, with entry and exit rates of new cohorts assumed to mimic the most recent ones. To construct scenarios, the model allows a number of policy settings to influence employment rate projections, notably the legal retirement age, tax wedges, family benefits, etc. The sizes of these effects are sourced from recent OECD work on the quantification of structural reforms, and are also specific to sex and age groups. The trend total employment projection is obtained by aggregating age/sex-specific employment rate projections using external demographic projections.

JEL classification codes: E24, E27, J21, C53

Keywords: Trend employment, potential employment, projections, cyclical adjustment, cohort model, employment gap, long-term model, long-term scenarios

$* * * * * * * * * * *$

\section{Une approche révisée pour les projections d'emploi tendanciel dans les scénarios à long terme}

L'étude décrit les révisions de la composante d'emploi tendanciel de la fonction de production qui sous-tend les scénarios économiques à long terme. À partir des taux d'emploi par âge et sexe, une approche nouvelle est développée pour enlever les effets cycliques en utilisant l'écart d'emploi du pays, tout en permettant que les différents groupes d'âge et de sexe aient des sensibilités différentes au cycle économique. Les séries résultantes de taux d'emploi par âge/sexe ajustées pour le cycle sont utilisées pour calculer des taux tendanciels d'entré et de sorti d'emploi en utilisant l'approche traditionnelle par cohorte. Les propensions différentes à l'emploi des cohortes existantes sont ensuite utilisées pour projeter les futurs taux d'emploi, en faisant l'hypothèse que les taux d'entré et de sorti des nouvelles cohortes seront égaux à ceux des plus récentes. Pour construire des scénarios, le modèle permet aux politiques publiques d'influencer les futurs taux d'emploi, notamment l'âge légal de la retraite, les coins fiscaux, les prestations familiales, etc. Les tailles de ces effets proviennent des travaux récents de l'OCDE sur la quantification des réformes structurelles, et sont aussi spécifiques aux sexes et aux groupes d'âge. L'emploi total tendanciel est obtenu en agrégeant les taux d'emploi par âge/sexe en utilisant des projections démographiques externes.

Classification JEL: E24, E27, J21, C53

Mots clefs : Emploi tendanciel, emploi potentiel, projections, ajustement cyclique, modèle de cohortes, écart d'emploi, modèle long terme, scénarios à long terme 


\section{TABLE OF CONTENTS}

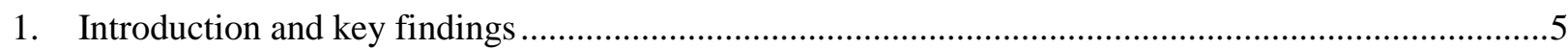

2. Methodology for initial age/sex-specific employment rate projections ..........................................6

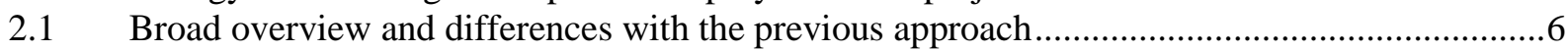

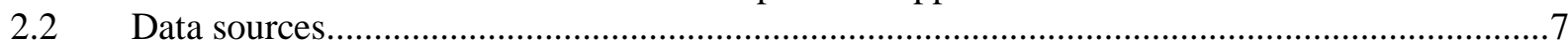

2.3 Methodology for cyclically adjusting age/sex-specific employment rates................................7

2.4 Computing historical trend entry and exit rates from trend employment rates ..........................12

$2.5 \quad$ Projections of age/sex-specific employment rates...................................................................12

3. Structural and policy effects on employment rates........................................................................17

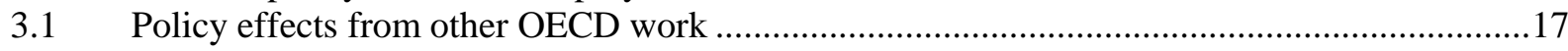

3.2 Effect of educational attainment on youth employment rates .................................................19

3.3 Applying structural and policy effects to baseline employment rates and aggregating ............20

3.4. Simulations with rising educational attainment and an illustrative policy package ..................21

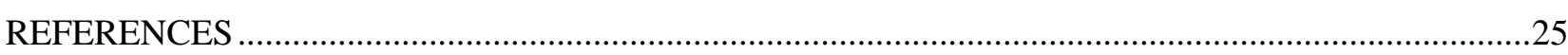

APPENDIX 1. COMPARISON OF PREVIOUS AND REVISED APPROACHES ..................................27

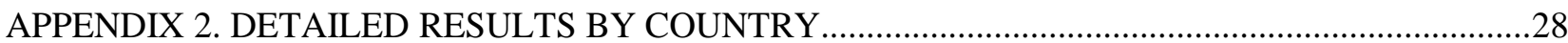

\section{Tables}

Table 1. Estimated cyclical adjustment coefficients on the employment gap rates ...................................

Table 2. Long-run effects of policy and structural variables on employment rates .................................19

Table 3. Long-run effects of example policy reform package on German employment rates..................24

\section{Figures}

Figure 1. Employment rates for 30-to-34-year-olds in Spain, per cent..................................................11

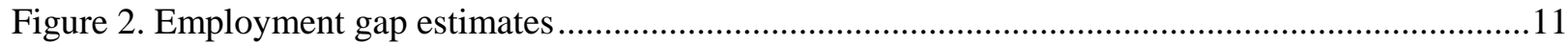

Figure 3. Employment rates for Argentinian men, per cent ..................................................................14

Figure 4. Cyclically-adjusted employment rates for different cohorts of German women, per cent..........15

Figure 5. Projections of aggregate ${ }^{1}$ employment rate (15-74) in Germany ..............................................15

Figure 6. Employment rates for 25-to-29-year-olds in Italy, per cent .................................................16

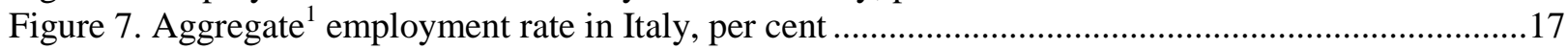

Figure 8. Impacts of example policy package on projections for Germany ...........................................23 


\title{
A REVISED APPROACH TO TREND EMPLOYMENT PROJECTIONS IN LONG-TERM SCENARIOS
}

\author{
by Maria Chiara Cavalleri and Yvan Guillemette ${ }^{1}$
}

\section{Introduction and key findings}

1. This paper is the second module describing methodological revisions to the model underlying OECD long-term scenarios. This model is anchored to projections of potential output, which are obtained using a production function with three main inputs corresponding to the disaggregation used in the new framework for evaluating the effects of structural reforms (Égert and Gal, 2017): trend labour efficiency, trend employment and the productive capital stock. The first module described how the labour efficiency projection equation was re-specified and re-estimated to include more policy and structural determinants. This module takes up projections of the trend employment component. A third module will eventually address revisions to the method for projecting the productive capital stock.

2. The evolution of trend employment is central to any long-run economic projection and is primarily the result of three sets of dynamics: the evolving size of the working-age population, its age composition and trends in the employment rates of different age/sex groups. The size and composition of the working age population (here taken to be 15-74 year-olds) varies according to changes in fertility, mortality and migration. For the purposes of the long-term scenarios, population projections are sourced externally and considered exogenous. This paper is thus concerned with identifying and projecting trends in the employment rates of existing and future cohorts of workers. These generational trends reflect societal changes such as rising female employment rates but also structural changes such as higher educational attainment. Projections must also be able to take into account the impact of recent and future policy changes on trend employment rates. For this purpose, the proposed approach integrates recent OECD empirical work on the quantification of structural reforms.

3. The key findings are:

- It is important for long-term projections to take into account generational cohort effects (i.e. the tendency for later generations to work more or less than previous ones).

- It is also important to correct historical employment rates for cyclical effects before using them to estimate the entry and exit rates that underlie the cohort approach.

- Rising educational attainment is not expected to have a significant impact on the aggregate employment rate but it is expected to shift the age profile of employment for a typical cohort, with lower youth employment rates and higher prime-age rates.

- Policy reforms have the potential to raise employment rates and alleviate some of the negative impact of changing demographics on employment growth.

1. The authors are members of the OECD Economics Department's Macroeconomic Analysis Division. They would like to thank Hervé Boulhol, Peter Gal, Christian Geppert, Marius Luske, Catherine Mann, Patrice Ollivaud, Elena Rusticelli and David Turner for comments and discussions; Thomas Chalaux for statistical support; and Veronica Humi for editorial support (all from the OECD Economics Department). The paper also benefited from discussions by Working Party No. 1 of the OECD's Economic Policy Committee. 
4. The paper is structured in two sections: section 2 overviews the new methodology, highlighting the main differences with the previous approach, and then presents in detail the cohort employment model used to generate initial projections of trend employment rates by age and sex. Section 3 then presents the education and policy effects, also specific to sex and age groups, that are layered on top of the initial trend employment projections, and concretises them with a simulation of an illustrative policy package.

5. The main text illustrates key parts of the methodology and results using specific country examples. Results for all countries - assuming no changes in policies or educational attainment - are in Appendix 2.

\section{Methodology for initial age/sex-specific employment rate projections}

6. This section presents in detail the methodology used to derive the initial set of employment rate projections by age and sex, before policy effects are applied, which will be the subject of section 3 .

\subsection{Broad overview and differences with the previous approach}

7. The revised approach can be summarised in the following steps:

1. Historical data on employment rates by age and sex are cyclically adjusted to obtain estimates of trend employment rates. The cyclical adjustment uses estimated equations linking employment rates to the country-level employment gap (actual less trend) from the OECD Economic Outlook.

2. The trend employment rates by age and sex are used to calculate trend rates of entry and exit into/from employment using a cohort-based approach. For future years and cohorts, trend entry and exit rates are assumed to remain fixed at their last estimated values.

3. Trend entry and exit rates are used to project trend employment rates by age and sex into the future.

4. Policy effects are added to the projected age/sex-specific trend employment rates.

5. The disaggregated age/sex-specific trend employment rates are weighted by the relevant population shares/totals to obtain an aggregate trend employment rate/total.

This revised approach introduces two main changes to the previous methodology (see Appendix 1 for further details): 1) the new approach is based on employment rates as opposed to participation rates; and 2) the piecewise linear regression method used to separate trend and cyclical components is replaced by a simpler linear regression method based on the aggregate employment gap, which should ensure greater consistency with the corresponding OECD Economic Outlook estimates and projections.

8. Using employment rates in the cohort model as opposed to participation rates is rendered necessary by the use of employment rather than participation rates as dependent variables in the recent OECD work on the quantification of structural reforms. The disadvantage is that the long-term projections will no longer be able to illustrate or decompose the impact of policies between trend participation and unemployment rates, although, arguably, the employment rate is a more relevant policy objective. The advantage is that long-run scenarios will use the same set of estimated policy effects as, and therefore be consistent with, any other work that uses results from the quantification of structural reforms exercise.

9. The revision also expands the country coverage to 46 countries. These include the 35 OECD member countries as well as 11 additional ones that are currently part of the long-term model or might 
soon be added (Argentina, Brazil, Colombia, Costa Rica, China, India, Indonesia, Lithuania, Russian Federation, Saudi Arabia and South Africa). For five non-OECD economies (China, India, Indonesia, Argentina and Saudi Arabia), insufficient data on employment rates and/or on the cyclical indicator are available to apply all the steps above, so a simplified approach is used: age/sex-specific employment rates are projected by assuming that they remain constant at the average of the five last historical observations.

\subsection{Data sources}

10. Two types of series are used in the analysis:

1. Age/sex-specific historical employment rates, expressed as per cent of the relevant population. For most countries, 12 five-year age groups (15-19 to 70-74) are considered, but there are a few exceptions where series for the oldest age groups (65-69 and/or 70-74) are not available or not long enough to be used, so in these cases the analysis is done using only 10 or 11-year age groups. The series are sourced from the OECD Employment and Labour Market Statistics database, which contains data from national labour force surveys for all countries considered here except Argentina and Saudi Arabia. Data for Argentina and Saudi Arabia are sourced from the International Labour Organisation (ILO). For several countries, series start as early as the 1970s but a number of countries have shorter time series.

2. Aggregate employment gaps, expressed as per cent of potential employment. The employment gap is calculated as EGAP $=\frac{E T N A-E T P T}{E T P T} \cdot 100$ where, following standard OECD Economic Outlook mnemonics, ETNA is a nation's total employment according to National Accounts statistics and ETPT is potential employment of the total economy. Both series are sourced from the OECD Economic Outlook No. 100 database. Potential employment refers to the concept used in the calculation of potential output and is obtained by combining estimates of the aggregate trend participation rate, the non-accelerating inflation rate of unemployment (NAIRU) and trend population. ${ }^{2}$ A negative employment gap indicates that total employment is below its estimated potential (or trend) level, and vice-versa for a positive gap. Employment gap estimates are therefore independent of the disaggregated age/sex-specific series described above.

\subsection{Methodology for cyclically adjusting age/sex-specific employment rates}

11. Entry and exit rates estimated directly on raw employment rates would risk being biased by the economy's cyclical position and would not be a solid basis for projecting future employment trends, particularly at the end points of the employment rate series. Therefore, it is desirable to remove the cyclical component from raw employment rates so as to isolate the employment trends that will form the basis of projections.

12. Different approaches can be used for this purpose. In the previous approach, as mentioned above, piecewise linear regressions were used to extract trends from labour force participation rates. The main limitation of this approach is that the start and end points of the linear time segments used for identifying cycles could be rather arbitrary. And experience has shown that trend estimates were not always robust to even small changes to these start and end points.

13. Filtering using Kalman or Hodrick-Prescott (HP) filters is another widely used approach for disentangling cyclical and trend components of a macroeconomic variable. While these techniques are

2. See Appendix 3 in Turner et al. (2016) for a brief overview of potential output estimation for the $O E C D$ Economic Outlook. See Rusticelli et al. (2015) for more details on NAIRU estimates, which are based on anchored-expectations Phillips curves. 
simple to apply, they suffer from the well-known end-point problem, an especially acute issue when trend entry and exit rates are estimated using the last few historical employment rate data points. The end-point problem is sometimes alleviated by extending historical series with forecast values. Besides the fact that forecasts are often poor, in the current context this approach could not be used because forecasts of age/sex-specific employment rates are not available.

14. The approach used here to estimate the trend component in age/sex-specific employment rates mimics the approach used in Turner et al. (2016) for estimating the trend component in aggregate labour efficiency. The method exploits the correlation between the cyclical component of employment rates and independent estimates of the degree of slack in the economy. More specifically, the economy's cyclical position is measured by the country-level employment gap from the OECD Economic Outlook, and simple regression equations estimate the historical correlation between this country-level measure and age/sexspecific employment rates. Essentially, then, the approach decomposes the country-level employment gap into age/sex-specific employment gaps. It is hoped, and will be checked subsequently, that aggregating the resulting age/sex-specific gaps yields an overall measure close to the original country-level gap. A simpler alternative would be to assume that all age/sex-specific employment gaps are equal to the country-level measure, but the approach used here recognises that different age/sex groups may respond differently to changing cyclical conditions.

15. The regression equations are first estimated separately for each age/sex-specific employment rate in each country. Inevitably, however, some of the estimated cyclical coefficients are wrongly signed and/or not statistically significant. In these cases, coefficient estimates derived from a second estimation method that pools information from all countries together are used instead. The two sets of estimation are described in turn below. The resulting historical correlation coefficients then serve to cyclically adjust historical age/sex-specific employment rates, thus obtaining trend estimates from which trend entry and exit rates can be calculated.

\subsubsection{Individual-level regressions}

16. The employment rate for sex $s$, age group $a$, country $i$ at time $t\left(E R_{s, a, i, t}\right)$, an individual time series, is regressed on a constant $(\alpha)$, the aggregate employment gap $(E G A P)$ and a time trend:

$$
E R_{s, a, i, t}=\alpha+\beta \cdot E G A P_{i, t}+\lambda t+\varepsilon_{s, a, i, t}
$$

where $\beta$ is the coefficient of interest measuring the sensitivity of the employment rate to the aggregate employment gap. The time trend picks up any trend in historical age/sex-specific employment rates such as rising female participation over time due to factors that would be difficult to include otherwise. Econometrically, the left-hand side variable (employment rate) can be trending while the right-hand side variable $(E G A P)$ is stationary by definition, so a trend term is needed to get an unbiased estimate of $\beta$. The time trend serves only this purpose and is not re-used elsewhere in the analysis.

\subsubsection{System regression}

17. The second method combines all countries together, forming a system of equations which is estimated simultaneously using seemingly unrelated regressions (SURE):

$$
E R_{i, t}^{s, a}=\alpha_{i}^{s, a}+\beta^{s, a} \cdot E G A P_{i, t}+\lambda_{i}^{s, a} t+\varepsilon_{i}^{s, a} \quad \forall i,
$$

with the cross-equation restriction that the cyclical adjustment coefficient for the specific age and sex group $\left(\beta^{s, a}\right)$ is the same across countries. Twenty-four such systems are estimated, one for each age/sex combination. Table 1 compares the cyclical adjustment coefficients estimated individually for the G7 
economies with those estimated jointly with all 41 countries (results for all countries can be found in Table A2.1 in Appendix 2).

Table 1. Estimated cyclical adjustment coefficients on the employment gap

\begin{tabular}{|c|c|c|c|c|c|c|c|c|}
\hline $\begin{array}{l}\text { Age group / } \\
\text { gender } \\
\text { Men }\end{array}$ & Canada & France & Germany & Italy & Japan & $\begin{array}{l}\text { United } \\
\text { Kingdom }\end{array}$ & $\begin{array}{l}\text { United } \\
\text { States }\end{array}$ & System \\
\hline $15-19$ & $1.93^{\star * *}$ & $1.90^{\star \star \star}$ & $0.73^{\star \star \star}$ & 0.05 & $0.73^{\star * *}$ & $2.42^{\star * \star}$ & $1.47^{\star * \star}$ & $0.86^{* * *}$ \\
\hline $20-24$ & $1.56^{\star * *}$ & $3.47^{\star \star \star}$ & $0.97^{\star \star *}$ & $1.25^{\star \star \star}$ & $1.94^{\star \star *}$ & $1.83^{\star \star \star}$ & $1.25^{\star \star \star}$ & $1.37^{\star \star \star}$ \\
\hline $25-29$ & $1.20^{\star * *}$ & $1.62^{\star \star *}$ & $1.01^{* * *}$ & $1.49^{\star \star *}$ & $1.06^{\star * *}$ & $1.10^{\star \star *}$ & $1.05^{\star \star *}$ & $1.07^{\star \star \star}$ \\
\hline $30-34$ & $1.04^{* \star *}$ & $1.04^{* \star *}$ & $0.78^{\star \star \star}$ & $0.94^{\star \star \star}$ & $0.91^{* * *}$ & $0.78^{\star \star *}$ & $0.80^{* \star *}$ & $0.80^{* * *}$ \\
\hline $35-39$ & $0.70^{* * *}$ & $0.83^{* * \star}$ & $0.61^{\star \star \star}$ & $0.71^{\star \star \star}$ & $0.67^{* * *}$ & $0.69^{* * *}$ & $0.55^{\star \star \star}$ & $0.70^{* * *}$ \\
\hline $40-44$ & $0.72^{\star \star \star}$ & $0.95^{\star * \star}$ & $0.50^{\star * \star}$ & $0.63^{\star * \star}$ & $0.57^{\star \star *}$ & $0.66^{\star \star \star}$ & $0.50^{* \star *}$ & $0.68^{\star \star *}$ \\
\hline $45-49$ & $0.68^{* * *}$ & $0.90^{* * *}$ & $0.53^{\star * \star}$ & $0.71^{\star * *}$ & $0.66^{\star * *}$ & $0.52^{\star * \star}$ & $0.55^{\star * *}$ & $0.68^{* * *}$ \\
\hline $50-54$ & $0.61^{* * *}$ & $0.41^{*}$ & $0.75^{\star \star \star}$ & $1.04^{\star \star \star}$ & $0.88^{* * *}$ & $0.47^{* * *}$ & $0.55^{\star * *}$ & $0.65^{\star * *}$ \\
\hline $55-59$ & 0.57 & -0.52 & $1.48^{* \star}$ & -0.95 & $1.18^{* * *}$ & 0.44 & $0.25^{\star * *}$ & $0.62^{\star \star *}$ \\
\hline $60-64$ & 0.11 & 0.34 & $1.80^{* *}$ & $-0.64^{*}$ & $1.82^{* \star *}$ & 0.23 & -0.09 & $0.56^{\star \star *}$ \\
\hline $65-69$ & -0.35 & 0.00 & $1.41^{\text {** }}$ & -0.04 & 0.76 & -0.27 & -0.18 & $0.30^{\text {*** }}$ \\
\hline $70-74$ & -0.27 & 0.27 & $0.60^{\text {** }}$ & $-0.10^{\star *}$ & 0.05 & -0.07 & $-0.25^{* *}$ & $0.14^{* * *}$ \\
\hline \multicolumn{9}{|l|}{ Women } \\
\hline $15-19$ & $1.60^{\star \star \star}$ & $1.26^{\star \star \star}$ & $0.96^{\star \star \star}$ & $0.17^{\star \star}$ & $0.43^{\star \star *}$ & $2.12^{\star \star \star}$ & $1.46^{\star \star \star}$ & $0.71^{* * *}$ \\
\hline $20-24$ & $1.02^{\star \star \star}$ & $2.58^{\star \star \star}$ & $1.16^{\star \star \star}$ & $1.32^{\star \star \star}$ & $1.61^{\star * *}$ & $1.22^{\star \star \star}$ & $0.94^{\star \star \star}$ & $1.03^{* \star *}$ \\
\hline $25-29$ & $0.90^{\star * *}$ & $1.06^{\star \star *}$ & $0.60^{\text {** }}$ & $1.42^{\star \star \star}$ & $0.87^{\star \star *}$ & $1.01^{* * *}$ & $0.90^{* * *}$ & $0.85^{\text {***}}$ \\
\hline $30-34$ & $0.86^{\star * *}$ & $0.62^{* *}$ & 0.30 & $1.17^{* * *}$ & 0.15 & $0.93^{* * *}$ & $0.86^{\star * *}$ & $0.69^{* * *}$ \\
\hline $35-39$ & $0.86^{\star * *}$ & 0.32 & $0.34^{*}$ & $0.88^{\star * \star}$ & $0.99^{* * *}$ & $0.65^{\star * *}$ & $0.89^{* \star *}$ & $0.62^{* * *}$ \\
\hline $40-44$ & $0.69^{\star \star \star}$ & 0.14 & 0.21 & $0.68^{\star * \star}$ & $1.04^{* \star *}$ & $0.47^{\star * *}$ & $1.02^{* \star *}$ & $0.61^{\text {*** }}$ \\
\hline $45-49$ & $0.67^{* *}$ & -0.15 & 0.36 & $0.76^{\star * *}$ & $1.07^{* * *}$ & $0.39^{\star * \star}$ & $1.19^{* \star *}$ & $0.57^{\star * *}$ \\
\hline $50-54$ & $0.61^{* * *}$ & 0.25 & $0.54^{* *}$ & $0.58^{* *}$ & $1.30^{* * *}$ & $0.13^{*}$ & $1.07^{\star \star \star}$ & $0.44^{\star * *}$ \\
\hline $55-59$ & 0.32 & -0.05 & 0.72 & -0.56 & $1.04^{* * *}$ & 0.04 & $0.49^{* \star *}$ & $0.32^{* * *}$ \\
\hline $60-64$ & -0.14 & -0.30 & $1.29^{\star}$ & $-0.66^{\star \star}$ & $1.04^{\star *}$ & -0.12 & -0.13 & $0.21^{\text {***}}$ \\
\hline $65-69$ & -0.24 & 0.08 & $0.65^{\star}$ & $-0.12^{\star \star \star}$ & 0.03 & $-0.34^{\star *}$ & $-0.20^{\star *}$ & $0.12^{\star * \star}$ \\
\hline $70-74$ & -0.13 & 0.15 & $0.38^{* * *}$ & $-0.07^{\star \star *}$ & -0.17 & -0.11 & $-0.16^{\star * *}$ & $0.04^{* * *}$ \\
\hline
\end{tabular}

Note: The table reports the estimated impact of a one-percentage point aggregate employment gap in the relevant country on the employment rates of different age/sex groups. The sample period is 1980-2015 for most countries. Asterisks '***', '**', and '*' denote statistical significance at the $1 \%, 5 \%$ and $10 \%$ levels, respectively. See Table A2.1 in Appendix 2 for all individual country results.

\subsubsection{Discussion of regression results}

18. A reasonable a priori expectation would be for cyclical adjustment coefficients $(\hat{\beta})$ to be positive and around one. Positive because an increase in the aggregate employment gap, indicating a tightening labour market, would generally be expected to raise employment rates for all age/sex groups; and around one because, starting from an equilibrium position with a zero aggregate gap, and assuming a stable aggregate structural rate, moving to a one-percentage point positive aggregate gap would require a weighted average of employment rates to increase by one percentage point. Reflecting the different sensitivities of different age/sex groups to the economic cycle, some coefficients would be expected to be somewhat above one and others somewhat below.

19. The results for age groups up to 55-59 broadly conform to these expectations: estimated coefficients are generally positive, with some above one and others below, and most are statistically significant. They are generally higher for younger age groups relative to prime-age groups, an intuitive result considering that younger people typically have more tenuous attachment to the labour market, while prime-age workers generally have more stable jobs and are less affected by cyclical fluctuations. This pattern of coefficients across age groups is most easily visible in the system-based coefficients. 
20. For age groups 60-64 to 70-74, however, estimated coefficients are sometimes negative and, even when they are positive, are often small and not statistically significant. They indicate that the employment status of older workers is much less sensitive to the economic cycle and, in some cases, perhaps even countercyclical. Countercyclical employment rates could be explained by the propensity of older workers to retire earlier in good times, and to keep working longer in bad times, for instance to make up for shortfalls in housing and pension wealth in view of nearing retirement. Because of conflicting signs for coefficients and their general lack of statistical significance, age groups 60-64 and over are left out of the cyclical adjustment method. In other words, structural employment rates for people aged 60 and over are assumed equal to observed employment rates.

21. As a general rule, for the remaining age groups (15-19 to 55-59), country-specific coefficients are used in the cyclical adjustment, except when they are negative. Negative coefficients are replaced by the relevant system-based coefficients. For instance, in Table 1, the adjustment coefficients for French and Italian men aged 55 to 59 are replaced by the system-based coefficient this age/sex group. Only a small fraction (less than 4\%) of all the country-specific coefficients is replaced in this manner. Alternative specifications of the regression equations, one adding the square of the time trend and another including the labour force participation gap separately from the unemployment gap, yielded broadly similar results with no systematic improvement in fit.

\subsubsection{Computation of structural employment rates}

22. Using the final set of cyclical adjustment coefficients for each country, age and sex $\left(\hat{\beta}_{s, a, i}\right)$ from [1] or [2], the cyclically adjusted employment rate time series $\left(\widetilde{E R}_{s, a, i, t}\right)$ is obtained with:

$$
\widetilde{E R}_{s, a, i, t}=E R_{s, a, i, t}-\hat{\beta}_{s, a, i} \cdot E G A P_{i, t}
$$

The time trends estimated in [1] and [2] do not appear in [3] because the objective of [3] is only to adjust for the cycle. The impact of this cyclical adjustment is illustrated for Spanish men and women aged 30 to 34 in Figure 1. Spain is used as an example because it experienced a strong economic boom in the years leading up to the global financial and economic crisis, followed by a deep slump. This pattern is visible in raw employment rates, particularly for men, but is much less visible in the cyclically-adjusted rates. For instance, despite falling actual employment rates for both men and women in the 30-34 age group from 2009 to 2013, the estimated structural employment rate for men is roughly flat over this period and that of women remains on the same uptrend as before the crisis. The use of cyclically-adjusted employment rates in the rest of the analysis therefore helps to reduce imprecision due to cyclical noise, although it does not eliminate it completely. 
Figure 1. Employment rates for 30-to-34-year-olds in Spain, per cent

Men

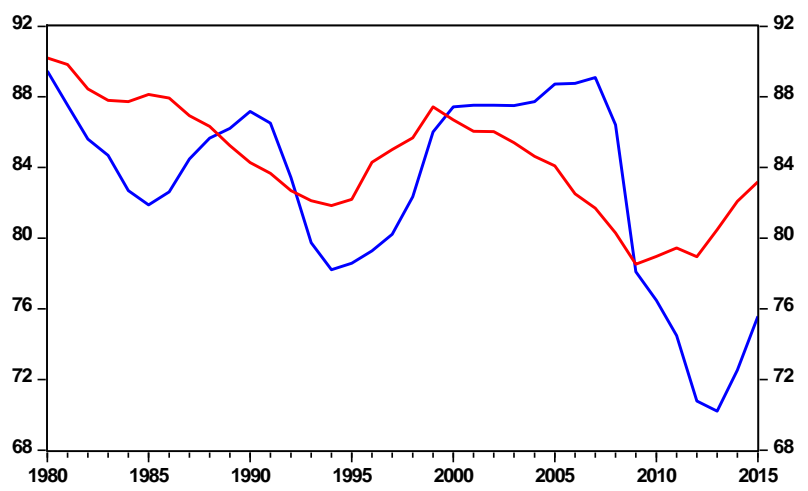

Women

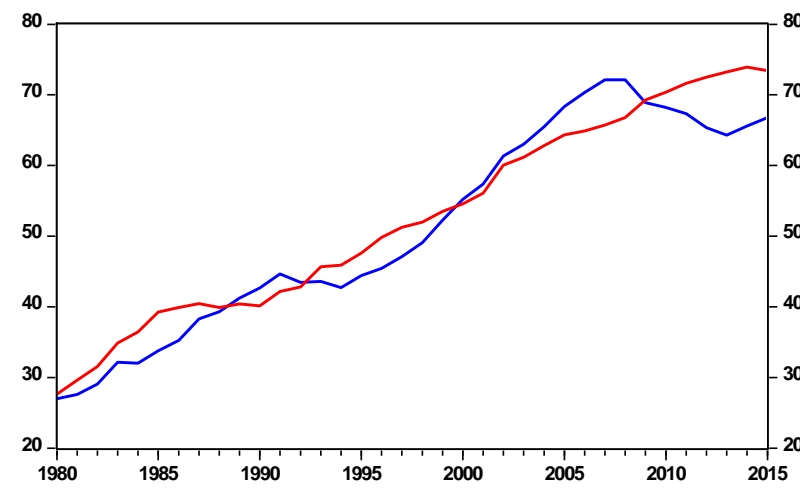

23. Relative to the a priori expectations outlined above, it is generally not the case that an employment-weighted average of estimated coefficients across age/sex groups in a given country sums to one. Often, estimated coefficients are above one for only a few age/sex groups and all others are between zero and one, leaving a weighted average somewhat below one. This pattern is also visible in the systembased coefficients. The procedure is therefore at risk of under adjusting the raw employment rates, in other words leaving some cyclicality in the structural employment rate estimates. As a check, the raw and cyclically-adjusted age/sex-specific employment rates can be used to calculate alternative aggregate employment and potential employment series, from which an alternative employment gap can be calculated and compared to the country-level employment gap used in the regressions. A close alignment of the two gaps would support the magnitude of estimated adjustment coefficients. Two typical examples appear in Figure 2, one (Canada) where the correspondence between the two gaps is strong, and another (Italy) where it is less strong, but close enough to lend credence to the methodology. This is generally the case for all countries (results not shown).

Figure 2. Employment gap estimates

Per cent of potential employment

Canada

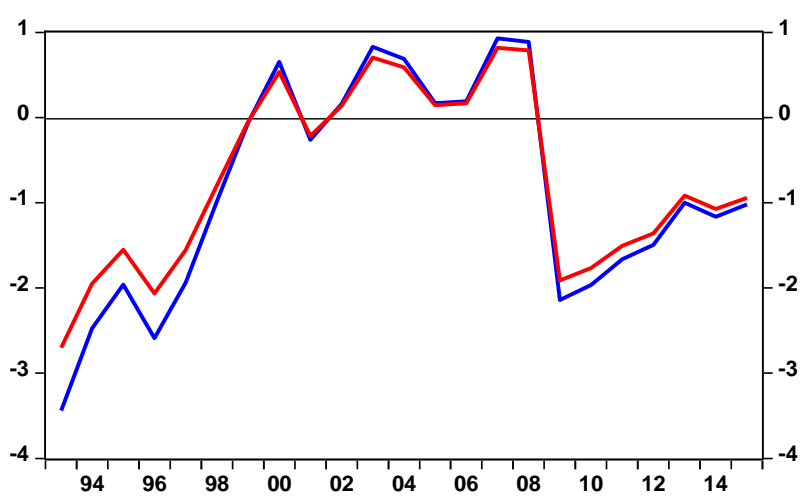

Italy

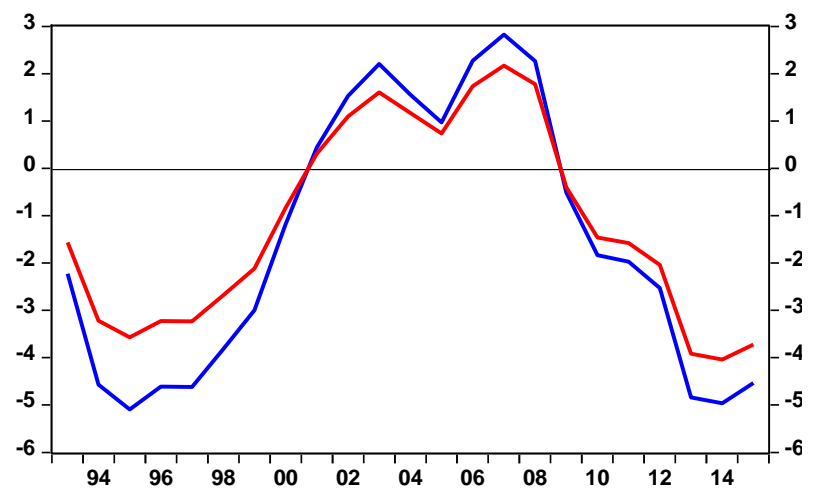

_ From disaggregate estimates __ Economic Outlook aggregate estimate 


\subsection{Computing historical trend entry and exit rates from trend employment rates}

24. The time series variation in age/sex-specific structural employment rates, in particular the time trends left over after cyclical adjustment, can be exploited to tease out how employment behaviours differ across generations. Albeit to a lesser extent than across countries or age groups, employment patterns also vary within individual age/sex groups in a given country for people born in different years (so-called "cohorts"). Successive cohorts may respond to evolving social norms (for example, the increasing tendency for women to work), display varying aptitudes to work (depending on education levels for instance), or respond differently to changes in the structure and functioning of labour markets. Such trends have implications for the evolution of future employment rates.

25. To capture such trends, a cohort approach is used based on the original work of Burniaux et al. (2004) and similar to the one applied to labour force data in the previous iteration of the long-term model (Johansson et al., 2013). A cohort here refers to a group of people born over a five-year period. The cohort approach tracks the employment patterns of cohorts over time as people age and go through different life stages. Entry and exit rates into and out of work are calculated by comparing structural employment rates for a given cohort across two subsequent five-year periods, corresponding to the five-year age groups used in the previous analysis. This requires using employment rates for two different age groups, because a given cohort will have aged into the following five-year age group over this five-year period.

26. Specifically, the cyclically-adjusted rate of entry into employment for sex $s$, age group $a$ in country $i$ at time $t\left(\tilde{e}_{s, a, i, t}\right)$ is computed from the change in structural employment rates between age group $a$ and the previous age group (denoted $a-5)$ between two adjacent five-year periods $(t-5$ and $t$ ):

$$
\tilde{e}_{s, a, i, t}=1-\frac{E R^{m}-\widetilde{E R}_{s, a, i, t}}{E R^{m}-\widetilde{E R}_{S, a-5, i, t-5}}
$$

where $E R^{m}$ is the maximum structural employment rate that can potentially be observed. Entry rates measure the number of people in an age group who have become employed during the last five-year period as a percentage of non-employed people (either out of the labour force or unemployed) in the previous five-year period. For all age/sex groups, $E R^{m}$ is set to $98 \%$, reflecting the assumption of an incompressible small rate of frictional unemployment $(2 \%)$. In other words, if employment rates reached this level, the entry rate would be one, meaning that everybody who could possibly be employed was.

27. The cyclically-adjusted rate of exit out of employment $\left(\tilde{x}_{s, a, i, t}\right)$ is computed in a similar manner:

$$
\tilde{x}_{s, a, i, t}=1-\frac{\widetilde{E R}_{s, a, i, t}}{\widetilde{E R}_{s, a-5, i, t-5}}
$$

Entry and exit rates are 'net' concepts. Distinguishing what portion of the change in the employment rate of a given cohort over successive periods is due to entry as opposed to exit is not possible, hence the symmetry in the entry and exit rate formulae. If the employment rate of a given cohort increases from one period to the next, a net entry is recorded, even if part of the change reflects people leaving employment. In other words, positive net entry is equivalent to negative net exit. A zero entry (or exit) rate does not represent immobility, but rather perfect balance between flows into and out of employment.

\subsection{Projections of age/sex-specific employment rates}

28. The historical entry and exit rates previously calculated, or the structural employment rates themselves in the case of the exception countries, serve as bases for projecting future employment rates, but a few assumptions are first necessary. 


\subsubsection{Assumptions for the cohort approach}

29. For the purposes of the long-term scenarios, the following assumptions are made regarding future entry and exit rates in the cohort approach:

- For each country and sex, the entry rate of the youngest age group (15-19) is set equal to the last observed employment rate for that age group, and this rate is assumed to remain constant over the projection period.

- For each country and sex, future entry rates for age groups 20-24 to 45-49 are assumed constant at their last calculated values and exit rates are assumed to be zero. This assumption reflects the fact that, before age 50, inflows into the labour force tend to dominate outflows and the approach cannot distinguish between inflows and outflows as explained previously.

- For each country and sex, future exit rates for age groups 50-54 to 70-74 are assumed constant at their last calculated values and entry rates are assumed to be zero. This assumption again reflects the fact that, after age 50, outflows from the labour force tend to dominate inflows and the model can only distinguish the net flow.

- The exit rate at age 75 is assumed equal to 1 , implying that all people are retired by that age.

30. Removing time subscripts to denote the last calculated entry and exit rates $\left(\tilde{e}_{s, a, i}\right.$ and $\tilde{x}_{s, a, i}$,), which are assumed constant over the projection period, future structural employment rates by 5-year increments are obtained with:

$$
\widetilde{E R}_{s, a+5, i, t+5}=\widetilde{E R}_{s, a, i, t}+\tilde{e}_{s, a, i} \cdot\left(E^{m}-\widetilde{E R}_{s, a, i, t}\right)-\tilde{x}_{s, a, i} \cdot \widetilde{E R}_{s, a, i, t}
$$

The resulting series is filtered using the Hodrick-Prescott filter with a low value of lambda to smooth out any wriggles. The assumptions listed previously imply that all future cohorts will exhibit the same entry and exit rates as those measured from the most recent observations of existing cohorts. At the same time, the cohorts that are currently alive do maintain their current structural employment rates as starting points for the projections. As a consequence, projected changes in potential employment arise from differences in the employment propensities of different cohorts combined with shifts in the demographic structure of the population.

\subsubsection{Projections based on assuming constant structural employment rates}

31. For the five countries mentioned previously for which data are insufficient to apply the full cohort approach (China, India, Indonesia, Argentina and Saudi Arabia), future age/sex-specific structural employment rates are assumed to remain constant at their last observed values. This means that the projected aggregate (structural) employment rate changes only to the extent that the age structure of the working-age population changes according to external demographic projections (in these cases United Nations projections). An example for Argentinian men is shown in Figure 3. 
Figure 3. Employment rates for Argentinian men, per cent

By age group

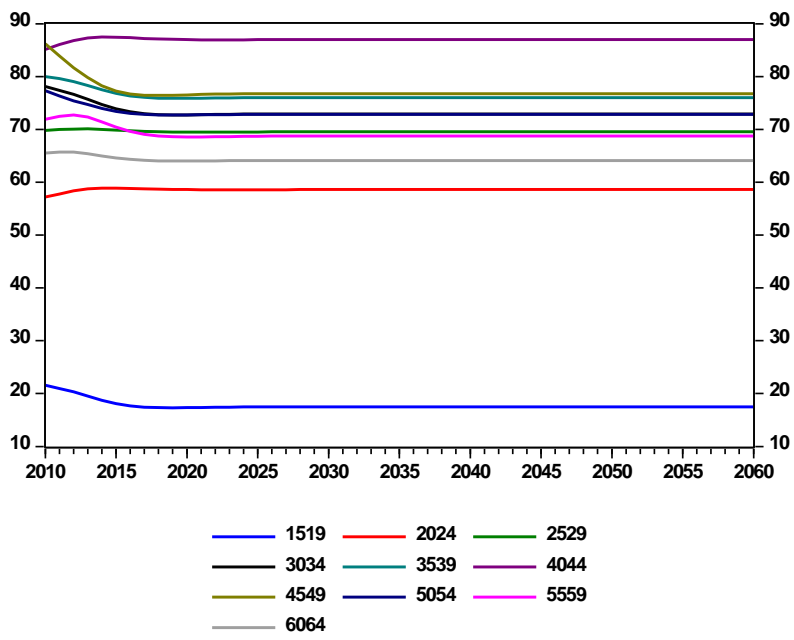

Aggregate 15-64 ${ }^{1}$

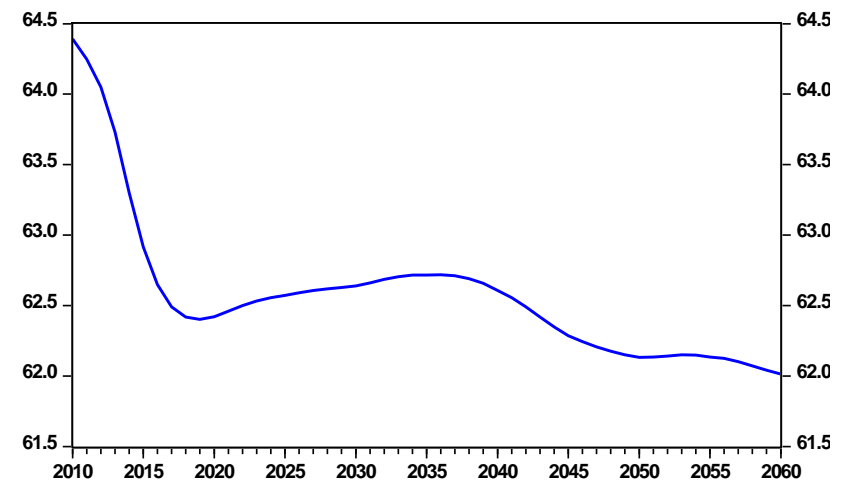

1. The aggregate is a weighted sum of the age/sex-specific employment rates, using United Nations population projections.

\subsubsection{Benefits of the cohort approach over using constant age/sex-specific employment rates}

32. By contrast to the simplified approach of keeping constant recently observed age/sex-specific employment rates, the cohort approach instead keeps constant the rates at which individuals have recently been entering and exiting employment at various life stages. Consequently, cohorts born in different years may show similar dynamics in the future, but the employment rate of each cohort remains unique. In other words, the main advantage of the cohort approach is that it allows recently observed differences in employment propensities across different cohorts to persist, potentially affecting projections for decades to come.

33. Figure 4 shows German female workers as an example. Each line in the left-hand chart shows the evolution through time of the employment rate of a specific cohort spanning five birth years, referred to by the earliest possible birth year (in the legend). All these birth cohorts were present in the German labour market in 2015. The most recent observation is the rightmost point of each line. Female German workers born around 1945 were between 70 and 74 years of age in 2015 and their employment rate was around 3\% (end of the light blue line). Yet, in previous years when they were younger, a larger percentage of them were employed. Back when they were in their forties - in the late 1980s - around 55\% of them had a job. However, at the same stage in their life cycles, cohorts that were born later had higher employment rates than the 1945 cohort. Around three-quarters of German women born in 1960 were employed in their forties, and more than three-quarters for the following (1965) cohort. In fact, successive cohorts have systematically had higher prime-age employment rates than their predecessors. 
Figure 4. Cyclically-adjusted employment rates for different cohorts of German women, per cent

Historical

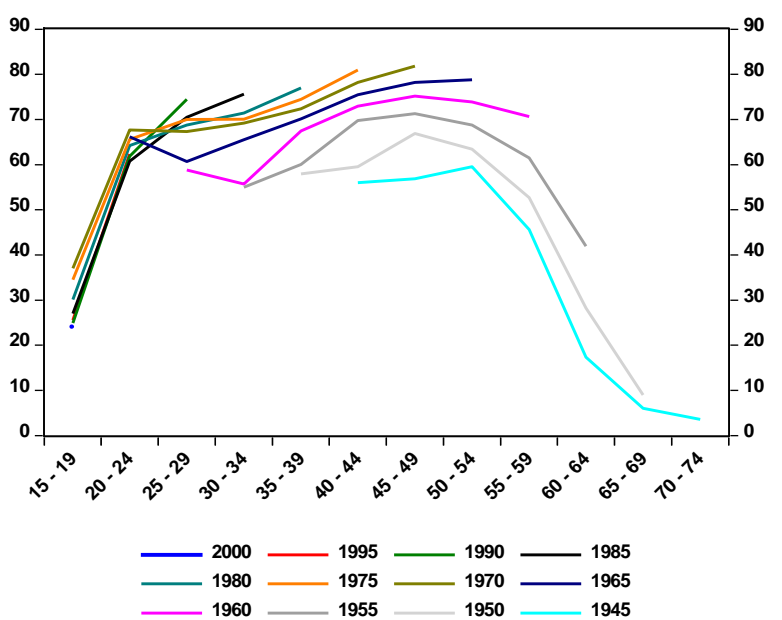

Including projections

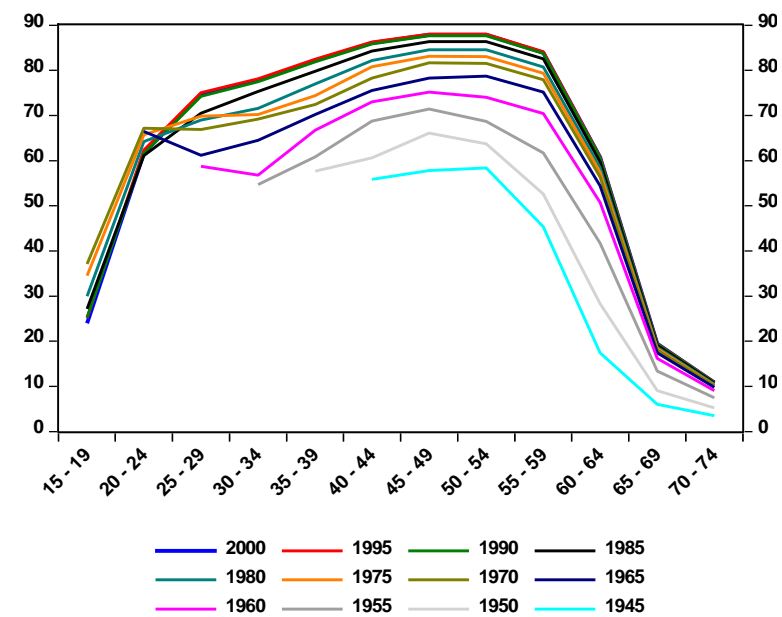

Note: The legend indicates the first year of five-year spans separating different cohorts. All of the cohorts shown were last observed in 2015. For the youngest cohort (i.e. those born in 2000), only one data point is available, since this group just entered the labour market in 2015, when they were 15 years old.

34. Asked to make employment rate projections for the youngest cohorts by looking at the left-hand panel of Figure 4, one would be tempted to reproduce the pattern of older cohorts, with rising employment rates into prime age and falling rates afterwards. All the while, one would be careful to preserve the generally higher level of employment rates for more recent cohorts. In doing so, one would effectively be reproducing what equation [6] does, as shown in the right-hand panel of Figure 4. Looking for instance at the oldest age group (70-74), the cohort approach predicts a rising employment rate as successive cohorts pass through this age range. Ignoring this trend would risk under-predicting employment in the long-run scenarios. And indeed, keeping with Germany as an example, the cohort-based aggregate employment rate projection is noticeably higher than if age/sex-specific employment rates are simply kept constant into the future (Figure 5). A large part of the explanation is rising female employment rates in the cohort approach.

Figure 5. Projections of aggregate ${ }^{1}$ employment rate (15-74) in Germany

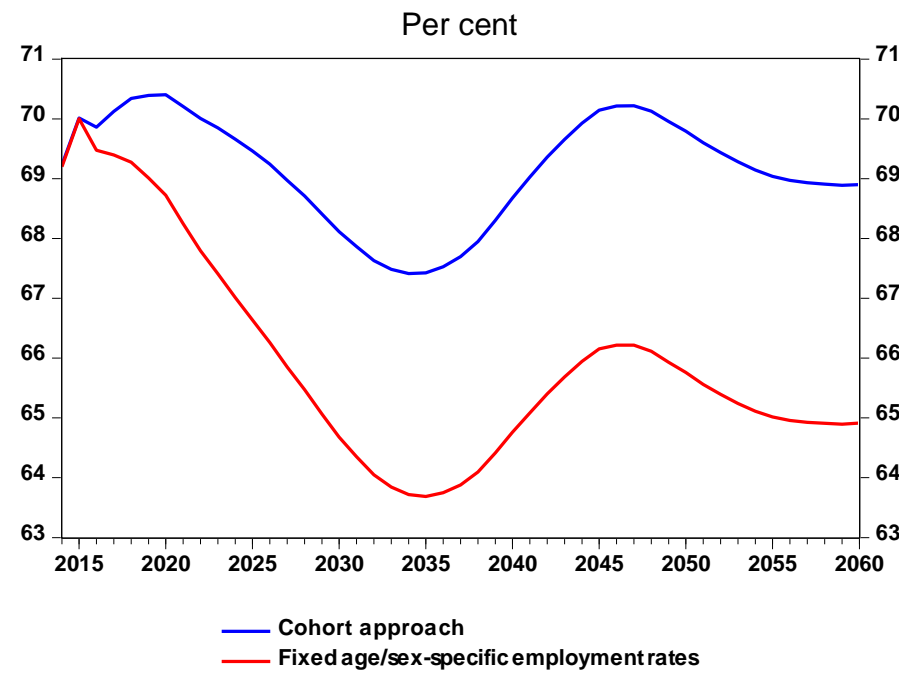

1. The aggregate is a weighted sum of age/sex-specific employment rates, using Eurostat population projections. 
35. Also visible in Figure 5, although more subtle, is that most of the divergence between the two approaches occurs at the start of the projection period. This is because, as useful as it is to foresee the evolution of employment rates for existing cohorts, the cohort-based approach provides no guidance on how to model work attachment for cohorts that have not yet reached working age, including those yet to be born, hence the assumption of fixed entry and exit rates for all future cohorts. Consequently, as time passes and new generations come to represent a larger share of employment, cohort heterogeneity gradually fades away and changes in the aggregate employment rate mimic more and more those of the simplified approach, reflecting only changes in population structure. So while projected employment levels clearly remain distinct in the two approaches, projected employment growth rates eventually converge.

36. Relaxing the assumption of constant future entry and exit rates would require modelling trends in their historical evolution. Such modelling, or the development of alternative scenarios for the future evolution of entry and exit rates, is left to future work.

\subsubsection{Benefits of the cyclical adjustment before calculating entry/exit rates in the cohort approach}

37. The Spanish example above showed that the cyclical adjustment step can yield structural employment rates that are significantly different from the unadjusted series. This in turn leads to different trend entry and exit rate estimates and thus can substantially affect projections of future employment rates. This subsection provides another example for the case of Italy, showing how cyclically adjusting all age/sex groups affects aggregate employment projections.

38. In Italy, as in Spain, the recent recession has dramatically lowered the employment rates of younger age groups, and particularly women (Figure 6). Once adjusted for the cycle using the aggregate employment gap, however, employment rates for men and women aged 25 to 29 in 2015 are some five percentage points higher than the unadjusted series. If the position of the business cycle were not taken into account when calculating entry rates for this and other age groups, they would be too low. Similarly, estimated exit rates for the 50-54 and 55-59 age groups would be too high. In turn, the aggregate employment rate projection would be heavily biased downward (Figure 7). The aggregate cyclicallyadjusted employment rate is $2 \frac{1}{2}$ percentage points higher in 2015 than the unadjusted rate and, instead of being on a sharp downward trend, is on a slight upward trend. So not only the starting point of the aggregate series, but also its near-term dynamics, are affected by the cyclical adjustment. The level gap between the two employment rate projections keeps widening and reaches 8 percentage points by the end of the projection period, demonstrating the importance of the cyclical adjustment.

Figure 6. Employment rates for 25-to-29-year-olds in Italy, per cent

Men

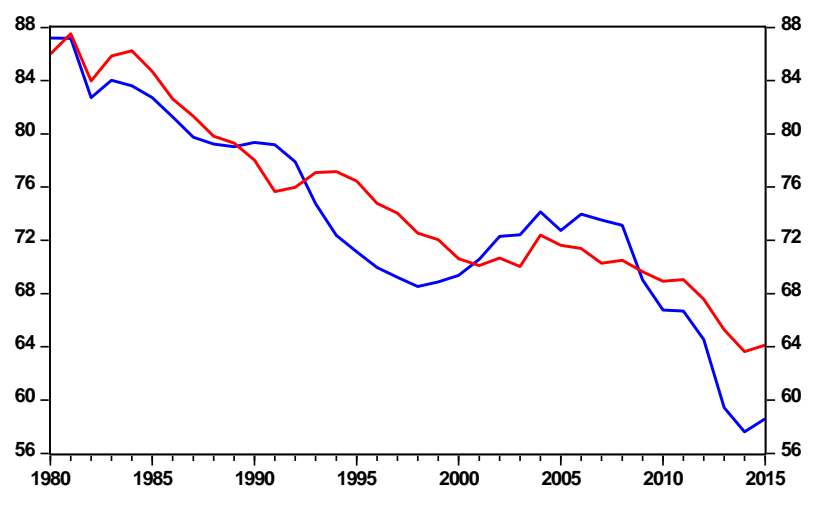

Women

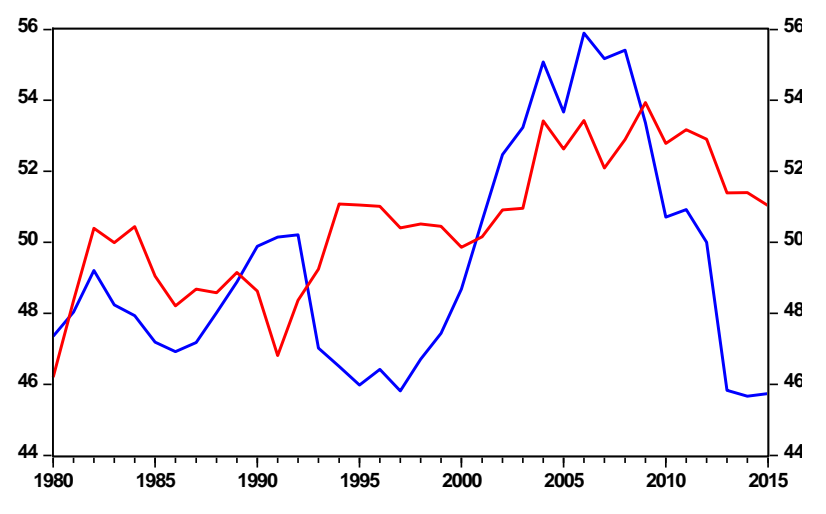

— Raw _ Cyclically adjusted 
Figure 7. Aggregate ${ }^{1}$ employment rate in Italy, per cent

Observations/estimates to 2015 and projections thereafter

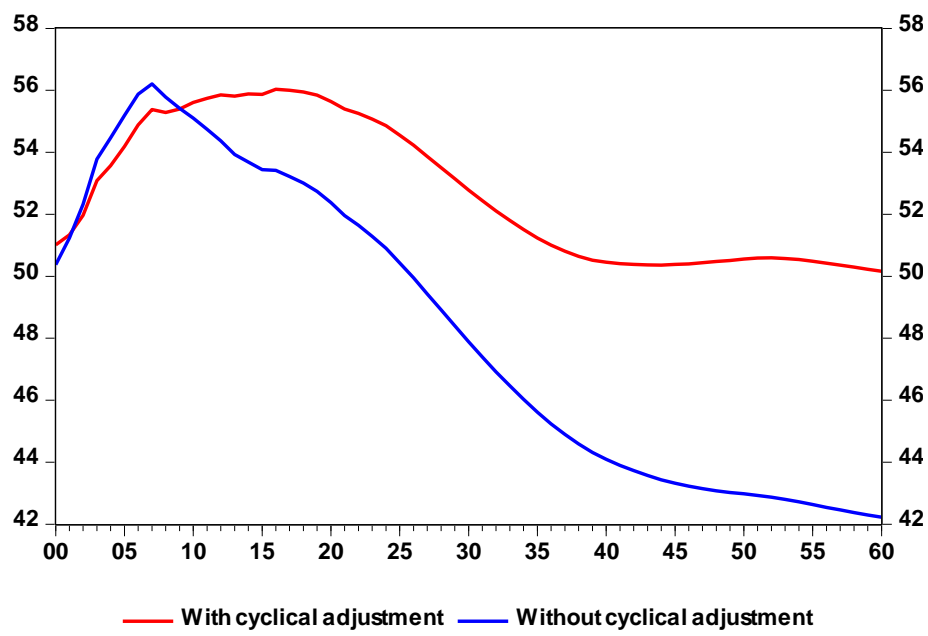

1. The aggregate is a weighted sum of age/sex-specific employment rates, using Eurostat population projections.

39. While less extreme than in Spain and Italy, which is why these two countries were used as illustrations, depressed employment conditions were found in almost all advanced economies over the period 2010 to 2015 , over which structural entry and exit rates are currently estimated. In this post-crisis period, then, it is all the more important to work with structural entry and exit rates calculated using cyclically adjusted employment rates.

\section{Structural and policy effects on employment rates}

40. The previous section's calculations establish a baseline projection of employment rates by age and sex that take account of cohort and demographic influences. This section explains how additional structural and policy effects are then layered onto these initial age/sex-specific employment rates.

\subsection{Policy effects from other OECD work}

41. Almost all of the policy effects included in the model come from recent OECD work on the quantification of structural reforms (Table 2). This work is summarized in Égert and Gal (2017), with most of the labour market effects originally estimated and discussed in more details in Gal and Theising (2015). The work covers OECD countries only, but, pending future estimations for non-OECD countries, it is assumed to apply to non-OECD countries as well. Only the statistically significant long-run policy effects are retained for the long-term projections, specifically:

- The unemployment (UE) benefits replacement rate is estimated to have negative effects on employment rates for all workers, especially the elderly.

- Spending on active labour market policies (ALMPs) is estimated to have positive effects on employment rates for all workers, especially the young.

- The labour tax wedge on single earners is estimated to have a negative effect on youth employment rates, while the tax wedge on couples is estimated to have a negative effect on the employment rates of prime-age men and the elderly. 
- Excess coverage of wage bargaining agreements is estimated to have a negative impact on the employment rates of prime-age women.

- The level of the minimum wage is estimated to have a negative effect on the employment rates of youth and prime-age women.

- Spending on in-kind benefits for families, as well as the number of weeks of maternity leave, are estimated to have positive effects on employment rates for prime-age women.

- A higher legal retirement age is estimated to raise elderly employment rates.

- Higher average educational attainment is estimated to have positive effects on prime-age employment rates.

- The speed at which policies affect employment rates is specific to the different age/sex groups as estimated in the reference studies. It is relatively slow (about $15 \%$ per annum) for prime-age women and elderly workers and relatively fast (about 30\% per annum) for youth and prime-age men. In other words, each year, these percentages of any remaining difference between current and predicted long-run employment rates (i.e. those predicted on the basis of policy changes) is eliminated.

A few of the long-run statistically significant effects estimated in the reference studies are nevertheless omitted or modified for the purposes of the long-term model, for various reasons. Specifically:

- The estimated long-run effects of employment protection legislation (EPL) are omitted. These are not always of the expected sign and/or statistically robust. Instead, the studies cited above align with previous OECD work and support the hypothesis that EPL matters in the short run, by muting employment adjustments to shocks, but not so much for the long-run trend level of employment.

- The estimated long-run effects of the government primary balance are omitted. They are statistically significant but lack a clear and intuitive mechanism of action. The government primary balance was also not of central interest in the reference studies but used only as a control variable.

- The electricity, transport and communications regulation (ETCR) effect is statistically significant in the reference studies only for prime-age women. However, plenty of studies, using both micro and macro data, support the hypothesis that more restrictive product market regulations depress long-run employment rates (Fiori et al., 2012; Bouis et al., 2016; De Serres and Gal, 2015; Gal and Hijzen, 2016; Bassanini, 2015; OECD, 2016). On this basis, an ETCR effect with the same magnitude for both men and women of prime age is calibrated so that the effect of a typical ETCR reform (a reduction of 0.3 points) yields the same improvement in the aggregate employment rate that is reported in Égert and Gal (2017), taking into account the typical share of prime-age employment in total employment. The resulting effects, reported in Table 2, mean that a one-point reduction in the ETCR index raises the employment rates of prime age workers by $3 / 4$ of a percentage point.

- Besides its positive effects on prime-age employment rates, higher average educational attainment is also estimated to raise long-run youth employment rates, a counterintuitive result considering that acquiring more education obviously requires staying in school longer, even 
though many students have jobs. So the education effect on youth reported in Table 2 is instead based on new estimation work described in the next sub-section.

Table 2. Long-run effects of policy and structural variables on employment rates

Percentage point change in age/sex-specific employment rate for a one-unit change in indicator

\begin{tabular}{|c|c|c|c|c|c|}
\hline & Standard deviation $^{1}$ & Youth (15-24) & Prime-age women & Prime-age men & Elderly $(55+)$ \\
\hline UE benefit replacement rate (in pp) & 9.5 & -0.183 & -0.204 & -0.147 & -0.343 \\
\hline ALMP spending (pp of GDP per capita) & 20.8 & 0.147 & 0.092 & 0.047 & 0.063 \\
\hline Tax wedge single (pp of labour costs) & 9.4 & -0.866 & & & \\
\hline Tax wedge couple (pp of labour costs) & 11.9 & & & -0.274 & -0.26 \\
\hline Excess coverage (pp of workforce) & 23.6 & & -0.171 & & \\
\hline Minimum wage (pp of median wage) & 12.3 & -0.311 & -0.421 & & \\
\hline Family benefits in kind ( $p p$ of GDP) & 0.6 & & 4.698 & & \\
\hline Number of weeks of maternity leave & 9 & & 0.265 & & \\
\hline Legal age for pensions & 3.8 & & & & 0.851 \\
\hline ETCR (index, higher is more restrictive) ${ }^{2}$ & 1.5 & & -0.762 & -0.762 & \\
\hline Educational attainment (years of schooling) ${ }^{3}$ & 2.3 & -2.83 & 1.706 & 0.582 & \\
\hline
\end{tabular}

1. Except for educational attainment, standard deviations are from Table 5 in Gal and Theising (2015). All figures include both within- and between-country variation and generally cover OECD countries.

2. In Égert and Gal (2017), the ETCR effect is only statistically significant for prime-age women. Here it is assumed to apply equally to men and women but is calibrated to match the overall effect reported by these authors.

3. The educational effects for prime-age men and women are from the empirical work underlying Égert and Gal (2017), even though these effects are not reported in the paper. The youth effect is from new estimation work described in the next sub-section.

Source: Égert and Gal (2017), Gal and Theising (2015).

\subsection{Effect of educational attainment on youth employment rates}

42. As pointed out above, the reference studies from which structural and policy effects are sourced do not yield compelling results for the impact of educational attainment on youth employment rates. Eschewing educational effects on youth employment, and using only the estimated positive effects on prime-age workers, would risk biasing upward the effect of higher educational attainment on the aggregate employment rate. In reality, one would expect more education to not so much raise aggregate employment as to redistribute the age pattern of employment rates, with lower employment rates in youth as education is obtained, and higher employment rates later on as more education solidifies attachment to the labour market. But the overall impact on the aggregate employment rate should be modest. This sub-section therefore completes the set of policy effects discussed previously by estimating the effects of higher average educational attainment on youth employment rates.

43. The empirical approach relates country-level variation in youth employment rates (so using only age groups 15-19 and 20-24) to average educational attainment in the adult population. Specifically, the employment rate of sex $s$ and age group $a$ in country $i$ in year $t\left(E R_{s, a, i, t}\right)$ is explained by a constant, by average educational attainment in the adult population $\left(E D U C_{i, t}\right)$ and by the employment gap $\left(E G A P_{i, t}\right)$ to correct for cyclical effects ${ }^{3}$ :

$$
E R_{s, a, i, t}=\alpha_{s, a, i}+\theta \cdot E D U C_{i, t}+\gamma_{s, a, i} \cdot E G A P_{i, t}+\varepsilon_{s, a, i, t} \quad \forall s, a \text { and } i .
$$

This system of equations - one equation for each of 36 countries (all OECD countries plus Lithuania), two sexes and two age groups, so 144 equations in total - is estimated using seemingly unrelated regressions

3. An alternative to including the employment gap on the right-hand side of the specification would be to use the structural employment rate calculated in [3] $\left(\widetilde{E R}_{s, a, i, t}\right)$ as the dependent variable. However, given the similarity of the educational attainment variable with the time trend used in [1] and [2], the result for the coefficient of interest $(\theta)$ would be virtually the same. 
(SURE), imposing the cross-equation restriction that the education effect $(\theta)$ be common across all equations. The historical data on average educational attainment (years of schooling) come from Barro and Lee (2013). Because these estimates end in 2010, projections are needed so as to use the full dataset on employment rates which currently extends to 2015. Projections of educational attainment are from Barro and Lee (2015).

44. The $\hat{\theta}$ estimate is -2.83 and statistically significant at the $1 \%$ level. The interpretation is that one additional year of schooling on average in the adult population is associated with youth employment rates that are 2.83 percentage points lower. When combining this negative youth effect with the positive primeage effects from Égert and Gal (2017) reported in Table 3, and using typical shares in total employment of different age groups (here those of the US), the estimated effect of one additional average year of schooling in the adult population on the aggregate (15-74) employment rate is +0.1 percentage point, in line with the hypothesis that average educational attainment should not have a large impact on the aggregate employment rate.

\subsection{Applying structural and policy effects to baseline employment rates and aggregating}

45. This sub-section explains how policy and education effects are added to the initial employment rate projections from section 2 and how the final aggregate potential employment series is aggregated. Then it presents an illustrative policy simulation to demonstrate the impact that policies could have in long-run scenarios on aggregate employment.

\subsubsection{Phasing in policy and education effects}

46. The method described in section 2 yields sex-specific employment rates for 12 different age groups (fewer for some countries). The education and policy effects in Table 2 are differentiated among four age/sex categories. When applied to the more disaggregated series, the youth coefficients are assumed to apply equally to the 15-19 and 20-24 age groups for both men and women; the prime-age women/men coefficients are applied equally to women/men aged 25 to 54 , and the elderly coefficients are assumed to apply equally to age groups 55 and over for both women and men.

47. Using the initial structural employment rate projection for sex $s$, age group $a$, country $i$ and year $t$ $\left(\widetilde{E R}{ }_{s, a, i, t}^{\text {init }}\right)$, obtained from either the cohort approach or the constant structural employment rate assumption, the incorporation of policy and education effects into the final estimate $\left(\widetilde{E R}_{s, a, i, t}^{\text {final }}\right)$ is done in first differences from the last available historical employment rate (time $t_{0}$ ) using:

$$
\Delta \widetilde{E R}_{s, a, i, t}^{\text {final }}=\Delta \widetilde{E R}_{s, a, i, t}^{\text {init }}-\gamma_{s, a} \cdot\left[\widetilde{E R}_{s, a, i, t-1}^{\text {final }}-\left(\widetilde{E R}_{s, a, i, t-1}^{\text {init }}+\sum_{j} \hat{\beta}_{j}\left(P_{j, i, t-1}-P_{j, i, t_{0}}\right)\right)\right]
$$

where $P_{j, i, t}$ denotes the value of policy indicator $j, \hat{\beta}_{j}$ its estimated effect from Table 2 and $\gamma_{s, a}$ the age/sexspecific convergence speed. For simplicity, it is assumed that, in year $t_{0}$, observed employment rates are at their long-run equilibria. Any policy change known to have occurred since $t_{0}$ can be incorporated via $P_{j, i, t}$, while policy reforms that occurred before $t_{0}$ with effects continuing after $t_{0}$ are more difficult to take into account. Ideally, for each country, $t_{0}$ would also correspond to the last historical data points for all structural/policy indicators. In practice, official estimates of structural/policy indicators are usually less timely than for employment rates. Therefore, some of them might need to be extended forward for a few years, ideally incorporating any recent policy changes. For some indicators, such as the retirement age, this is easily done, but for others, such as the tax wedge, it is not so simple to estimate the impact that recent policy changes might have on the indicator, so some judgment might be imposed or simple assumptions made. 


\subsubsection{Aggregation}

48. Once education and policy effects have been applied to the disaggregated initial employment rate series, an aggregate potential employment series is obtained by weighting and adding up the age/sexspecific employment rate projections by age/sex-specific population projections. So aggregate potential employment for country $i$ and year $t\left(E T P T_{i, t}\right)$, is:

$$
\operatorname{ETPT}_{i, t}=\sum_{s, a}\left(\widetilde{E R}_{s, a, i, t}^{\text {final }} \cdot P O P_{s, a, i, t}\right)
$$

where $P O P_{s, a, i, t}$ is the population projection for sex $s$, age group $a$, country $i$ and year $t$. As in the longterm scenarios model, the latest Eurostat population projections (medium scenario) are used for European countries and United Nations population projections are used for all other countries. This aggregate potential employment series enters the calculation of aggregate potential output with a weight of two-thirds given the assumed Cobb-Douglas production function.

49. When back casting the series thus obtained and comparing them to the OECD Economic Outlook (EO) series that serve as starting points for the long-run scenarios, the two sets do not always match very closely. Mostly, there are differences in level terms, but also sometimes in growth rates. The differences can be attributed to using different original sources for the disaggregated employment rates versus the aggregate EO series, differences in the cyclical adjustment methodology, differences in EU/UN population estimates versus population estimates implicit in total employment estimates from national sources, etc. To eliminate any level difference at the jump-off point between the last EO data point and the first year of the long-term projection, the ETPT series calculated with equation [9] is spliced onto the EO series in growth rates. When even growth rates differ too much at the jump-off point, differences are smoothed over a number of years to ensure no sudden jump in potential employment and in potential output.

\subsection{Simulations with rising educational attainment and an illustrative policy package}

50. For the published OECD long-term scenarios, it is envisaged to include the effect of rising educational attainment as part of the baseline scenario, using projections of educational attainment by Barro and Lee (2015). The reason is that rising educational attainment is in large part a 'mechanical' effect due to less-educated workers leaving the working-age range and more educated younger people coming to represent a larger share of the workforce. It will occur even if governments do not take any policy initiative. Including some increase in educational attainment in the baseline scenario does not, however, preclude running alternative scenarios with faster improvement that could be linked to education policy reforms. In any case, because the aggregate education effect is, as explained above, very small, the aggregate employment rate will be very close to the initial projection from the cohort approach. Only in the projections by age groups would there be noticeable differences.

51. The potential impact of rising educational attainment and policy reforms on employment rates can be illustrated with a simulation, using Germany as an example. First, average educational attainment in Germany is projected to increase by 2.4 years of schooling between 2020 and 2060. In addition, the following permanent policy package is assumed to be implemented in 2020, with the magnitudes of the policy changes matching those of typically-observed reforms as estimated by Égert and Gal (2017):

- Public spending on active labour market policies per unemployed person goes up by 3.18 percentage points of GDP per capita.

- $\quad$ Product market reforms lower the ETCR index by 0.31 points.

- Union bargaining excess coverage declines by 1.89 percentage points of the workforce. 
- The minimum wage falls by 2.48 percentage points of the median wage (not necessarily via a fall in the legal minimum but maybe through increases in other wages).

- Public spending on family benefits in kind increase by 0.11 percentage point of GDP and maternity leave is extended by 4.83 weeks.

- The legal pension age is raised by 0.57 years over the 2020 -to-2025 period.

- The tax wedges for singles declines by 1.39 percentage points of labour costs and that of couples by 2.28 percentage points.

- The unemployment benefits replacement rate is cut by 1.42 percentage points.

The simulation is not meant to be realistic, but only illustrative. Germany and the year 2020 are chosen because the initial projection without policy or education effects is for potential employment in Germany to start declining in 2021 (Figure 8, Panel A).

52. The dynamics of aggregate and selected age/sex-specific employment rates are shown in Figure 8, with and without the education and policy impacts. Rising educational attainment by itself is projected to depress youth employment rates (illustrated with women aged 15 to 19 in Panel C), but the positive effects the policy package on the year-to-year change in the employment rate overcome the negative impact of rising educational attainment for a few years and raise youth employment rates significantly above the no-policy scenario. The biggest policy impacts are on prime-age women (illustrated with the 30-to-34 age group in Panel D). Their employment rates rise steeply in the first five years or so after the policy reforms. Thereafter, the shallower uptrend in the employment rate is due to rising educational attainment. Because several reforms, including those pertaining to family benefits and maternity leave, do not affect prime-age men, their employment rates rise less than those of prime-age women (illustrated with the 30-to-34 age group in Panel E). Finally, while elderly employment rates are not affected by rising educational attainment, they are nevertheless positively impacted by policy reforms (illustrated with women aged 60 to 64 in Panel F). In aggregate, the trend employment rate rises significantly above the initial projection, by some 2 percentage points once policy effects are fully phased in (Panel B). Although potential employment is still expected to start declining soon given the exogenous population projections, the policy package is enough to delay the turnaround by two years and raise longrun trend employment by about one million workers (Panel A).

53. Given the relatively high convergence speeds, and as can be gleaned from Figure 8, about twothirds of the long-term reform effects are phased in after only five years, and $90 \%$ within ten years. The full long-term effects of the different policy reforms are shown in Table 3. 
Figure 8. Impacts of example policy package on projections for Germany

A Potential employment, millions of workers

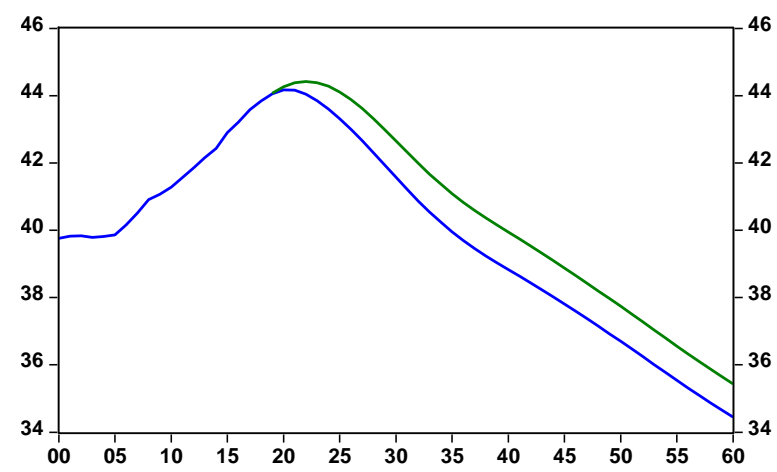

C. Trend employment rate of women aged 15 to 19 , per cent

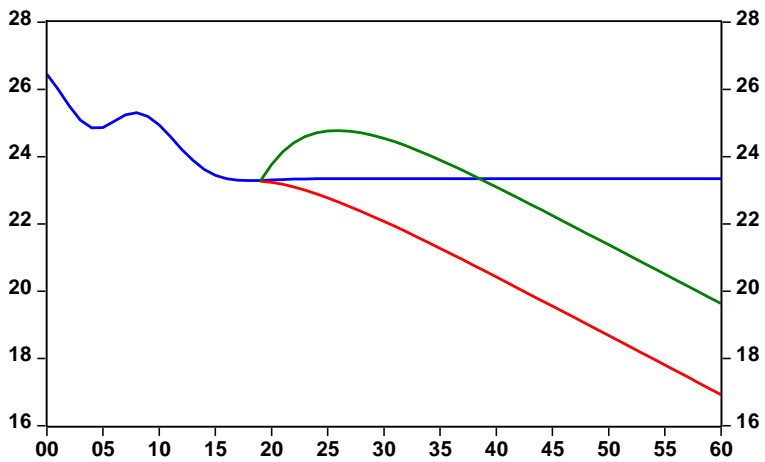

E. Trend employment rate of men aged 30 to 34 , per cent

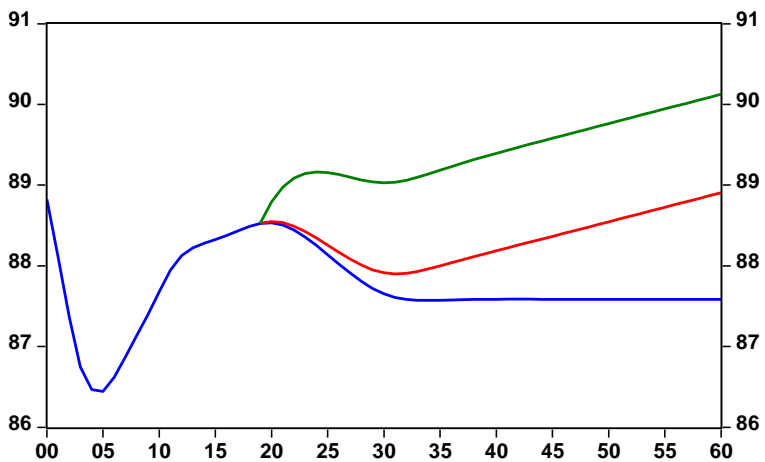

B. Trend aggregate employment rate, per cent

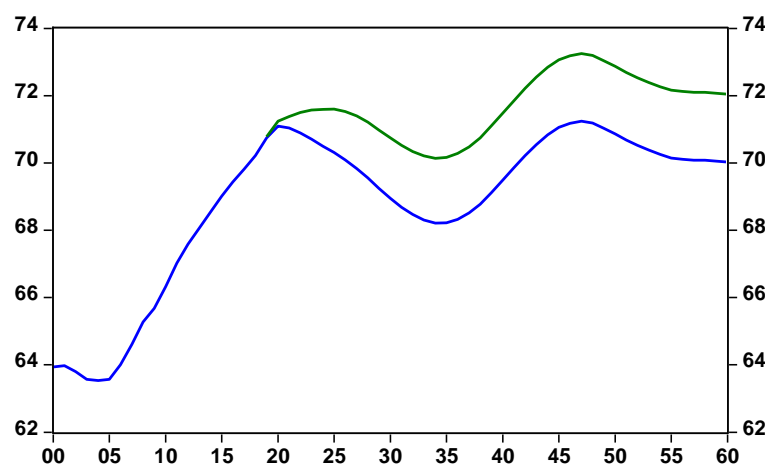

D. Trend employment rate of women aged 30 to 34

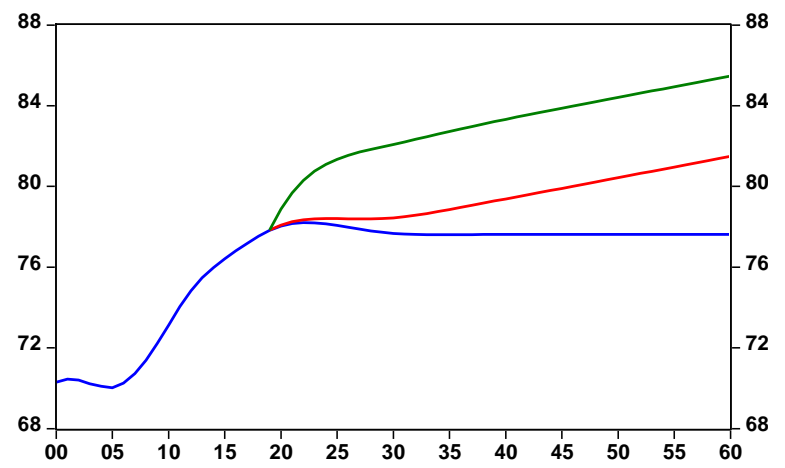

F. Trend employment rate of women aged 60 to 64 , per cent

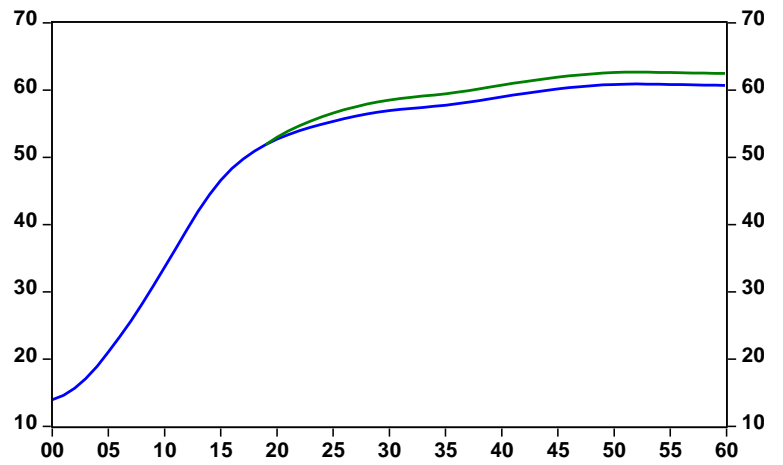

From cohort approach only —— With education effect $\_$With education and policy effects

Note: The projection with the education effect only is not shown for the 60-64 age group because there is no estimated education effect for elderly age groups (see Table 3). It is also not shown for the aggregates in Panels A and B because it has only a very small effect at the aggregate level given opposing effects for youth and prime-age workers (see main text). 


\section{ECO/WKP(2017)16}

\section{Table 3. Long-run effects of example policy reform package on German employment rates}

Percentage point change in age/sex-specific and total employment rates

\begin{tabular}{|c|c|c|c|c|c|c|}
\hline & Size of reform ${ }^{1}$ & Youth (15-24) & Prime-age women & Prime-age men & Elderly $(55+)$ & Aggregate $^{2}$ \\
\hline UE benefit replacement rate (in pp) & -1.42 & 0.260 & 0.290 & 0.209 & 0.487 & 0.306 \\
\hline ALMP spending ( $p p$ of GDP per capita) & 3.18 & 0.467 & 0.293 & 0.149 & 0.200 & 0.234 \\
\hline Tax wedge single (pp of labour costs) & -1.39 & 1.204 & & & & 0.109 \\
\hline Tax wedge couple (pp of labour costs) & -2.28 & & & 0.625 & 0.593 & 0.365 \\
\hline Excess coverage (pp of workforce) & -1.89 & & 0.323 & & & 0.100 \\
\hline Minimum wage ( $\mathrm{pp}$ of median wage) & -2.48 & 0.771 & 1.044 & & & 0.391 \\
\hline Family benefits in kind ( $p p$ of GDP) & 0.11 & & 0.517 & & & 0.159 \\
\hline Number of weeks of maternity leave & 4.83 & & 1.280 & & & 0.394 \\
\hline Legal age for pensions & 0.57 & & & & 0.485 & 0.119 \\
\hline ETCR (index, higher is more restrictive) & -0.31 & & 0.236 & 0.236 & & 0.156 \\
\hline Total & - & 2.702 & 3.982 & 1.219 & 1.765 & 2.334 \\
\hline
\end{tabular}

1. The magnitudes are those of typically observed reforms as estimated by Égert and Gal (2017).

2. The reform-specific effects on the aggregate employment rate are calculated using fixed age/sex shares in potential employment (those of 2020). Consequently, the total (bottom right cell) does not correspond exactly to the total effect illustrated in Figure 8, Panel B, which is based on variable (projected) employment shares.

Source: Égert and Gal (2017). 


\section{REFERENCES}

Barro, R.J. and J.W. Lee (2013), "A New Data Set of Educational Attainment in the World, 19502010”, Journal of Development Economics, Vol. 104, pp. 184-198.

Barro, R.J. and J.W. Lee (2015), Education Matters: Global Schooling Gains from the 19th to the 21st Century, Oxford University Press.

Bassanini, A. (2015), “A Bitter Medicine? Short-term Employment Impact of Deregulation in Network Industries”, IZA Discussion Paper, No. 9187, Bonn.

Bouis, R., R. Duval and J. Eugster (2016), "Product Market Deregulation and Growth: New CountryIndustry-Level Evidence", IMF Working Papers, No. WP/16/114, IMF, Washington, DC.

Burniaux, J., R. Duval and F. Jaumotte (2004), "Coping with ageing: a dynamic approach to quantify the impact of alternative policy options on future labour supply in OECD Countries", OECD Economics Department Working Papers, No. 371, OECD Publishing, Paris. DOI: http://dx.doi.org/10.1787/224538175006

De Serres, A. and P. Gal (2015), "Evidence on the Aggregate Employment Effects of Product Market Reforms: Which Types of Regulation Matter Most?", Presentation at the KDI-WB International Workshop, 12 November, Washington, DC.

Égert, B. and P. Gal (2017), "The quantification of structural reforms in OECD countries: a new framework", OECD Economics Department Working Papers, No. 1354, OECD Publishing, Paris. DOI: http://dx.doi.org/10.1787/2d887027-en

Fiori, G. et al. (2012), "Employment Outcomes and the Interaction between Product and Labor Market Deregulation: Are They Substitutes or Complements?", The Economic Journal, Vol. 122, No. 558, pp. 79-104.

Gal, P. and A. Theising (2015), "The macroeconomic impact of structural policies on labour market outcomes in OECD countries: A reassessment", OECD Economics Department Working Papers, No. 1271, OECD Publishing, Paris. DOI: http://dx.doi.org/10.1787/5jrqc6t8ktjf-en

Gal, P. and A. Hijzen (2016), "The short-term impact of product market reforms: a cross-country firmlevel analysis", OECD Economics Department Working Papers, No. 1311, OECD Publishing, Paris. DOI: http://dx.doi.org/10.1787/5jlv2jm07djl-en

Johansson, Å. et al. (2013), "Long-term growth Scenarios", OECD Economics Department Working Papers, No. 1000, OECD Publishing, Paris. DOI: http://dx.doi.org/10.1787/5k4ddxpr2fmr-en

OECD (2016), "Short-term labour market effects of structural reforms: pain before the gain?" in $O E C D$ Employment Outlook 2016, OECD Publishing, Paris. DOI: http://dx.doi.org/10.1787/empl_outlook2016-en 
Rusticelli, E., D. Turner and M. Cavalleri (2015), "Incorporating anchored inflation expectations in the Phillips Curve and in the derivation of OECD measures of equilibrium unemployment", OECD Economics Department Working Papers, No. 1231, OECD Publishing, Paris.

DOI: http://dx.doi.org/10.1787/5js1gmq551wd-en

Turner, D. et al. (2016), "An investigation into improving the real-time reliability of OECD output gap estimates", OECD Economics Department Working Papers, No. 1294, OECD Publishing, Paris. DOI: http://dx.doi.org/10.1787/5jm0qwpqmz34-en 
ECO/WKP(2017)16

\section{APPENDIX 1. COMPARISON OF PREVIOUS AND REVISED APPROACHES}

Table A1.1. Comparison of previous and revised approaches to trend employment projections

\begin{tabular}{|l|l|}
\hline \multicolumn{1}{|c|}{ Previous approach (see Johansson et al., 2013) } & \multicolumn{1}{|c|}{ Revised approach (as in main text) } \\
\hline $\begin{array}{l}\text { 1. Piecewise linear regressions were used to identify } \\
\text { the trend component of historical age/sex-specific } \\
\text { labour force participation rates. }\end{array}$ & $\begin{array}{l}\text { 1. Historical data on employment rates by age and } \\
\text { sex are cyclically adjusted to obtain estimates of } \\
\text { trend employment rates. The cyclical adjustment } \\
\text { uses estimated equations linking employment rates } \\
\text { to the aggregate employment gap from the } O E C D \\
\text { Economic Outlook. }\end{array}$ \\
\hline $\begin{array}{l}\text { 2. Trend labour force participation rates by age and } \\
\text { sex were then used to calculate trend labour force } \\
\text { entry and exit rates using a cohort approach. An } \\
\text { initial projection assumed constant trend entry and } \\
\text { exit rates for future years. }\end{array}$ & $\begin{array}{l}\text { 2. The trend employment rates by age and sex are } \\
\text { into/from employment using a cohort-based } \\
\text { approach. For future years and cohorts, trend entry } \\
\text { and exit rates are assumed to remain fixed at their } \\
\text { last estimated values. }\end{array}$ \\
\hline $\begin{array}{l}\text { 3. Policy effects were added to the initial projection } \\
\text { of constant age/sex-specific trend entry and exit } \\
\text { rates to obtain the final projections. }\end{array}$ & $\begin{array}{l}\text { 3. Trend entry and exit rates are used to project } \\
\text { trend employment rates by age and sex into the } \\
\text { future. }\end{array}$ \\
\hline $\begin{array}{l}\text { 4. Projected trend entry and exit rates were used to } \\
\text { project trend labour force participation rates by age } \\
\text { and sex into the future. }\end{array}$ & $\begin{array}{l}\text { 4. Policy effects are added to the projected age/sex- } \\
\text { specific trend employment rates }\end{array}$ \\
\hline $\begin{array}{l}\text { 5. The disaggregated age/sex-specific trend labour } \\
\text { force participation rates were weighted by the } \\
\text { relevant population shares/totals to obtain an } \\
\text { aggregate labour force participation rate/total. }\end{array}$ & $\begin{array}{l}\text { 5. The disaggregated age/sex-specific trend } \\
\text { employment rates are weighted by the relevant } \\
\text { population shares/totals to obtain an aggregate trend } \\
\text { employment rate/total. }\end{array}$ \\
\hline $\begin{array}{l}\text { 6. Projected aggregate participation was then } \\
\text { combined with a projection of the non-accelerating } \\
\text { inflation rate of unemployment (NAIRU) to obtain } \\
\text { an aggregate employment projection. }\end{array}$ & \begin{tabular}{l} 
and \\
\hline
\end{tabular}
\end{tabular}




\section{APPENDIX 2. DETAILED RESULTS BY COUNTRY}

\section{Table A2.1. Cyclical adjustment coefficient $(\widehat{\beta})$ estimated using equation [1]}

\begin{tabular}{|c|c|c|c|c|c|c|c|c|c|c|c|c|c|c|c|c|}
\hline \multirow[t]{2}{*}{$\begin{array}{l}\text { Age } \\
\text { group }\end{array}$} & \multicolumn{2}{|c|}{ Australia } & \multicolumn{2}{|c|}{ Austria } & \multicolumn{2}{|c|}{ Belgium } & \multicolumn{2}{|c|}{ Canada } & \multicolumn{2}{|c|}{ Switzerland } & \multicolumn{2}{|c|}{ Chile } & \multicolumn{2}{|c|}{ Czech Republic } & \multicolumn{2}{|c|}{ Germany } \\
\hline & Men & Women & Men & Women & Men & Women & Men & Women & Men & Women & Men & Women & Men & Women & Men & Women \\
\hline $15-19$ & $1.59^{\star \star *}$ & $1.05^{\star \star *}$ & 0.33 & $1.74^{* *}$ & -0.24 & -0.24 & $1.93^{* \star *}$ & $1.60^{* * *}$ & $0.91^{* *}$ & $0.72^{\star \star}$ & $1.15^{\star \star \star}$ & $0.75^{\star \star \star}$ & $1.85^{\star \star *}$ & $1.32^{\star \star *}$ & $0.73^{\star \star \star}$ & $0.96^{\star * *}$ \\
\hline-24 & $39^{* * *}$ & $0.79^{* * *}$ & $1.72^{* * *}$ & -0.55 & $0.86^{* *}$ & $1.02^{* * *}$ & $1.56^{\star \star \star}$ & $1.02^{* * *}$ & 48 & $10^{* * *}$ & $31^{* * *}$ & $1.15^{\star \star \star}$ & $1.76^{* * *}$ & 0.05 & $.97^{* * *}$ & $6^{* * *}$ \\
\hline $25-29$ & $0.96^{* \star *}$ & $0.48^{*}$ & $1.01^{* \star \star}$ & -0.70 & $0.91^{* * *}$ & $1.44^{* * *}$ & $1.20^{* \star *}$ & $0.90^{* * *}$ & $0.44^{*}$ & -0.00 & $0.90^{* * *}$ & $0.66^{* *}$ & $0.54^{* \star *}$ & $0.70^{* \star *}$ & $1.01^{* * *}$ & $0.60^{* *}$ \\
\hline $30-34$ & $.73^{* * *}$ & $0.61^{\star \star *}$ & $0.91^{\star \star \star}$ & 0.61 & $0.67^{\star * *}$ & $0.93^{* *}$ & $1.04^{* \star *}$ & $0.86^{* \star *}$ & $0.52^{\star \star *}$ & -0.37 & $0.59^{* * *}$ & $1.14^{\star \star *}$ & $0.37^{* *}$ & 0.40 & $0.78^{* * *}$ & 0.30 \\
\hline $35-39$ & $0.71^{\star * *}$ & $0.78^{* \star \star}$ & $0.96^{\star \star \star}$ & $0.91^{* *}$ & $0.50^{* * *}$ & $1.10^{\star \star \star}$ & $0.70^{\star \star \star}$ & $0.86^{* \star *}$ & $0.49^{\star \star *}$ & $0.93^{* \star *}$ & $0.40^{\star \star \star}$ & $1.20^{\star \star \star}$ & $0.55^{\star \star \star}$ & 0.16 & $0.61^{\star * *}$ & $0.34^{*}$ \\
\hline $40-44$ & $.66^{\star \star *}$ & $0.62^{* *}$ & $0.63^{\star *}$ & 0.51 & $0.59^{\star \star *}$ & $0.85^{\star *}$ & $0.72^{* \star *}$ & $0.69^{* * \star}$ & $0.46^{\star * *}$ & 0.03 & $0.40^{\star * *}$ & $1.32^{\star \star *}$ & $0.68^{* * *}$ & $0.79^{* \star *}$ & $0.50^{\star * *}$ & 0.21 \\
\hline $45-49$ & $62^{* * *}$ & 0.27 & 0.33 & 0.47 & $0.28^{*}$ & 0.40 & $0.68^{* \star *}$ & $0.67^{* *}$ & $0.47^{\star \star *}$ & $0.50^{* * *}$ & $0.40^{\star * *}$ & $1.15^{\star * *}$ & $0.69^{* * *}$ & $0.71^{* * *}$ & $0.53^{* * *}$ & 0.36 \\
\hline $50-54$ & $0.63^{* * *}$ & $0.44^{* *}$ & 0.29 & $0.78^{*}$ & $-0.92^{* * *}$ & $-1.18^{* * *}$ & $0.61^{* \star *}$ & $0.61^{* \star *}$ & 0.05 & $0.51^{* * *}$ & $0.39^{* * *}$ & $0.85^{\star * *}$ & $0.69^{* \star *}$ & $0.86^{\star * *}$ & $0.75^{\star \star *}$ & $0.54^{* *}$ \\
\hline $55-59$ & $1.08^{\star \star}$ & $0.60^{* *}$ & 0.21 & -1.36 & $-2.04^{* \star *}$ & $-1.55^{\star \star}$ & 0.57 & 0.32 & $0.70^{\star \star \star}$ & -0.32 & $0.40^{* \star *}$ & $03^{\star \star \star}$ & $0.60^{* \star *}$ & $1.40^{\star \star \star}$ & $1.48^{* *}$ & 0.72 \\
\hline $60-64$ & $1.37^{\star \star *}$ & $0.77^{*}$ & 0.30 & -0.08 & $-1.45^{\star \star *}$ & $-1.02^{* * *}$ & 0.11 & -0.14 & $1.33^{* *}$ & $0.99^{* * *}$ & $0.77^{\star * *}$ & $0.93^{\star \star *}$ & $1.65^{\star \star \star}$ & $0.52^{* *}$ & $.80^{\star \star}$ & $1.29^{*}$ \\
\hline $65-69$ & 0.49 & 0.28 & 0.03 & 0.05 & 0.05 & -0.02 & -0.35 & -0.24 & $1.47^{\star \star \star}$ & $0.91^{* * *}$ & $1.59^{* \star *}$ & $0.96^{* * *}$ & $0.53^{* * *}$ & 0.09 & 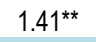 & $0.65^{\star}$ \\
\hline \multirow[t]{3}{*}{$70-74$} & NA & NA & .38 & 0.3 & 00 & 0.0 & .21 & -0.1 & .43 & $0.81^{*}$ & $1.74^{\star \star \star}$ & $0.62^{* * *}$ & .03 & 0.0 & $60^{* \star}$ & $0.38^{* * \pi}$ \\
\hline & \multicolumn{2}{|c|}{ Denmark } & \multicolumn{2}{|c|}{ Spain } & \multicolumn{2}{|c|}{ Estonia } & \multicolumn{2}{|c|}{ Finland } & \multicolumn{2}{|c|}{ France } & \multicolumn{2}{|c|}{ United Kingdom } & \multicolumn{2}{|c|}{ Greece } & \multicolumn{2}{|c|}{ Hungary } \\
\hline & Men & Women & Men & Women & Men & Women & Men & Women & Men & Women & Men & Women & Men & Women & Men & Women \\
\hline $15-19$ & $1.65^{\star * *}$ & $1.54^{\star \star *}$ & $0.88^{* * *}$ & $0.50^{\star * *}$ & $50^{n n n}$ & $0.28^{\star *}$ & $0.79^{\star * *}$ & $1.28^{\star * *}$ & $1.90^{\star \star *}$ & $1.26^{\pi \times x}$ & $2.42^{\star \star \star}$ & $2.12^{\star \star *}$ & $0.11^{k *}$ & & -0.13 & -0.14 \\
\hline $20-24$ & $2.05^{* * *}$ & $1.28^{* * *}$ & $1.46^{* * *}$ & $1.15^{\star \star *}$ & $1.04^{* * *}$ & $0.77^{\star * *}$ & $1.58^{* * *}$ & $1.88^{* * *}$ & $3.47^{\star * *}$ & $2.58^{* * *}$ & $1.83^{* * *}$ & $1.22^{\star \star *}$ & $0.83^{* * *}$ & $0.70^{\star * *}$ & 0.83 & $0.91^{* *}$ \\
\hline $25-29$ & $1.45^{\star \star \star}$ & $1.25^{\star \star \star}$ & $1.09^{\star \star \star}$ & $0.99^{\star * *}$ & $1.21^{\star \star *}$ & $0.41^{* *}$ & $1.43^{* \star *}$ & $1.41^{* \star *}$ & $1.62^{\star \star \star}$ & $1.06^{\star * *}$ & $1.10^{\star \star \star}$ & $1.01^{* * *}$ & $1.31^{* \star *}$ & $1.14^{\star \star *}$ & $1.10^{* * *}$ & $1.04^{* * *}$ \\
\hline $30-34$ & $0.84^{\star * *}$ & $0.88^{\star * *}$ & $0.83^{\star \star \star}$ & $0.72^{\star \star *}$ & $0.90^{\star * *}$ & $0.81^{* \star *}$ & 1.0 & 1.0 & $1.04^{* \star \star}$ & 0.6 & $0.78^{\star * *}$ & *** & 1.0 & $0.71^{* \star *}$ & $0.74^{* * \star}$ & $0.77^{\star \star * *}$ \\
\hline $35-39$ & $0.76^{\star * *}$ & $0.63^{\star * *}$ & $0.63^{\star \star *}$ & $0.50^{\star \star *}$ & $0.78^{\star * *}$ & 0.26 & $0.93^{* \star *}$ & $0.83^{* * *}$ & $0.83^{\star \star \star}$ & 0.32 & $0.69^{\star * *}$ & $0.65^{\star \star \star}$ & $0.86^{\star * *}$ & $0.70^{\star \star *}$ & $0.57^{\star \star *}$ & $0.46^{* *}$ \\
\hline $40-44$ & $0.56^{* * *}$ & $0.48^{* * *}$ & $0.62^{* \star *}$ & $0.48^{* \star *}$ & $0.94^{* * *}$ & $0.40^{* * *}$ & $0.91^{* \star \star}$ & $0.60^{* * *}$ & $0.95^{\star * *}$ & 0.14 & $0.66^{* \star *}$ & $0.47^{* * *}$ & $0.69^{* * *}$ & $0.78^{* \star *}$ & $0.47^{\star *}$ & 0.16 \\
\hline $45-49$ & $0.68^{* * *}$ & $0.59^{* * *}$ & $0.67^{*}$ & $0.40^{\star * *}$ & 1.16 & $0.42^{* *}$ & 0.8 & $0.64^{* \star *}$ & 0.90 & -0 . & $0.52^{\star * *}$ & $0.39^{* * *}$ & $0.80^{\star * *}$ & 0.5 & 0.28 & 26 \\
\hline $50-54$ & $55^{\star \star *}$ & $0.87^{\star \star \star}$ & $0.59^{\star \star \star}$ & 0.05 & $0.87^{\star * *}$ & $0.59^{\star \star \star *}$ & $0.79^{\star \star \star}$ & $0.51^{\star \star \star}$ & 0.41 & 0.2 & $0.47^{\star \star \star}$ & $0.13^{*}$ & $0.75^{\star \star \star}$ & $0.44^{\star \star *}$ & $0.39^{*}$ & $0.98^{* * *}$ \\
\hline $55-59$ & $0.73^{\star * *}$ & $0.95^{\star \star \star}$ & $0.43^{\star \star \star}$ & -0.23 & $1.00^{* * *}$ & $0.66^{* *}$ & $1.21^{\star \star \star}$ & $0.93^{* * *}$ & -0.52 & -0.0 & 044 & 0.04 & $0.68^{\star \star *}$ & $0.19^{*}$ & $1.05^{\star \star *}$ & 0.41 \\
\hline $60-64$ & -0.39 & $-0.81^{* *}$ & $0.26^{*}$ & $-0.21^{* *}$ & -0 . & 0. & 0.9 & 0.9 & 0. & -0 . & & -0 & 0.5 & $0.15^{\star \star *}$ & 0. & 10 \\
\hline $65-69$ & -0.24 & $-0.38^{* *}$ & $0.12^{* * *}$ & -0.01 & $0.67^{* * *}$ & 0 & 0.2 & 0 & 0.00 & 0. & -0.27 & $-0.34^{* *}$ & $0.29^{* * *}$ & 0.02 & $-0.16^{*}$ & $-0.11^{*}$ \\
\hline \multirow[t]{3}{*}{$70-74$} & 0.25 & 0.03 & $0.03^{* *}$ & 0.00 & 0.10 & $-0.32^{* * *}$ & $0.18^{* *}$ & 0.03 & 0.27 & 0.15 & -0.07 & -0.11 & $0.15^{\star * *}$ & $0.04^{* *}$ & $-0.11^{*}$ & $-0.07^{* *}$ \\
\hline & \multicolumn{2}{|c|}{ Iceland } & Irel & and & & ael & & aily & & & Ko & rea & Luxem & nbourg & & co \\
\hline & Men & Women & Men & Women & Men & Women & Men & Wor & Men & Won & Men & Women & Men & Women & Men & Wom \\
\hline $15-19$ & $1.52^{\star \star *}$ & $1.34^{\star \star \star}$ & $1.21^{\star \star \star}$ & $0.91^{* * *}$ & 0.49 & 0.34 & 0.05 & $0.17^{\star \star}$ & $0.73^{\star \star \star}$ & $0.43^{\star \star *}$ & 0.02 & 0.22 & 0.78 & 0.18 & $0.83^{\star * *}$ & $0.61^{\text {*** }}$ \\
\hline $20-24$ & $1.26^{* * *}$ & $0.77^{\star \star \star}$ & $1.77^{\star \star \star}$ & $0.93^{\star * *}$ & $1.88^{* * *}$ & $0.98^{* *}$ & $1.25^{* \star \star}$ & $1.32^{* * *}$ & $1.94^{* \star *}$ & $1.61^{* * *}$ & $0.99^{* * *}$ & $1.61^{\star \star *}$ & 0.58 & 0.10 & $0.53^{* * *}$ & $0.34^{*}$ \\
\hline $25-29$ & $0.98^{\star \star *}$ & $0.62^{\star \star \star}$ & $1.31^{\star \star \star}$ & $1.02^{\star \star *}$ & $0.83^{\star \star}$ & 0.24 & $1.49^{\star \star \star}$ & $1.42^{* \star *}$ & $1.06^{\star \star \star}$ & $0.87^{\star \star *}$ & $1.04^{\star \star \star}$ & $0.36^{* *}$ & -0.04 & & $0 . L^{-1}$ & 0.21 \\
\hline $30-34$ & $0.63^{\star * *}$ & $0.72^{\star \star \star}$ & $0.93^{\star * *}$ & $0.75^{\star \star *}$ & 0.14 & 0.25 & $0.94^{* \star *}$ & $1.17^{\star \star \star}$ & $0.91^{\star \star *}$ & 0.15 & $0.72^{\star \star \star}$ & $0.64^{* \star *}$ & $0.40^{* * *}$ & $1.28^{\star \star \star}$ & 0.27 & $0.31^{* *}$ \\
\hline $35-39$ & $0.44^{* * *}$ & 0.23 & $0.84^{* * *}$ & $0.79^{* * *}$ & $0.64^{*}$ & $0.94^{\star * *}$ & $0.71^{* \star \star}$ & $0.88^{* * *}$ & $0.67^{\star \star *}$ & $0.99^{* * *}$ & $0.60^{\star * *}$ & $0.76^{* * *}$ & $0.26^{* *}$ & $0.60^{*}$ & $0.28^{\star}$ & $0.43^{* *}$ \\
\hline $40-44$ & $0.48^{* * *}$ & $0.23^{* *}$ & $0.90^{* * *}$ & $1.00^{\star * *}$ & $1.10^{\star *}$ & $0.75^{\star * *}$ & $0.63^{* *}$ & $0.68^{* * *}$ & $0.57^{\star * *}$ & $1.04^{* * \star}$ & $0.70^{* * *}$ & $0.60^{* * *}$ & 0.03 & $0.51^{*}$ & $0.33^{*}$ & 0.13 \\
\hline $45-49$ & $0.28^{\star \star}$ & $0.38^{* *}$ & $0.76^{\star * *}$ & $0.87^{\star \star \star}$ & $1.16^{\star \star}$ & $0.64^{* \star}$ & $0.71^{\star \star \star}$ & $0.76^{* \star \star}$ & $0.66^{\star \star *}$ & $1.07^{\star \star \star}$ & $0.79^{\star \star \star}$ & $0.33^{* *}$ & -0.08 & 0.22 & 0.32 & 0.06 \\
\hline $50-54$ & $0.34^{* *}$ & 0.10 & $0.64^{* \star *}$ & $0.50^{\star \star *}$ & $1.21^{\star * *}$ & $0.90^{\star \star *}$ & $1.04^{* \star *}$ & $0.58^{\star *}$ & $0.88^{* * *}$ & $1.30^{* * *}$ & $0.74^{* * *}$ & $0.94^{* * *}$ & $0.48^{*}$ & 0.34 & $0.34^{*}$ & 0.22 \\
\hline $55-59$ & $0.60^{\star * *}$ & 0. & & 0.04 & & & -0 . & -0 & $1.18^{\star \star *}$ & $1.04^{\star \star *}$ & $1.24^{\star \star *}$ & $0.85^{\star \star *}$ & -0.35 & 0.40 & & .19 \\
\hline $60-64$ & $0.37^{\star \star}$ & 0.14 & $0.42^{\times x \times}$ & 0.01 & $2.23^{\star \star \star *}$ & $1.57^{* \pi x}$ & $-0.64^{*}$ & $-0.66^{\pi x}$ & $1.82^{\text {तxk }}$ & $1.04^{\star \star}$ & $1.50^{\star \star \star}$ & 0.23 & -0.38 & -0.13 & $0.66^{* * *}$ & $0.62^{* * *}$ \\
\hline $65-69$ & -0.02 & -0.53 & 0.01 & -0.07 & $1.48^{\star \star}$ & $1.34^{\star *}$ & -0.04 & $-0.12^{\star * \star}$ & 0.76 & 0.03 & $0.50^{* *}$ & 0.15 & -0.16 & 0.11 & 0.27 & 0.09 \\
\hline $70-74$ & -0.00 & -0.25 & 0.00 & -0.03 & $0.50^{*}$ & 0.10 & $-0.10^{\star *}$ & $-0.07^{\star \star *}$ & 0.05 & -0.17 & $0.39^{*}$ & $0.33^{* *}$ & -0.07 & -0.11 & 0.26 & 0.11 \\
\hline
\end{tabular}


ECO/WKP(2017)16

Table A2.1. Cyclical adjustment coefficient $(\widehat{\boldsymbol{\beta}})$ estimated using equation [1] (cont'd)

\begin{tabular}{|c|c|c|c|c|c|c|c|c|c|c|c|c|c|c|c|c|}
\hline \multirow[t]{2}{*}{$\begin{array}{l}\text { Age } \\
\text { group }\end{array}$} & \multicolumn{2}{|c|}{ Netherlands } & \multicolumn{2}{|c|}{ Norway } & \multicolumn{2}{|c|}{ New Zealand } & \multicolumn{2}{|c|}{ Poland } & \multicolumn{2}{|c|}{ Portugal } & \multicolumn{2}{|c|}{ Slovak Republic } & \multicolumn{2}{|c|}{ Slovenia } & \multicolumn{2}{|c|}{ Sweden } \\
\hline & Men & Women & Men & Women & Men & Women & Men & Women & Men & Women & Men & Women & Men & Women & Men & Women \\
\hline $15-19$ & $2.57^{\star * \star}$ & $2.75^{\star \star \star}$ & $1.88^{* * *}$ & $1.82^{\star \star *}$ & $1.71^{\star \star \star \star}$ & $1.73^{\star \star \star}$ & $0.16^{\star}$ & 0.08 & 0.16 & 0.07 & $0.50^{\star \star \star}$ & $0.35^{\star \star}$ & $1.27^{\star \star \star}$ & $1.04^{\star \star \star}$ & $2.05^{\star \star \star}$ & $2.22^{\star \star \star}$ \\
\hline $20-24$ & $1.89^{* * *}$ & $1.41^{* * *}$ & $1.68^{* * *}$ & $1.19^{\star \star \star}$ & $0.81^{\text {** }}$ & 0.18 & $2.07^{\star \star *}$ & $1.41^{* * *}$ & $1.74^{* * *}$ & $1.62^{* \star *}$ & $1.11^{\star \star *}$ & 0.07 & $2.13^{* * *}$ & $1.55^{\star \star \star}$ & $2.37^{\star \star *}$ & $2.21^{\star \star *}$ \\
\hline $25-29$ & $1.52^{* * *}$ & $0.98^{\star *}$ & $1.18^{* * *}$ & $0.63^{* *}$ & $0.54^{\star * *}$ & $0.91^{* * *}$ & $1.36^{\star \star \star}$ & $0.82^{\star * \star}$ & $1.12^{* * \star}$ & $1.34^{\star * \star}$ & $0.79^{* * *}$ & $0.28^{* *}$ & $1.19^{* \star *}$ & $1.15^{* \star *}$ & $1.29^{\star \star *}$ & $1.39^{\star * *}$ \\
\hline $30-34$ & $0.97^{* * *}$ & $1.55^{\star \star *}$ & $0.65^{* * *}$ & $0.46^{*}$ & $0.38^{* *}$ & $0.55^{\star \star *}$ & $0.86^{\star * *}$ & $0.67^{* * *}$ & $0.88^{* * *}$ & $1.03^{* * *}$ & $0.75^{\star * *}$ & 0.24 & $0.55^{\star * *}$ & $0.89^{* * *}$ & $1.20^{\star * *}$ & $1.23^{\star \star *}$ \\
\hline $35-39$ & $0.97^{* * *}$ & $1.31^{* * *}$ & $0.90^{* * *}$ & $0.44^{* * *}$ & $0.33^{* *}$ & 0.09 & $0.83^{\star * *}$ & $0.78^{* * *}$ & $0.69^{* * *}$ & $0.93^{* * *}$ & $0.98^{\star \star *}$ & $0.37^{\star *}$ & 0.23 & $0.39^{* *}$ & $1.05^{\star \star *}$ & $0.87^{\star \star *}$ \\
\hline $40-44$ & $0.86^{* * *}$ & $1.41^{* * *}$ & $0.66^{* * *}$ & $0.52^{* \star *}$ & 0.18 & 0.24 & $0.93^{* * \star}$ & $0.85^{\star \star \star}$ & $0.75^{\star * *}$ & $0.93^{* * *}$ & $0.70^{\star \star *}$ & $0.39^{* * *}$ & $0.42^{\star}$ & $0.51^{* *}$ & $0.96^{* \star *}$ & $0.74^{\star * *}$ \\
\hline $45-49$ & $0.59^{\star * *}$ & $1.16^{* \star *}$ & $0.51^{* \star *}$ & $0.64^{* \star *}$ & $0.34^{* * *}$ & $0.30^{\star \star}$ & $1.09^{* \star *}$ & $0.92^{\star \star *}$ & $0.74^{* * *}$ & $1.06^{\star \star *}$ & $0.90^{\star \star *}$ & $0.53^{\star \star *}$ & $0.55^{\star \star *}$ & $1.04^{\star * *}$ & $0.71^{* \star *}$ & $0.48^{\star \star \star}$ \\
\hline $50-54$ & $0.64^{* * *}$ & $0.34^{* \star}$ & $0.48^{* *}$ & $0.36^{* * *}$ & $0.51^{* * *}$ & $0.88^{* * *}$ & $1.44^{* * *}$ & $1.34^{* * *}$ & $0.71^{* * *}$ & $0.54^{\star * *}$ & $0.69^{* * *}$ & $0.21^{*}$ & 0.38 & $1.13^{* *}$ & $0.58^{* * *}$ & $0.22^{* *}$ \\
\hline $55-59$ & 0.43 & -0.04 & $0.71^{* * *}$ & $0.68^{\star * *}$ & $0.73^{\star \star \star *}$ & $0.75^{\star \star \star}$ & $1.40^{\star \star \star}$ & 0.83 & $0.37^{\star \star}$ & $0.35^{* \star *}$ & $0.66^{\star \star \star}$ & $1.15^{\star \star \star}$ & $1.14^{\star}$ & -0.05 & $0.88^{\star \star \star}$ & $0.46^{\star \star \star}$ \\
\hline $60-64$ & -0.22 & -0.46 & $0.72^{\star}$ & 0.20 & $1.75^{\star \star \star}$ & 0.29 & $0.83^{* *}$ & $0.31^{*}$ & $0.67^{* * *}$ & $0.87^{* * *}$ & $1.06^{\star \star *}$ & 0.15 & 0.26 & 0.22 & $1.27^{\star \star *}$ & $0.95^{\star * \star}$ \\
\hline $65-69$ & -0.42 & -0.07 & 0.63 & 0.18 & -0.42 & $-0.70^{* *}$ & $-0.24^{* *}$ & $-0.12^{\star *}$ & $0.71^{* * *}$ & $0.87^{\star \star *}$ & 0.09 & $0.07^{*}$ & -0.09 & 0.11 & 0.09 & $0.43^{\star \star *}$ \\
\hline \multirow[t]{3}{*}{ 70-74 } & $-0.29^{* *}$ & 0.04 & 0.12 & 0.04 & $-0.69^{\star *}$ & $-0.40^{\star *}$ & -0.03 & $-0.08^{*}$ & $0.67^{* \star *}$ & $0.78^{\star \star *}$ & 0.04 & $0.04^{*}$ & 0.28 & 0.19 & 0.10 & 0.06 \\
\hline & \multicolumn{2}{|c|}{ Turkey } & \multicolumn{2}{|c|}{ United States } & \multicolumn{2}{|c|}{ Costa Rica } & \multicolumn{2}{|c|}{ Latvia } & \multicolumn{2}{|c|}{ Lituania } & \multicolumn{2}{|c|}{ Colombia } & \multicolumn{2}{|c|}{ Brazil } & \multicolumn{2}{|c|}{ Russia } \\
\hline & Men & Women & Men & Women & Men & Women & Men & Women & Men & Women & Men & Women & Men & Women & Men & Women \\
\hline $15-19$ & $1.52^{\star \star *}$ & $0.99^{* * *}$ & $1.47^{\star \star *}$ & $1.46^{* \star *}$ & $0.98^{* * *}$ & $0.37^{\star \star \star}$ & $0.41^{* \star *}$ & $0.25^{\star \star *}$ & $0.16^{\star *}$ & 0.07 & $1.20^{\star \star *}$ & $0.80^{\star \star *}$ & $0.70^{\star \star}$ & $0.62^{* \star *}$ & $0.43^{*}$ & $0.46^{* * *}$ \\
\hline $20-24$ & $1.59^{* * *}$ & $1.04^{\star * *}$ & $1.25^{\star * *}$ & $0.94^{* * *}$ & $0.90^{* * *}$ & $1.16^{\star \star *}$ & $1.12^{\star \star *}$ & $0.66^{* * *}$ & $1.71^{* * *}$ & $0.69^{* \star}$ & $0.35^{\star * *}$ & $0.72^{\star * *}$ & $0.54^{* * *}$ & $0.50^{* *}$ & 0.54 & 0.58 \\
\hline $25-29$ & $1.06^{\star \star \star}$ & $0.89^{* \star *}$ & $1.05^{\star \star *}$ & $0.90^{* * *}$ & $0.53^{* \star}$ & $0.58^{\star \star}$ & $0.63^{\star \star \star}$ & $0.25^{\star \star \star}$ & $1.37^{* \star *}$ & $0.20^{*}$ & $0.14^{\star *}$ & $0.44^{\star \star \star}$ & 0.21 & $0.53^{* \star}$ & $0.99^{* \star \star}$ & $1.11^{* \star}$ \\
\hline $30-34$ & $1.00^{* * *}$ & $0.97^{* * *}$ & $0.80^{* * *}$ & $0.86^{* \star *}$ & $0.57^{\star * \star}$ & $0.45^{\star *}$ & $0.44^{* \star *}$ & 0.09 & $1.01^{* * *}$ & $0.42^{* * *}$ & 0.05 & $0.70^{\star * *}$ & $0.26^{*}$ & $0.48^{* *}$ & $0.82^{* \star *}$ & 0.91 \\
\hline $35-39$ & $0.98^{* * *}$ & $1.16^{\star \star \star}$ & $0.55^{\star \star *}$ & $0.89^{* \star *}$ & $0.54^{\star \star \star}$ & $0.60^{\star \star \star}$ & $0.57^{\star \star \star}$ & $0.43^{* \star *}$ & $1.03^{* * *}$ & $0.43^{\star \star \star}$ & -0.01 & $0.71^{\star * *}$ & $0.23^{\star \star}$ & 0.37 & $0.91^{* * \star}$ & $0.64^{*}$ \\
\hline $40-44$ & $0.84^{* * *}$ & $1.47^{\star \star *}$ & $0.50^{\star * *}$ & $1.02^{\star \star \star}$ & $0.29^{* *}$ & 0.22 & $0.68^{* \star *}$ & $0.31^{* * *}$ & $0.97^{* * *}$ & $0.33^{* * *}$ & -0.01 & $0.74^{\star \star *}$ & $0.38^{\star * *}$ & 0.39 & $0.44^{* * *}$ & $0.34^{*}$ \\
\hline $45-49$ & $1.41^{* * *}$ & $1.26^{\star \star *}$ & $0.55^{* * *}$ & $1.19^{* \star *}$ & 0.24 & 0.43 & $0.61^{* \star *}$ & $0.26^{* * *}$ & $1.00^{* * *}$ & $0.51^{\star \star *}$ & 0.07 & $0.69^{* * *}$ & $0.44^{* *}$ & 0.28 & $0.77^{\star * *}$ & $0.54^{\star \star *}$ \\
\hline $50-54$ & $1.69^{* * *}$ & $1.16^{* \star *}$ & $0.55^{\star * \star}$ & $1.07^{\star \star \star}$ & $0.31^{*}$ & 0.37 & $0.72^{\star \star \star}$ & $0.33^{* * *}$ & $0.86^{\star \star *}$ & $0.33^{*}$ & 0.15 & $0.71^{\star \star \star}$ & $0.22^{\star *}$ & 0.41 & $0.75^{\star \star \star}$ & $0.59^{\star * *}$ \\
\hline $55-59$ & $1.63^{* \star *}$ & $1.00^{\star \star *}$ & $0.25^{\star \star \star}$ & $0.49^{\star \star \star}$ & $0.59^{*}$ & 0.15 & $0.62^{\star \star \star}$ & $0.67^{\star \star *}$ & $0.70^{* * *}$ & $0.74^{* \star}$ & $0.32^{\star \star *}$ & $0.88^{\star \star *}$ & 0.11 & $0.64^{*}$ & 0.83 & 1.18 \\
\hline $60-64$ & $1.46^{* * *}$ & $0.76^{* * *}$ & -0.09 & -0.13 & $0.95^{\star * *}$ & $0.67^{\star \star *}$ & $0.87^{\star \star *}$ & $0.48^{* * *}$ & $0.98^{* * *}$ & $0.39^{\star *}$ & $0.73^{* * *}$ & $0.99^{* * *}$ & 0.28 & $0.72^{* \star}$ & $1.58^{*}$ & 0.53 \\
\hline $65-69$ & $1.17^{* * *}$ & $0.49^{* *}$ & -0.18 & $-0.20^{\star *}$ & $1.30^{* * *}$ & 0.23 & $0.91^{* * *}$ & $0.49^{* * *}$ & $0.53^{\star *}$ & 0.03 & $0.90^{* \star *}$ & $0.85^{\star \star *}$ & 0.52 & $0.58^{*}$ & NA & NA \\
\hline \multirow[t]{3}{*}{$70-74$} & $0.50^{\star *}$ & $0.29^{*}$ & $-0.25^{\star *}$ & $-0.16^{\star \star \star}$ & 0.45 & 0.25 & $0.55^{\star \star \star}$ & $0.14^{* * *}$ & -0.07 & 0.02 & $0.91^{* \star *}$ & $0.72^{\star * *}$ & NA & NA & NA & NA \\
\hline & South & Africa & & & & & & & & & & & & & & \\
\hline & Men & Women & & & & & & & & & & & & & & \\
\hline $15-19$ & $0.19^{\star * *}$ & $0.14^{\star * *}$ & & & & & & & & & & & & & & \\
\hline $20-24$ & $0.77^{\star \star \star}$ & $0.54^{* * *}$ & & & & & & & & & & & & & & \\
\hline $25-29$ & $0.77^{* \star *}$ & $0.56^{\star * *}$ & & & & & & & & & & & & & & \\
\hline 30-34 & $0.47^{* * *}$ & $0.58^{\star * \star}$ & & & & & & & & & & & & & & \\
\hline $35-39$ & $0.42^{* *}$ & $0.43^{* * *}$ & & & & & & & & & & & & & & \\
\hline $40-44$ & $0.37^{\star \star}$ & $0.26^{*}$ & & & & & & & & & & & & & & \\
\hline $45-49$ & $0.54^{* * *}$ & $0.36^{* * *}$ & & & & & & & & & & & & & & \\
\hline 50-54 & $0.39^{* * *}$ & $0.31^{* *}$ & & & & & & & & & & & & & & \\
\hline $55-59$ & $0.45^{\star *}$ & $0.30^{* \star *}$ & & & & & & & & & & & & & & \\
\hline $60-64$ & $0.77^{* * *}$ & $0.32^{*}$ & & & & & & & & & & & & & & \\
\hline $65-69$ & 0.24 & 0.01 & & & & & & & & & & & & & & \\
\hline $70-74$ & NA & NA & & & & & & & & & & & & & & \\
\hline
\end{tabular}


Figure A2.1. Employment rates by age and sex with no policy change, per cent

Australia - men

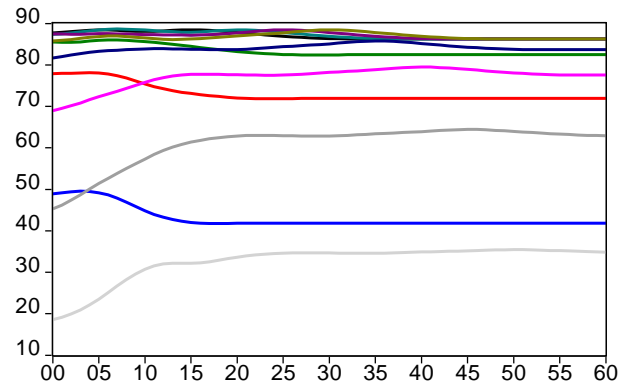

Austria - men

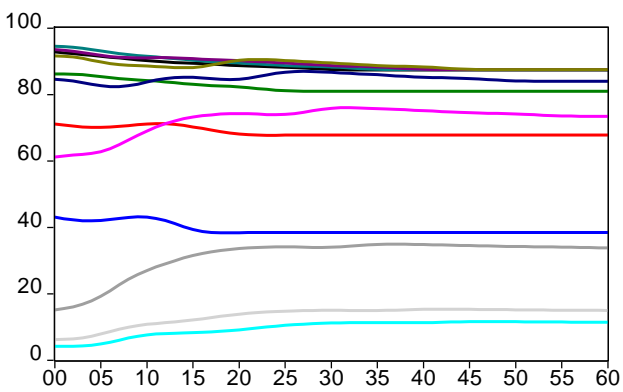

Belgium - men

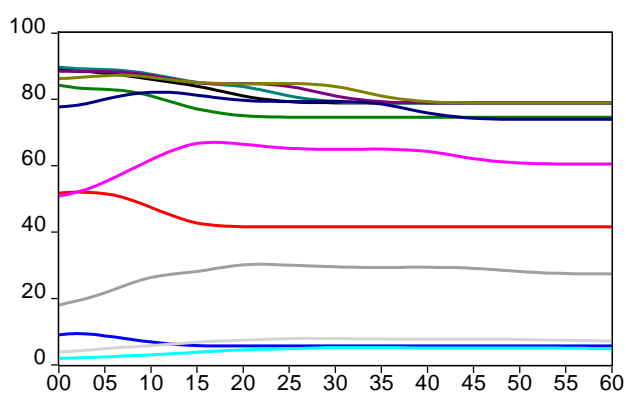

Canada - men

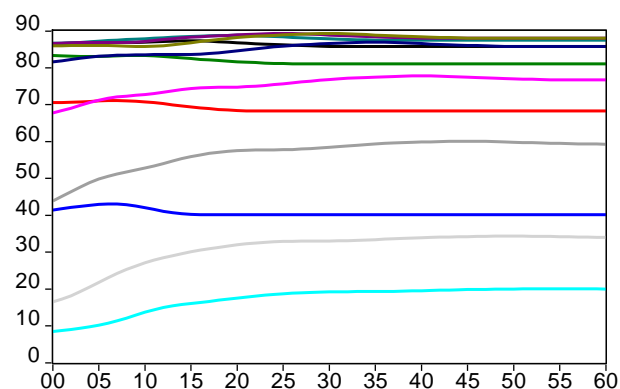

Australia - w omen

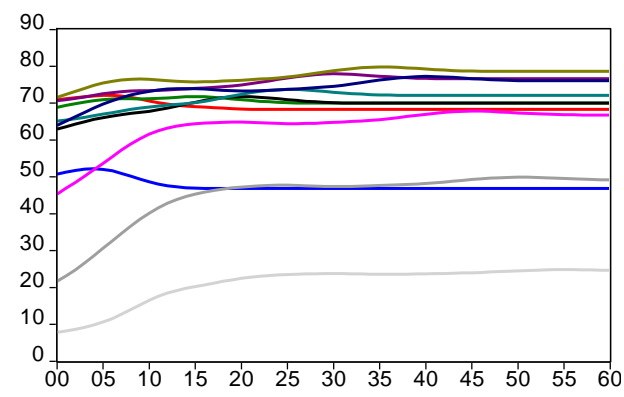

Austria - w omen

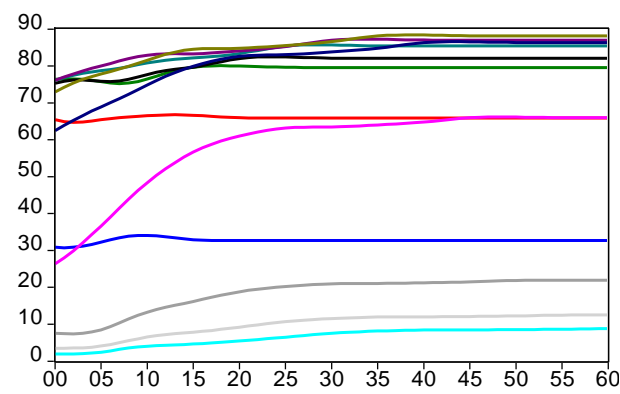

Belgium - w omen

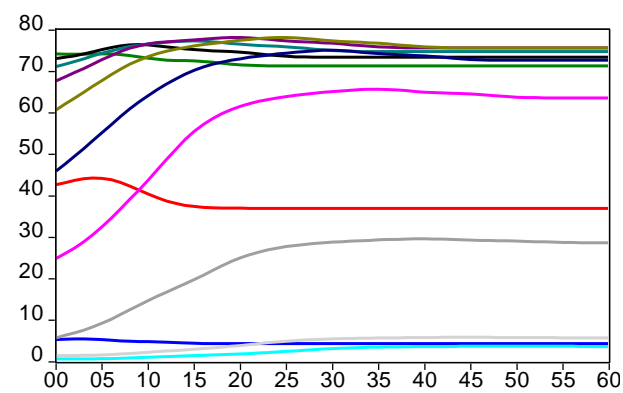

Canada - w omen

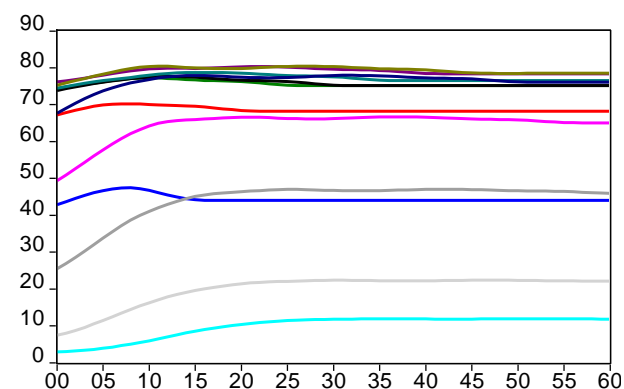

$\begin{array}{rrr}15-19 & 20-24 & 25-29 \\ 30-34 & 35-39 & 40-44 \\ 45-49 & 55-59 \\ 50-64 & 50-54 & 55-59 \\ & 65-69 & 70-74\end{array}$


Figure A2.1. Employment rates by age and sex with no policy change, per cent (contd.)

Sw itzerland - men

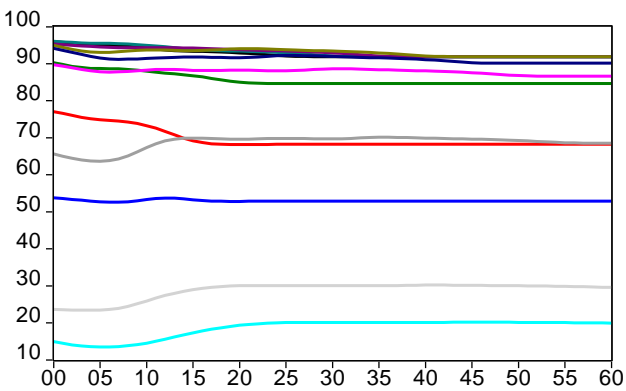

Chile - men

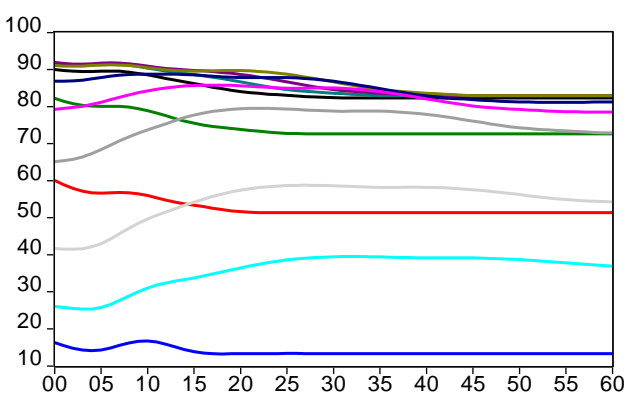

Czech Republic - men

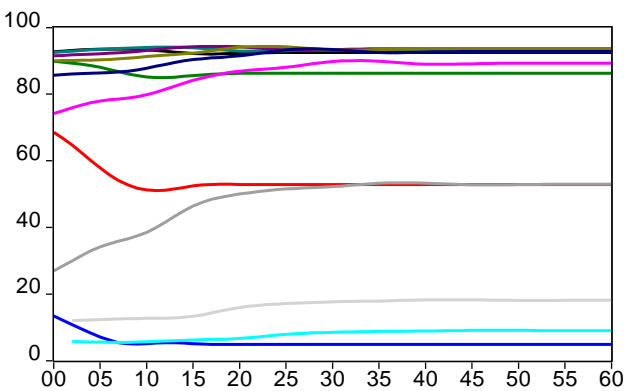

Germany - men

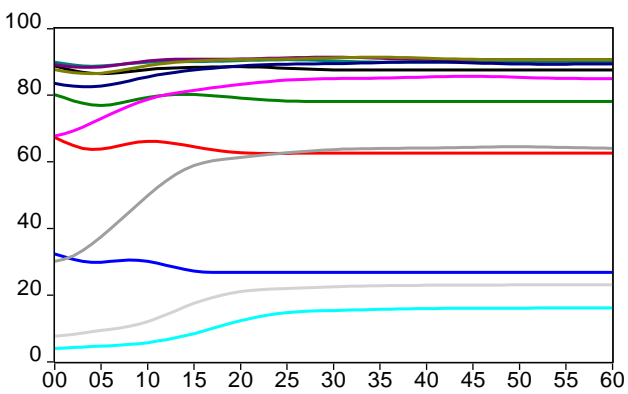

Sw itzerland - w omen

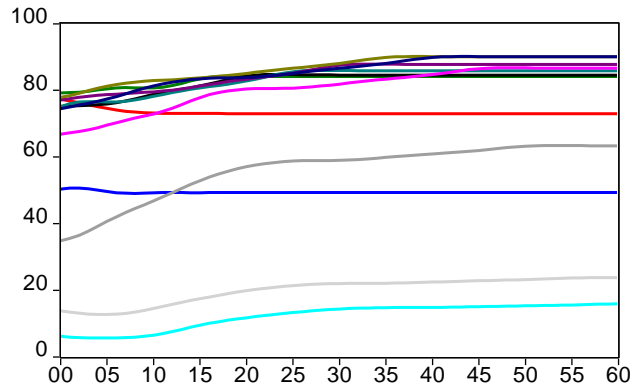

Chile - w omen

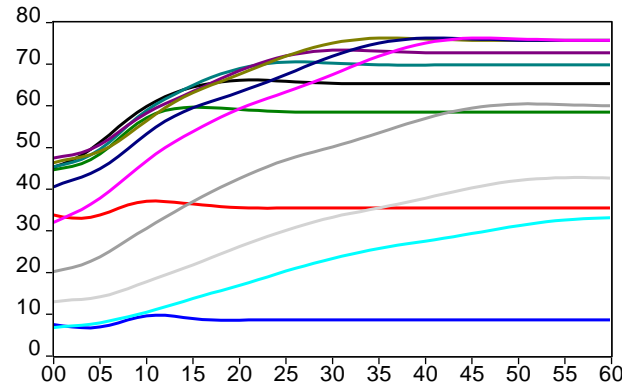

Czech Republic - w omen

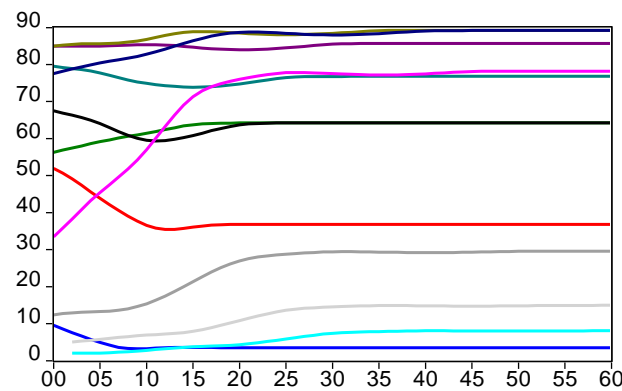

Germany - w omen

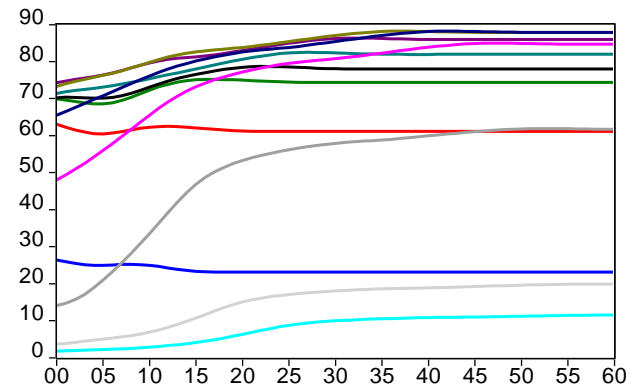

15-19 20-24 25-29

$30-34-35-39-40-44$

45-49-50-54-55-59

$60-64 \simeq 65-69-70-74$ 
Figure A2.1. Employment rates by age and sex with no policy change, per cent (contd.)

Denmark - men

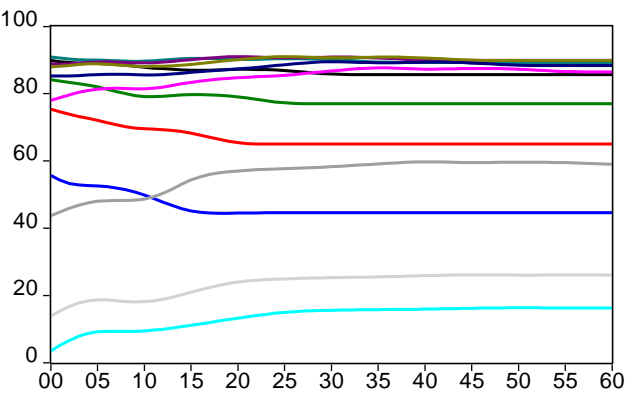

Spain - men

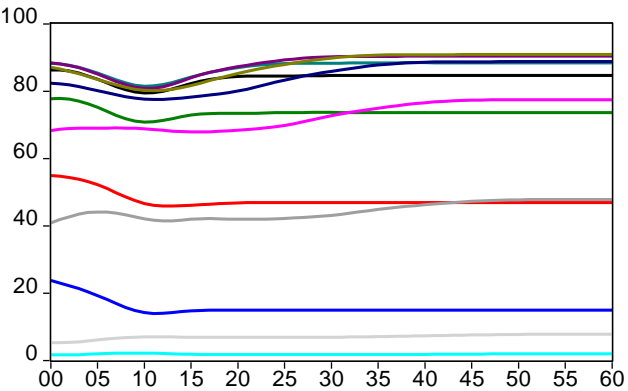

Estonia - men

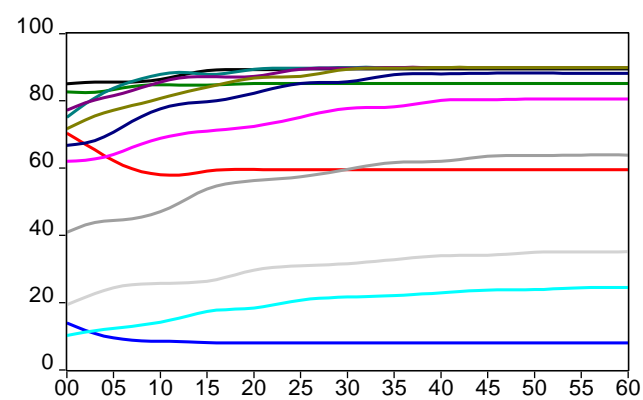

Finland - men

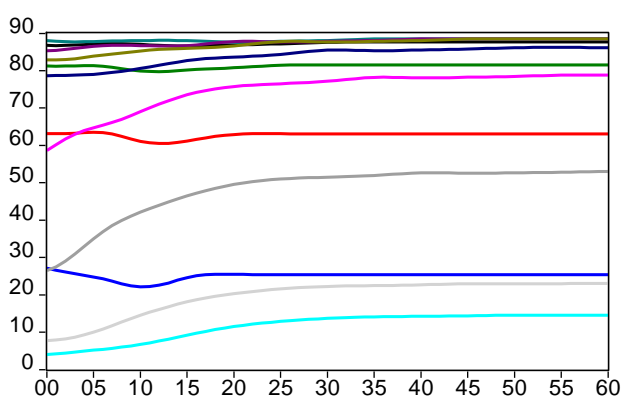

Denmark - w omen

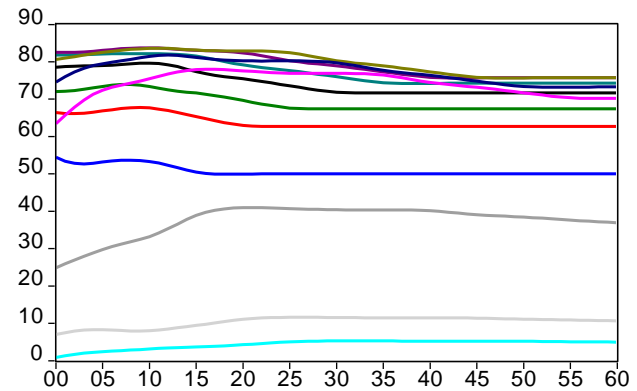

Spain - w omen

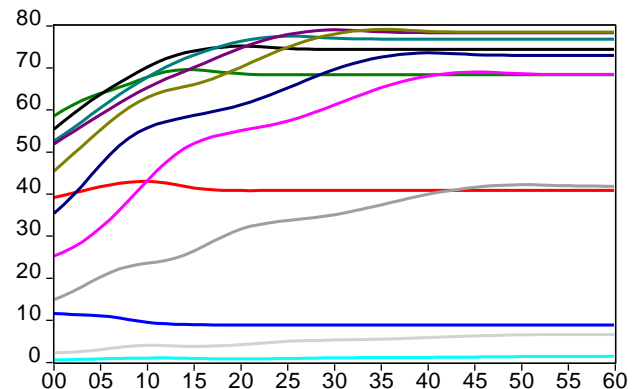

Estonia - w omen

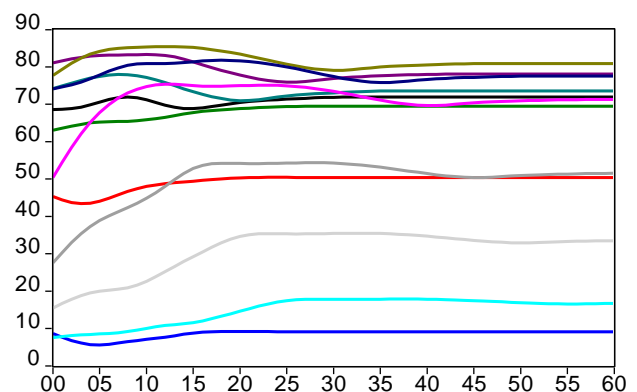

Finland - w omen

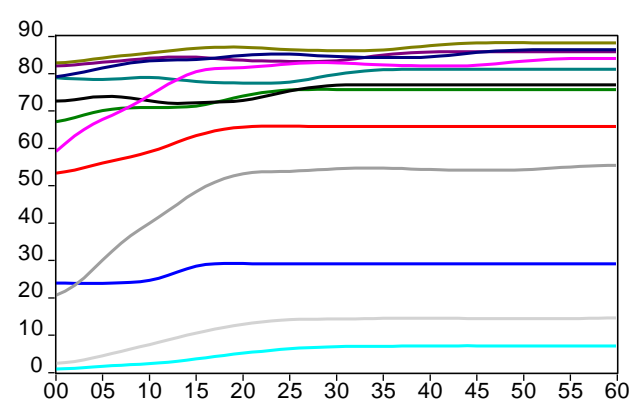

15-19

20-24

30-34

35-39

40-44

45-49

50-54

55-59

60-64

65-69

70-74 
Figure A2.1. Employment rates by age and sex with no policy change, per cent (contd.)

France - men

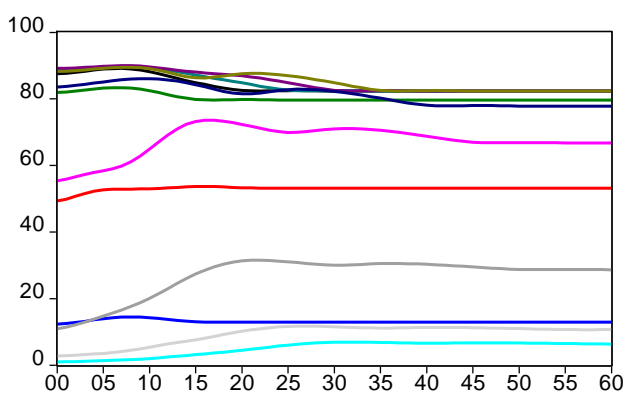

United Kingdom - men

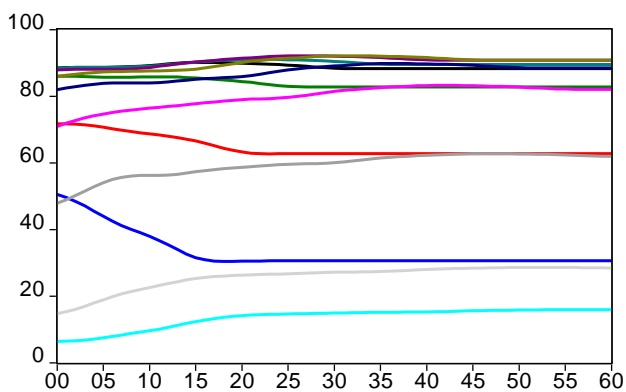

Greece - men

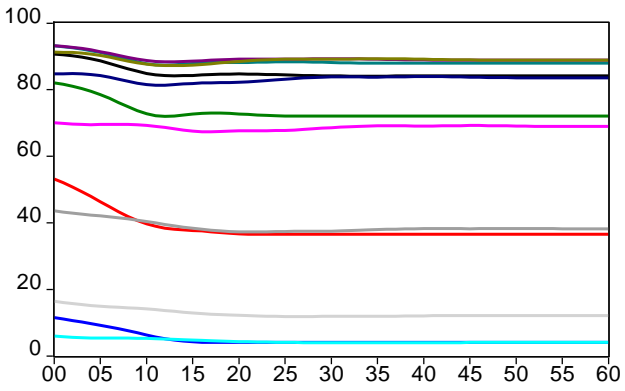

Hungary - men

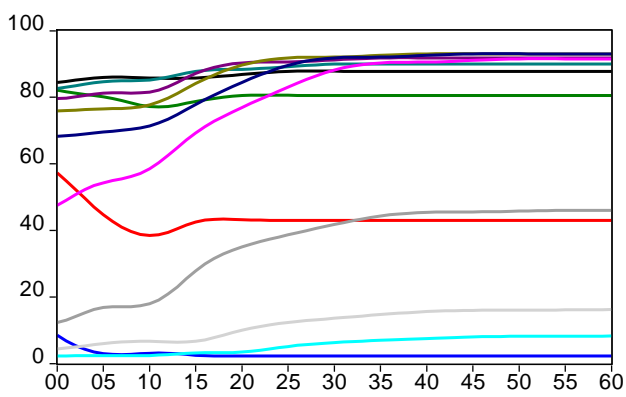

France - w omen

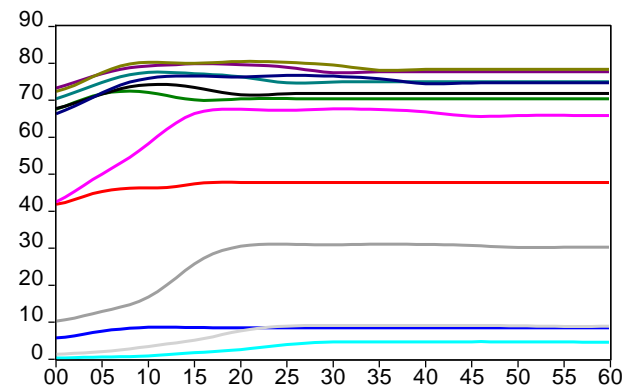

United Kingdom - w omen

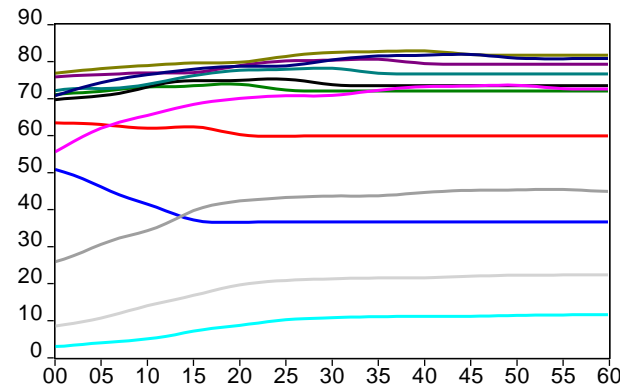

Greece - w omen

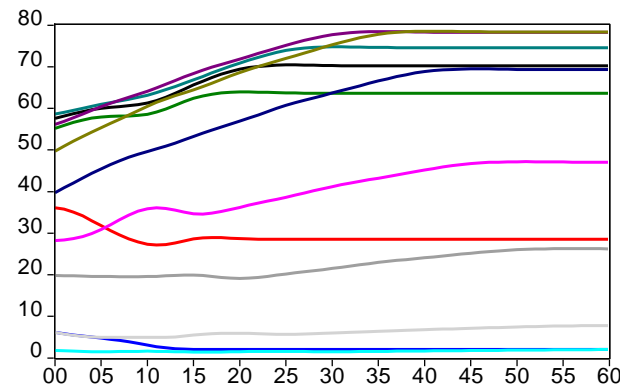

Hungary - w omen

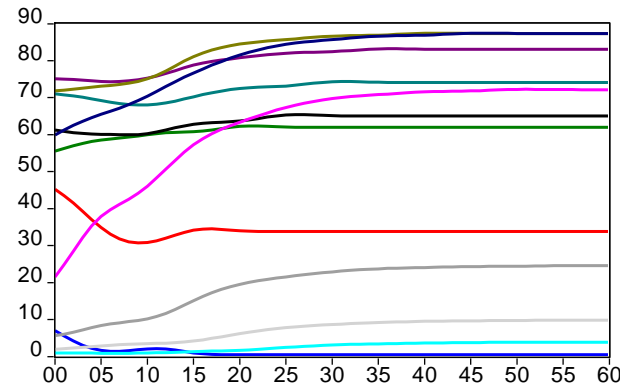

$15-19$

20-24 25-29

30-34

35-39

40-44

45-49 -50-54 55-59

$60-64 \longrightarrow 65-69 \_70-74$ 
Figure A2.1. Employment rates by age and sex with no policy change, per cent (contd.)

Iceland - men

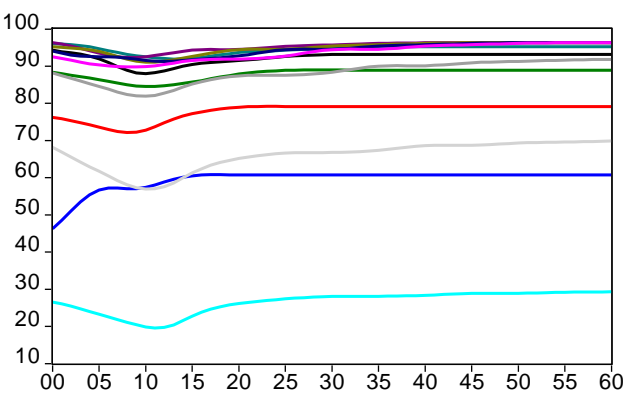

Ireland - men

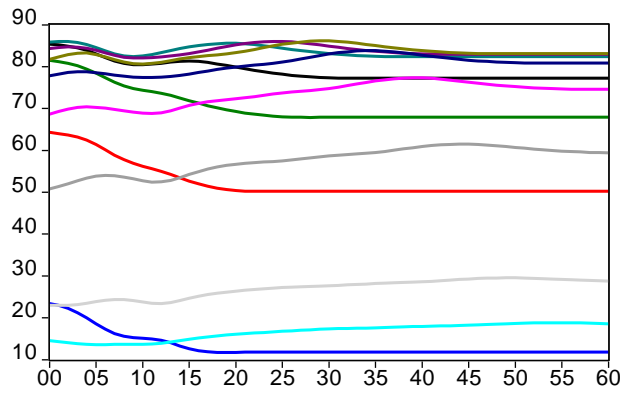

Israel - men

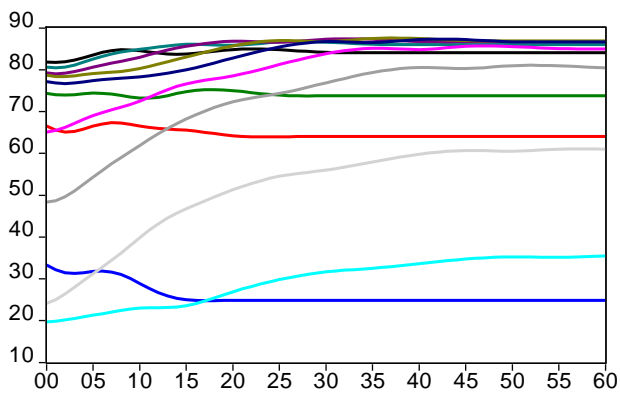

Italy - men

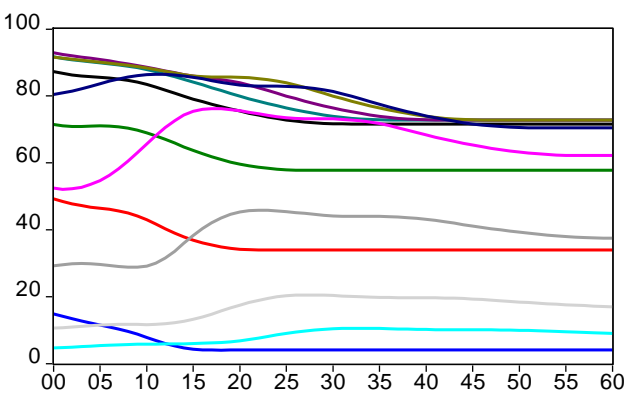

Iceland - w omen

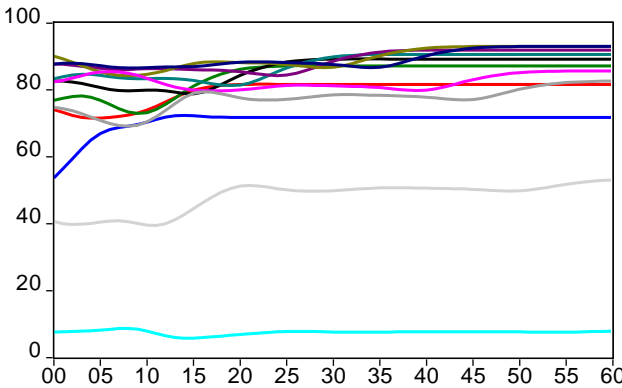

Ireland - w omen

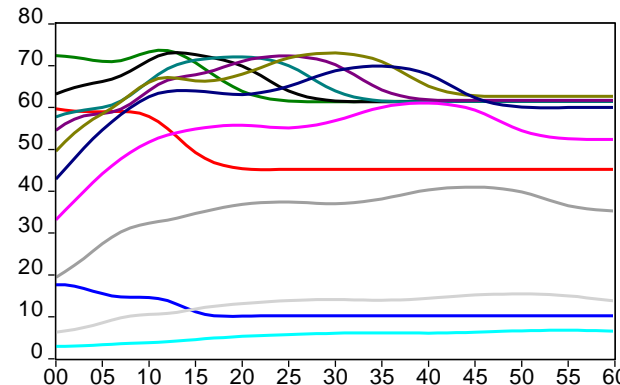

Israel - w omen

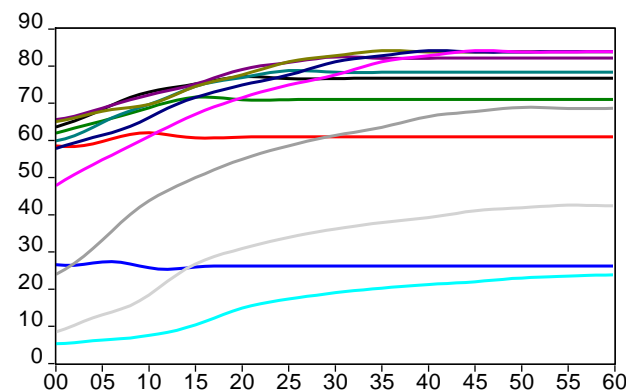

Italy - w omen

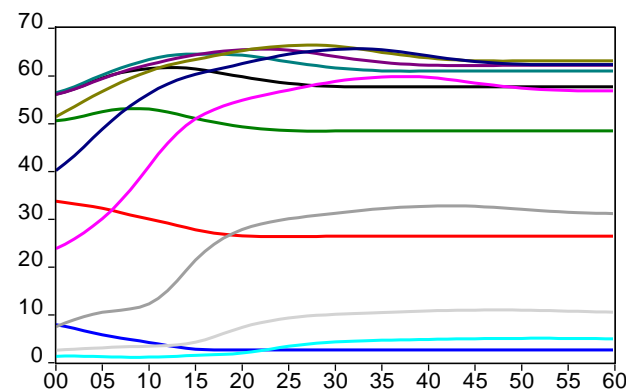


Figure A2.1. Employment rates by age and sex with no policy change, per cent (contd.)

Japan - men

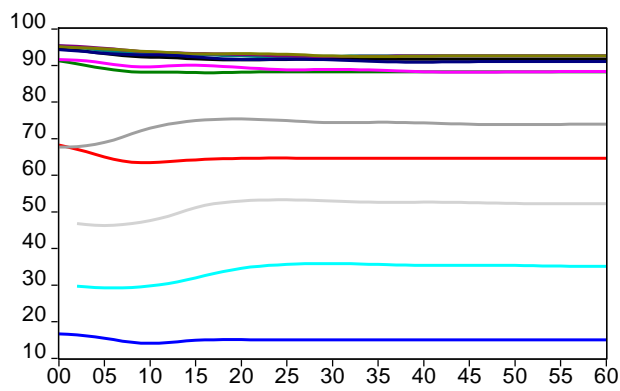

Korea - men

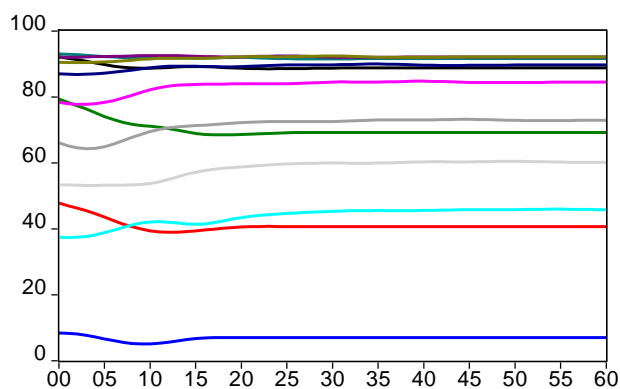

Luxembourg - men

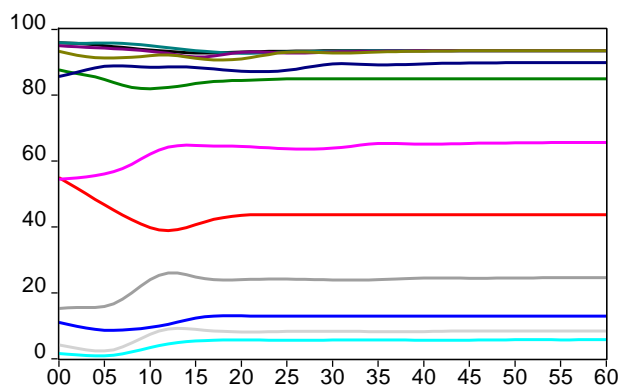

Mexico - men

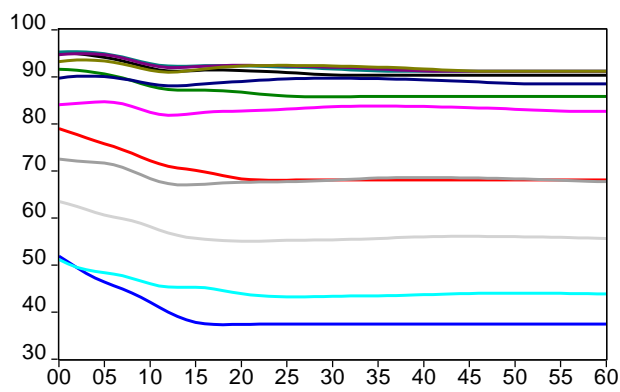

Japan - w omen

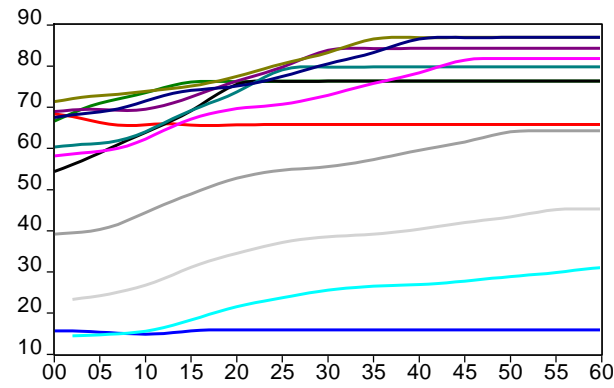

Korea - w omen

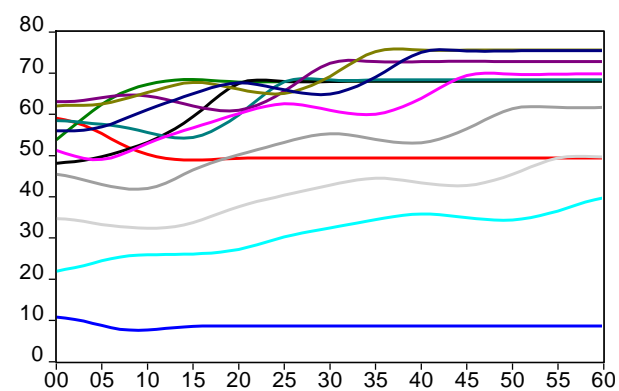

Luxembourg - w omen

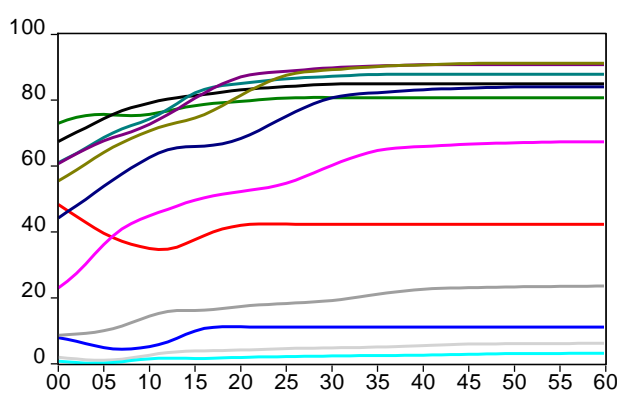

Mexico - w omen

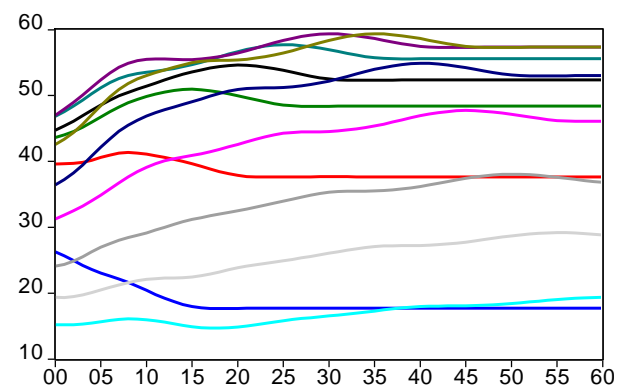

$\begin{array}{rrr}15-19 & 20-24 \\ 30-34 & 25-29 \\ 35-39 & 40-44 \\ 45-49 & -50-54 \\ 60-64 & 55-59 \\ 65-69 & 70-74\end{array}$


Figure A2.1. Employment rates by age and sex with no policy change, per cent (contd.)
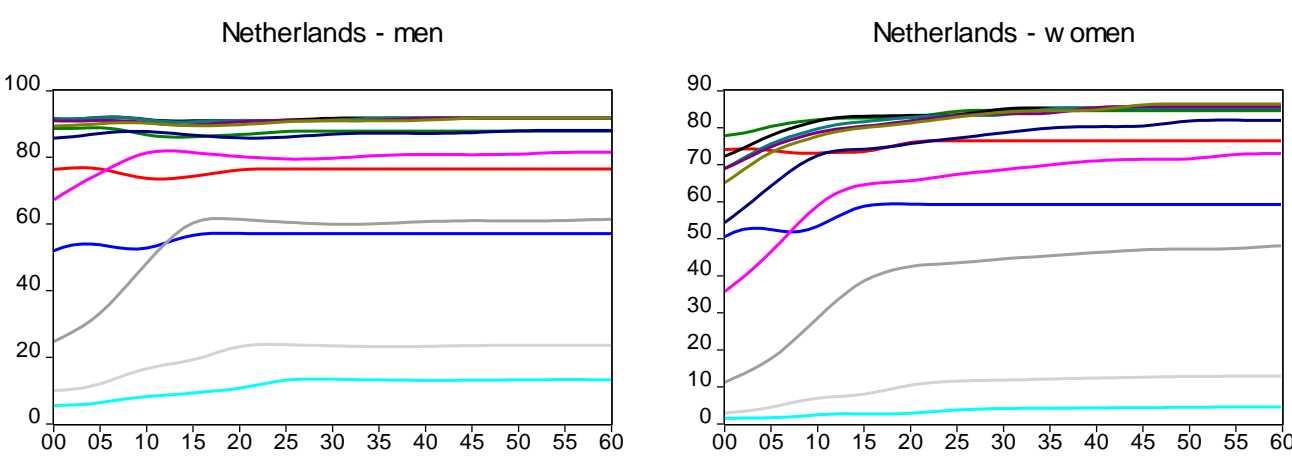

Norw ay - men

Norw ay - w omen
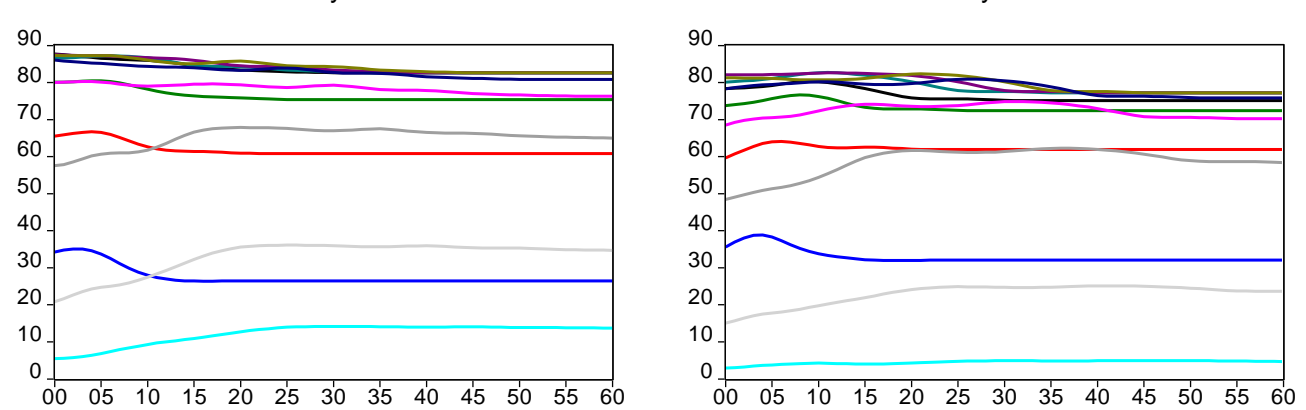

New Zealand - men

New Zealand - w omen
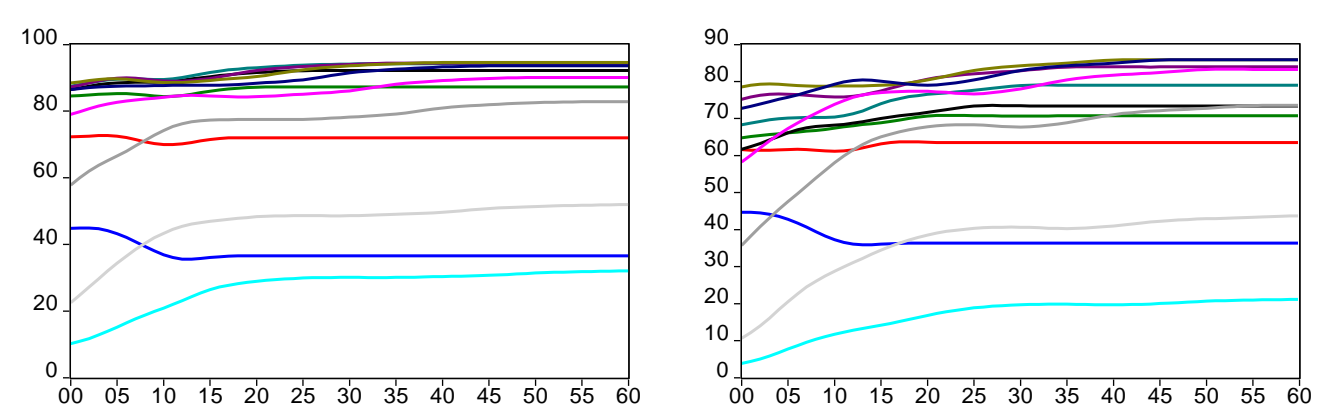

Poland - men

Poland - w omen
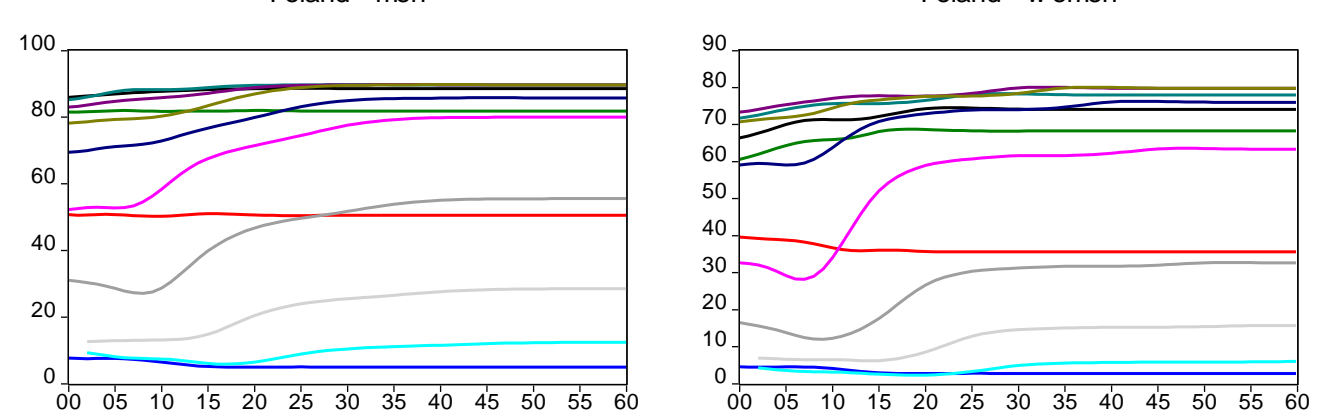

\begin{tabular}{rrr}
$15-19$ & $20-24$ & $25-29$ \\
$30-34$ & $-35-39$ & $40-44$ \\
$45-49$ & $55-59$ \\
$60-64$ & $50-54$ & $55-54$ \\
\hline $65-69$ & $70-74$
\end{tabular}


Figure A2.1. Employment rates by age and sex with no policy change, per cent (contd.)

Portugal - men

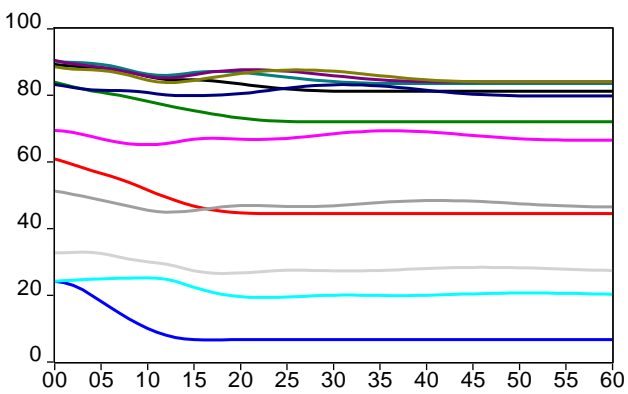

Slovak Republic - men

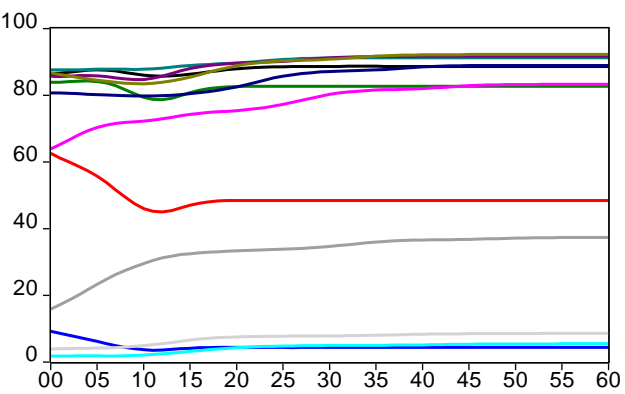

Slovenia - men

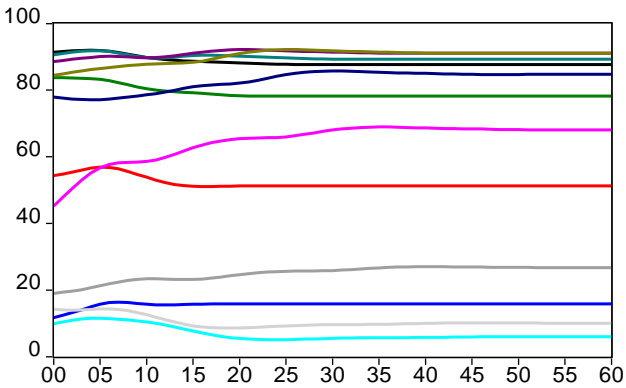

Sw eden - men

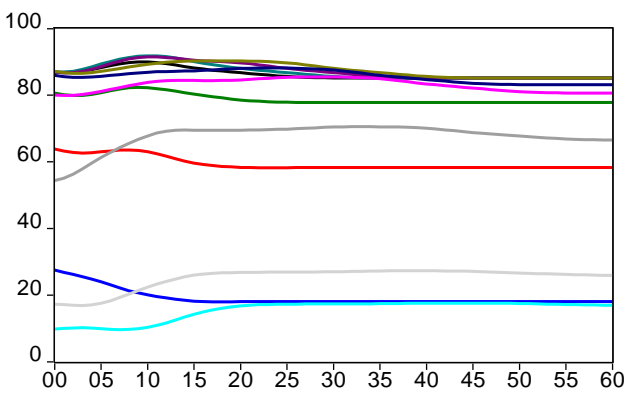

Portugal - w omen

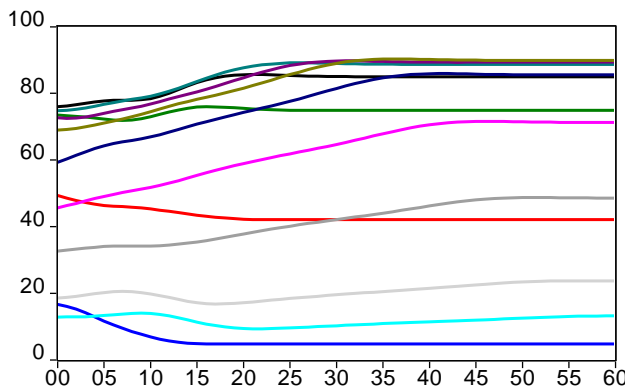

Slovak Republic - w omen

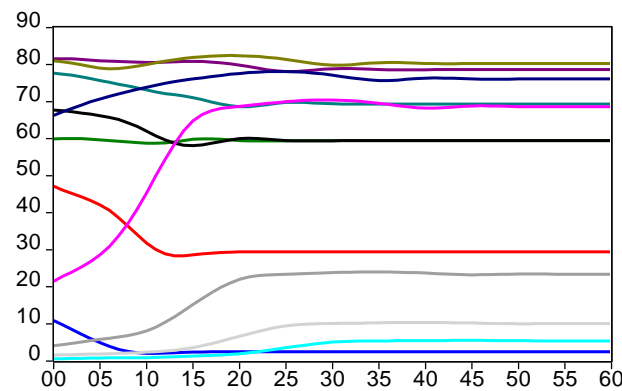

Slovenia - w omen

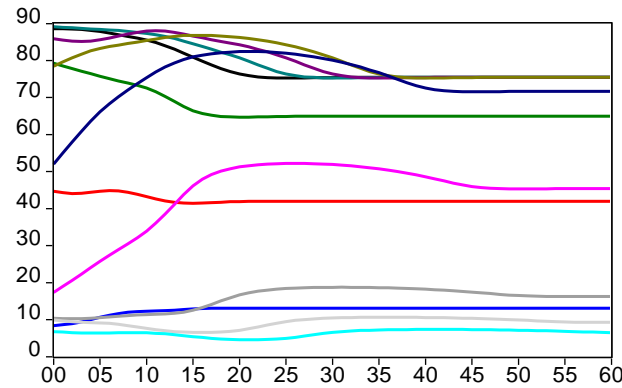

Sw eden - w omen

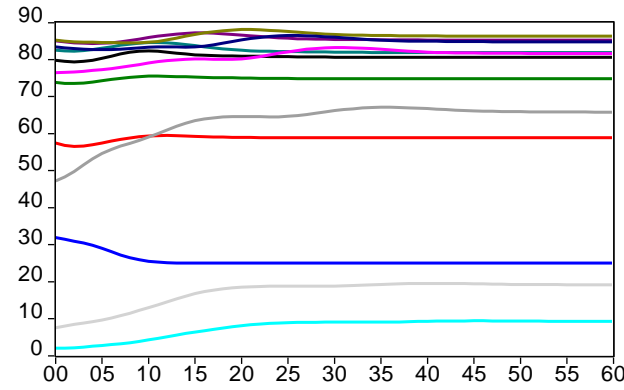

0-24 25-29

30-34 35-39 - 40-44

$45-49-50-54-55-59$

$60-64 \longrightarrow 65-69 \longrightarrow 70-74$ 
Figure A2.1. Employment rates by age and sex with no policy change, per cent (contd.)
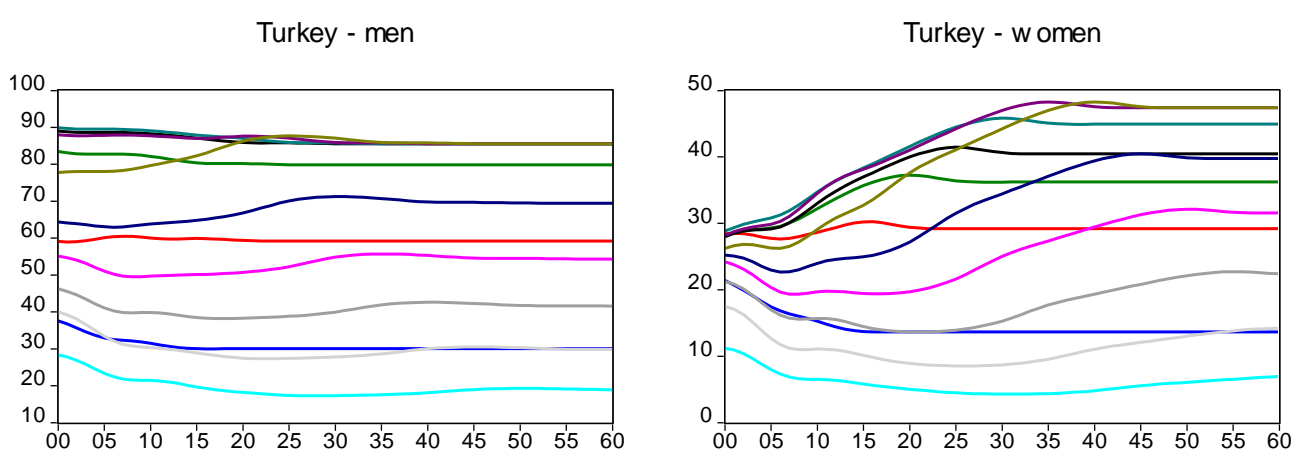

United States - men

United States - w omen
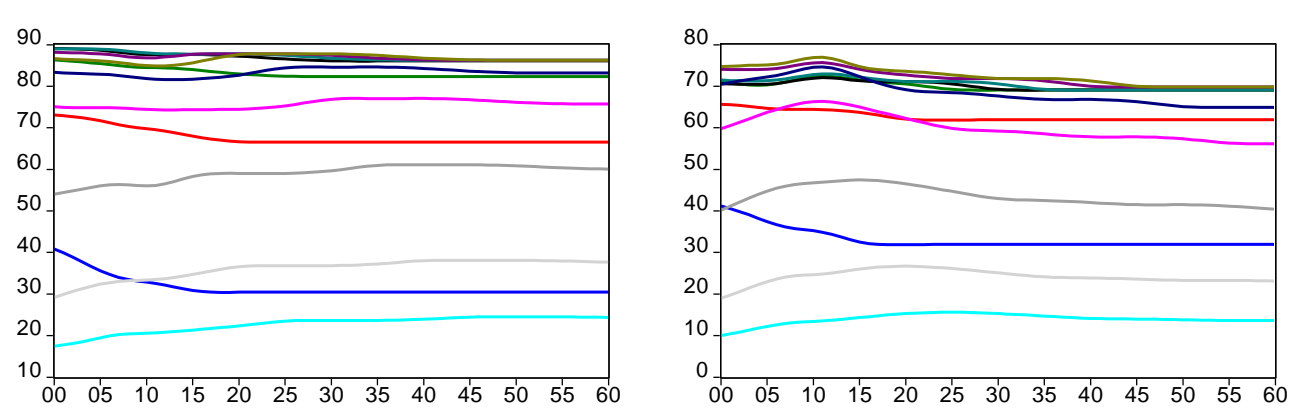

Costa Rica - men

Costa Rica - w omen
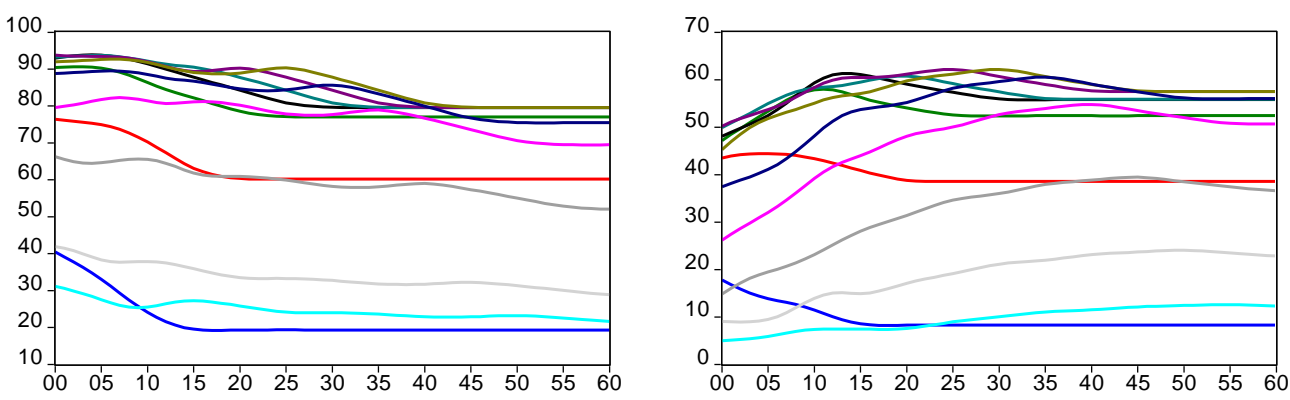

Latvia - men

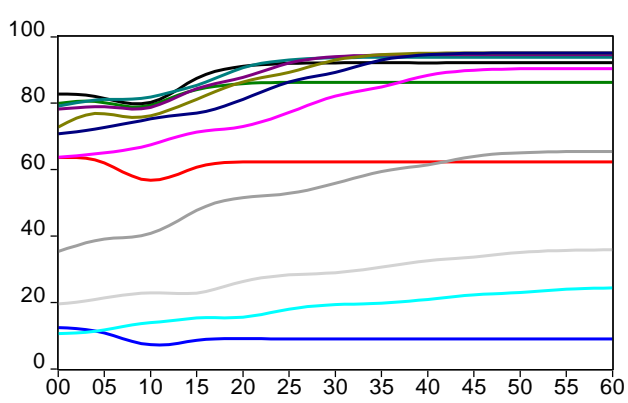

Latvia - w omen

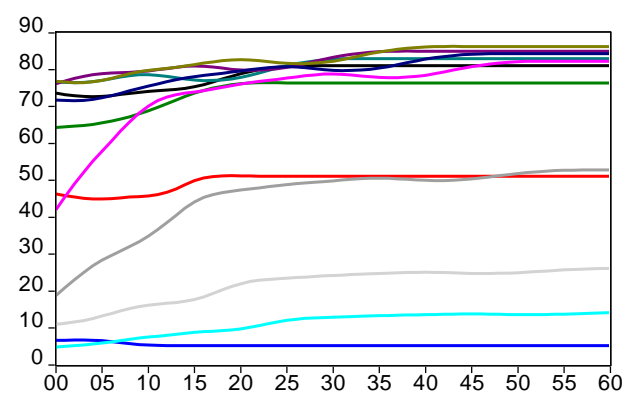

$\begin{array}{rrr}15-19 & 20-24 & 25-29 \\ 30-34 & 35-39 & 40-44 \\ 45-49 & 50-54 & 55-59 \\ 60-64 & 65-69 & 70-74\end{array}$


Figure A2.1. Employment rates by age and sex with no policy change, per cent (contd.)

Lithuania - men

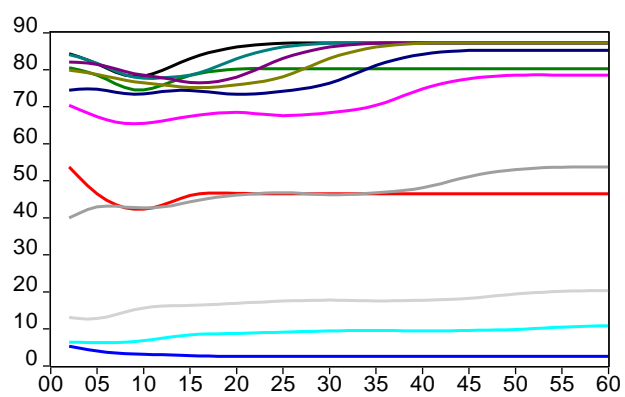

Brazil - men

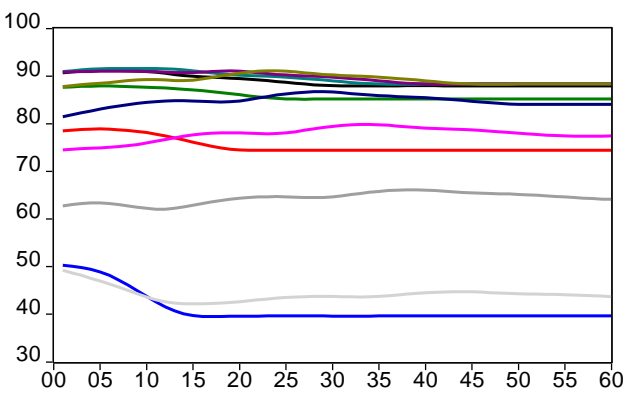

China - men

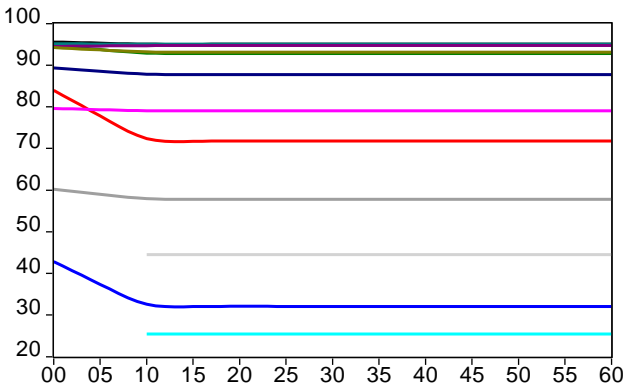

Colombia - men

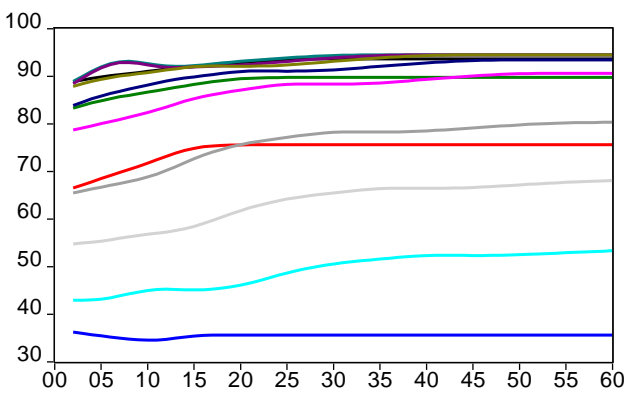

Lithuania - w omen

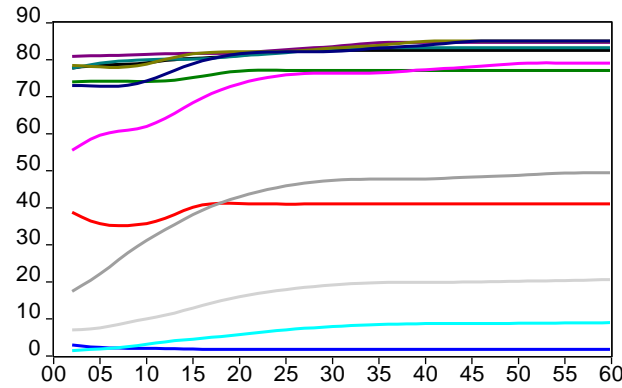

Brazil - w omen

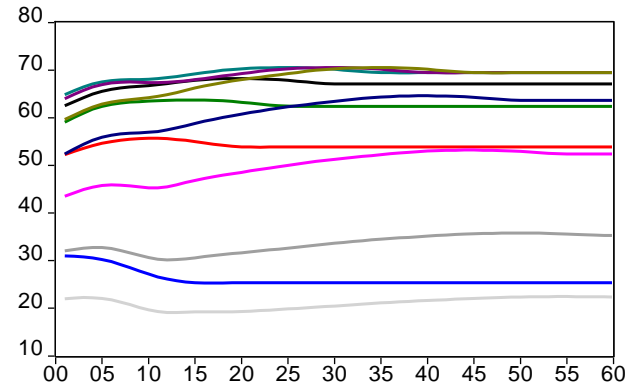

China - w omen

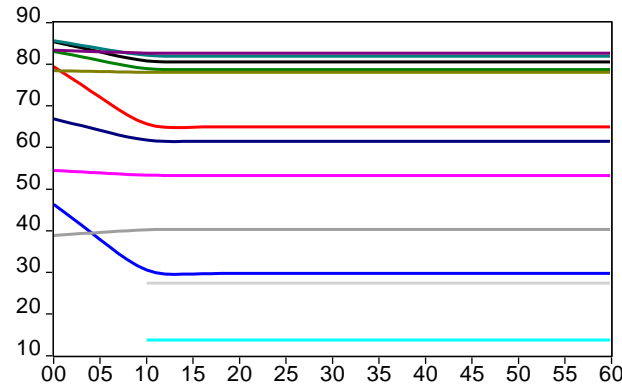

Colombia - w omen

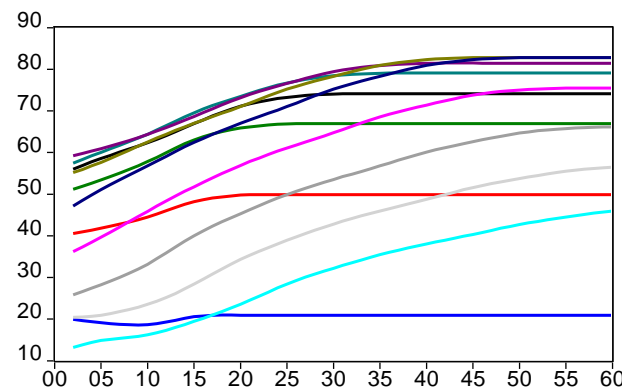

15-19 20-24 25-29

30-34-35-39-40-44

45-49-50-54-55-59

$60-64 \simeq 65-69-70-74$ 
Figure A2.1. Employment rates by age and sex with no policy change, per cent (contd.)

India - men

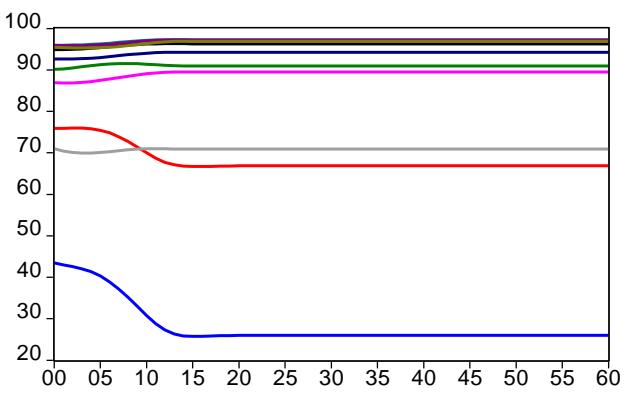

Indonesia - men

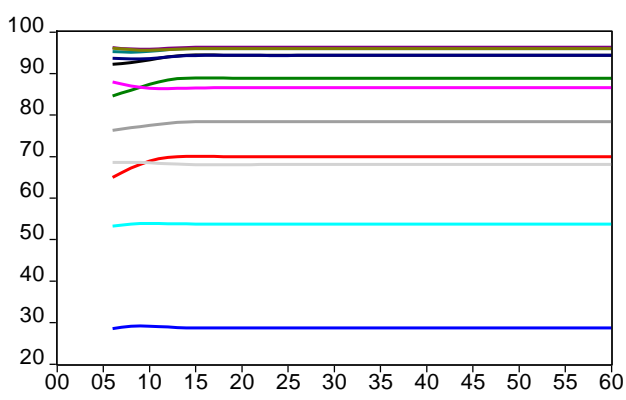

Russia - men

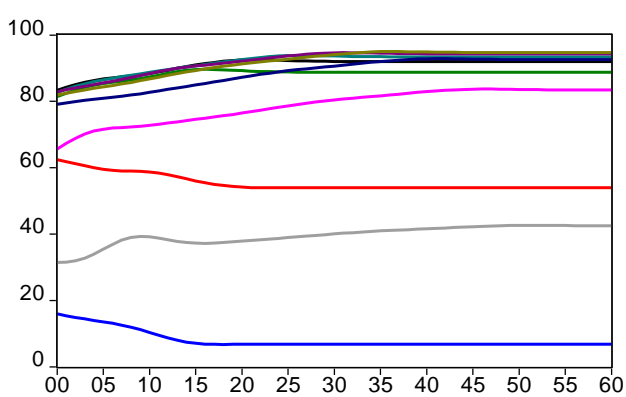

South Africa - men

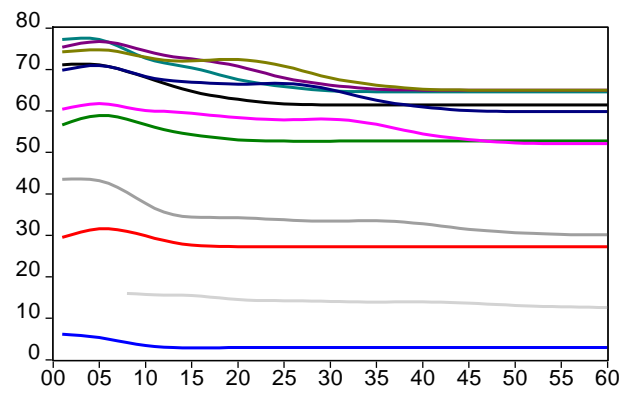

India - w omen

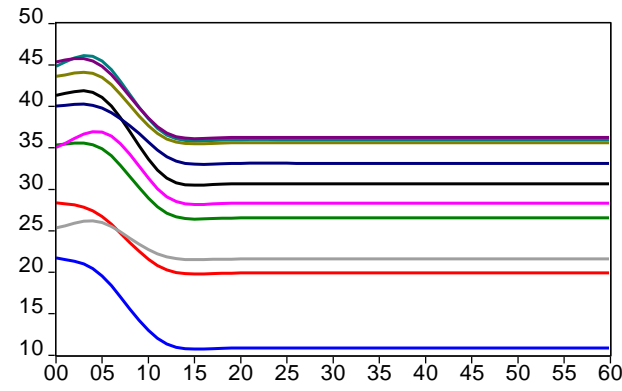

Indonesia - w omen

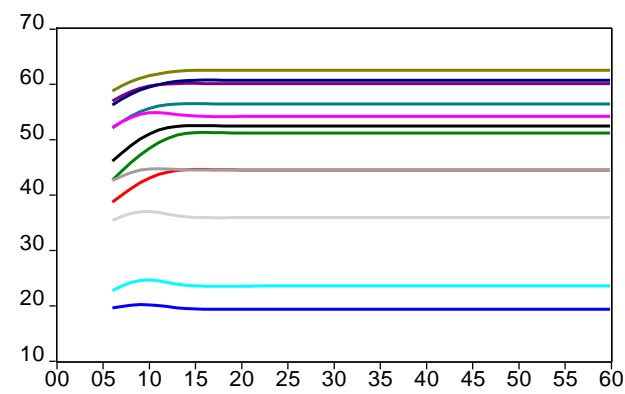

Russia - w omen

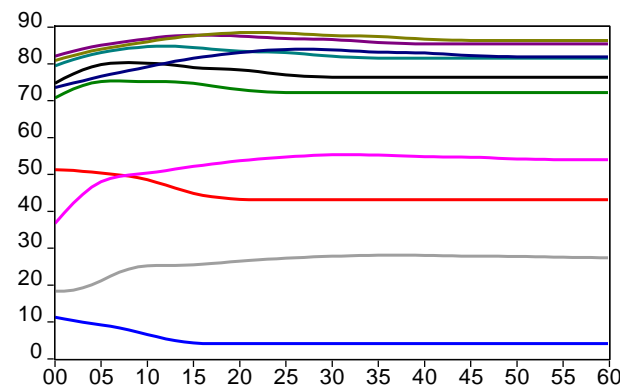

South Africa - w omen

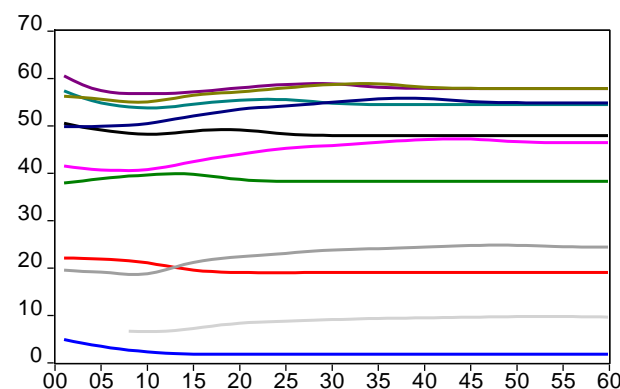

$\begin{array}{rrr}15-19 & 20-24 & 25-29 \\ 30-34 & 35-39 & -20-44 \\ 45-49 & 50-54 \\ 50-64 & 55-59 \\ 65-69 & \end{array}$


Figure A2.1. Employment rates by age and sex with no policy change, per cent (contd.)

Argentina - men

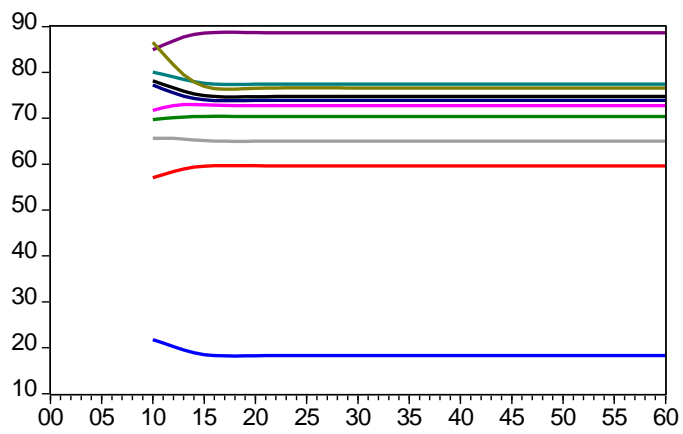

Saudi Arabia - men

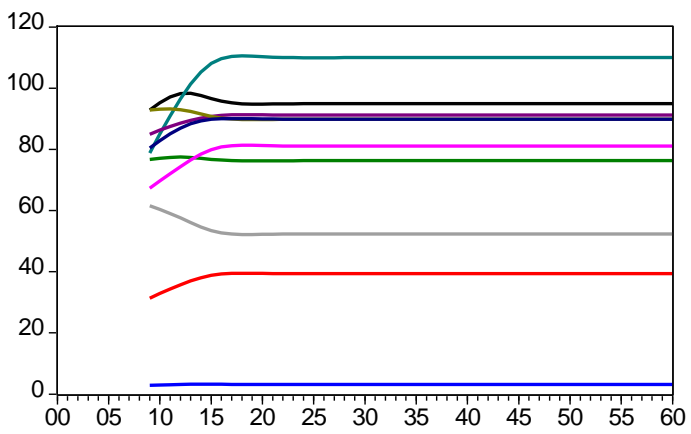

Argentina - women

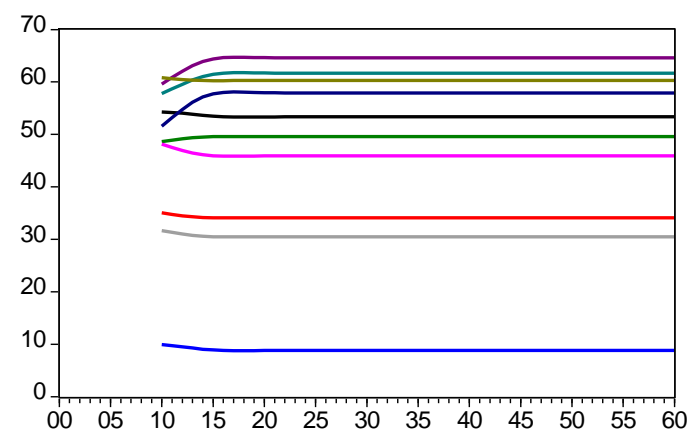

Saudi Arabia - women

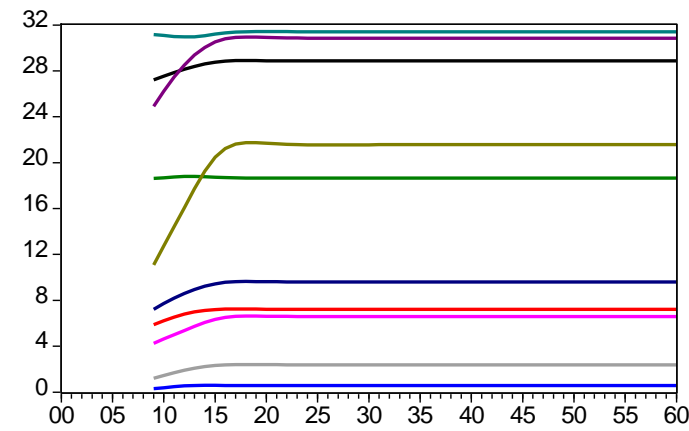

$-15-19$
$-20-24$
$-30-34$
$-35-39-49-25-29$
$-50-54-54$
$60-64$

Notes: The projected employment rates illustrate cohort effects but assume no policy change. China, India, Indonesia, Argentina and Saudi Arabia are exceptions: projected employment rates are assumed constant at their last observed values. 
Figure A2.2. Aggregate employment rates, by sex and total, per cent

Australia

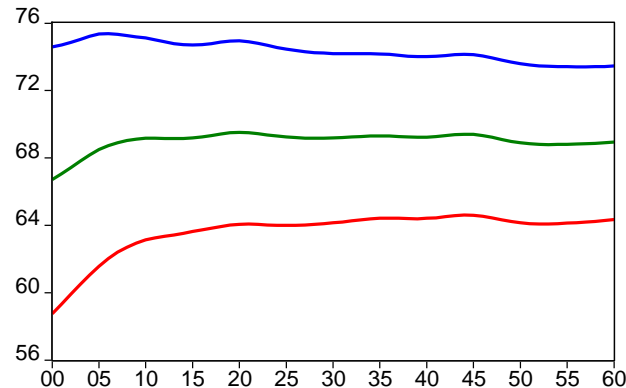

Belgium

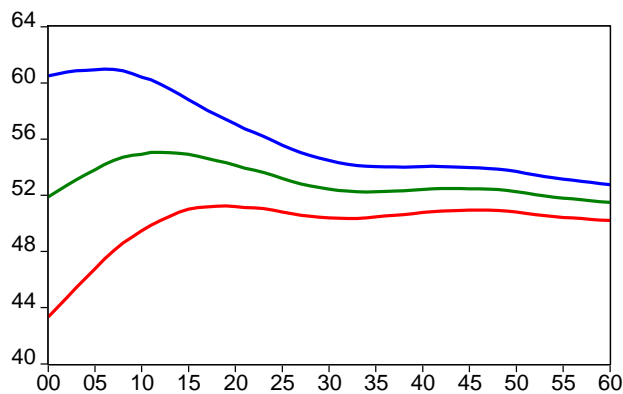

Switzerland

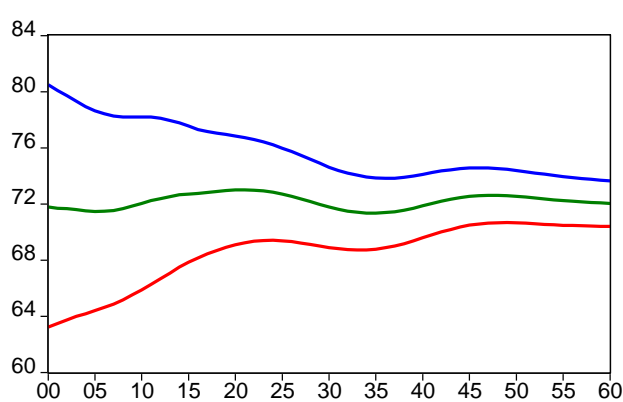

Czech Republic

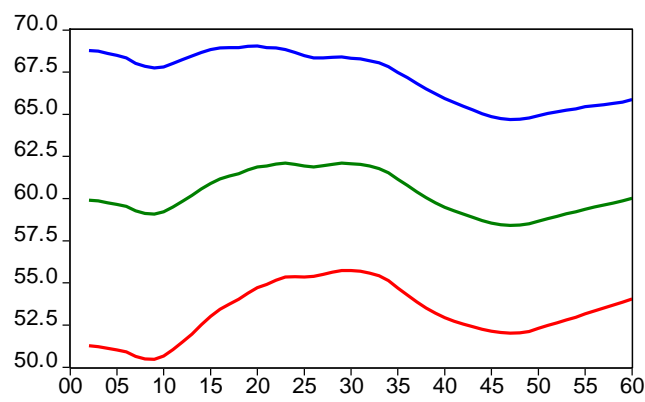

Austria

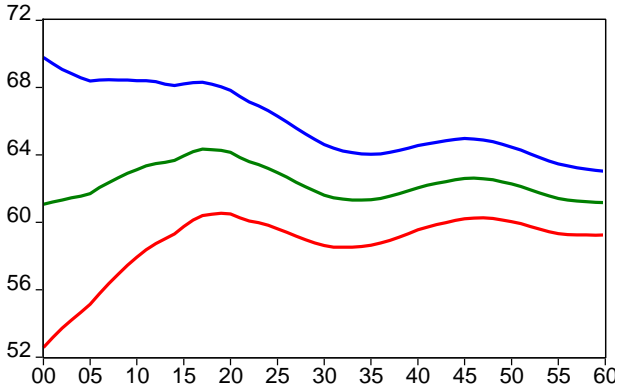

Canada

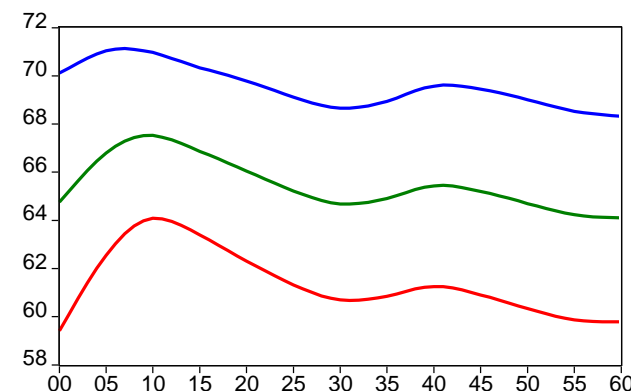

Chile

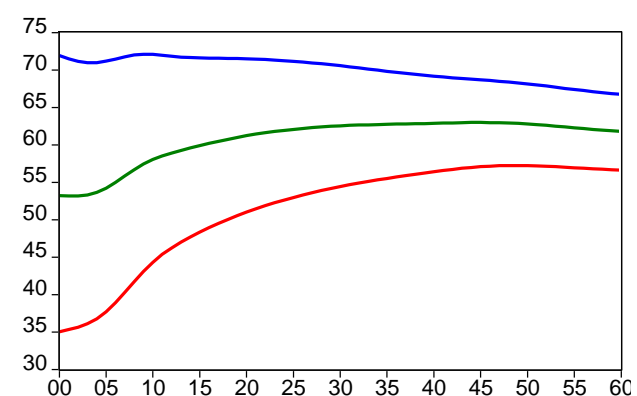

Germany

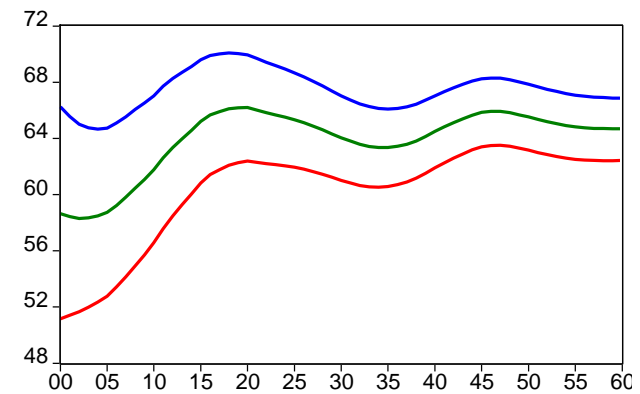

— Men _ Women _ Total 
Figure A2.2. Aggregate employment rates, by sex and total, per cent (contd.)

Denmark

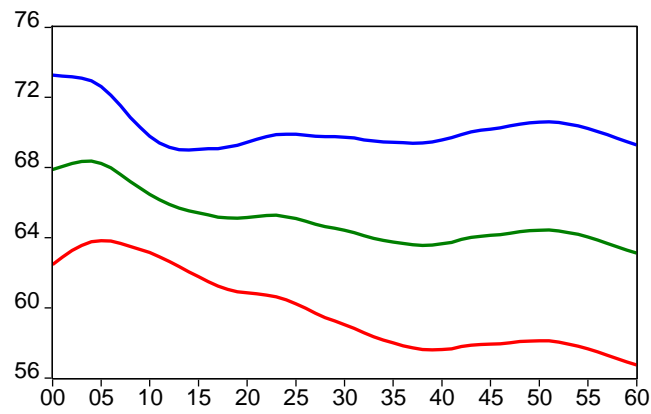

Estonia

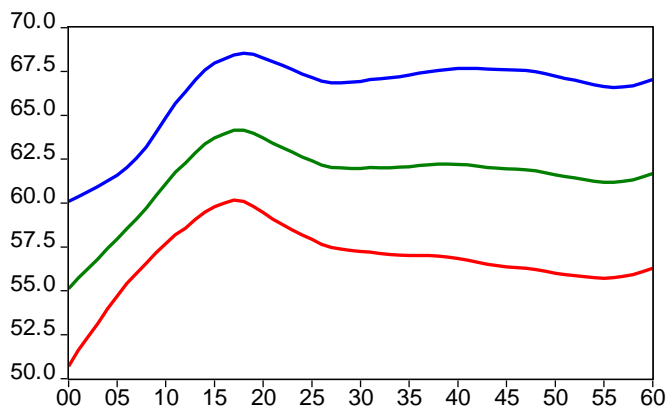

France

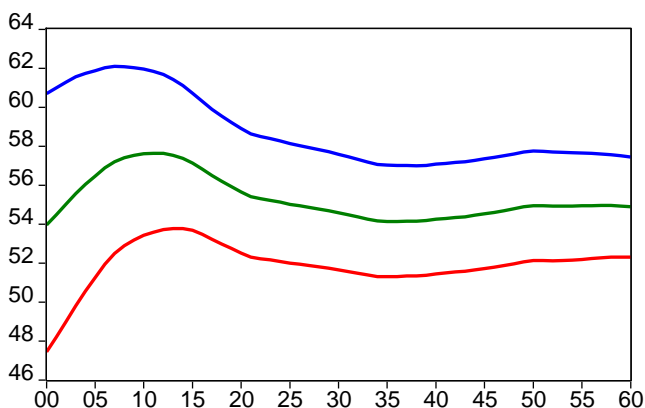

Greece

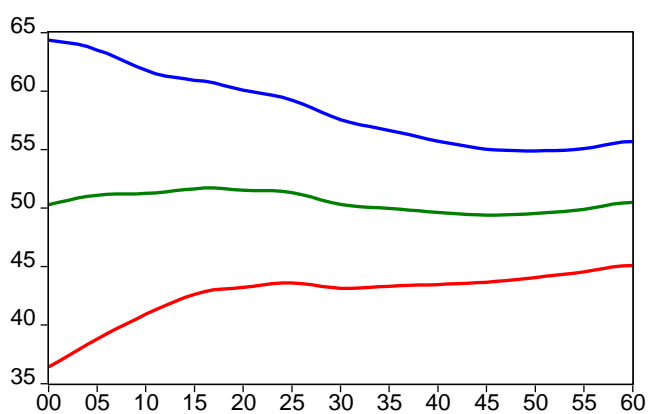

Spain

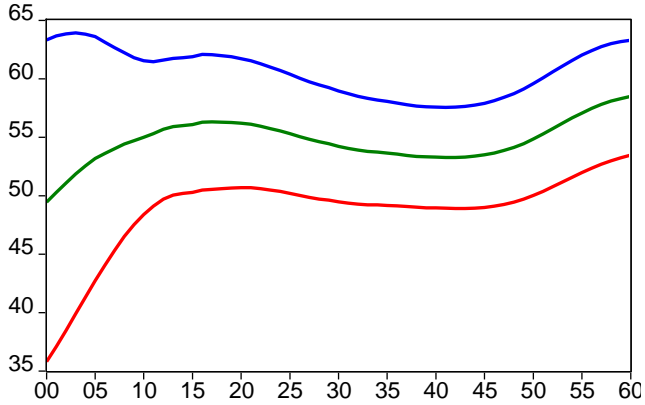

Finland

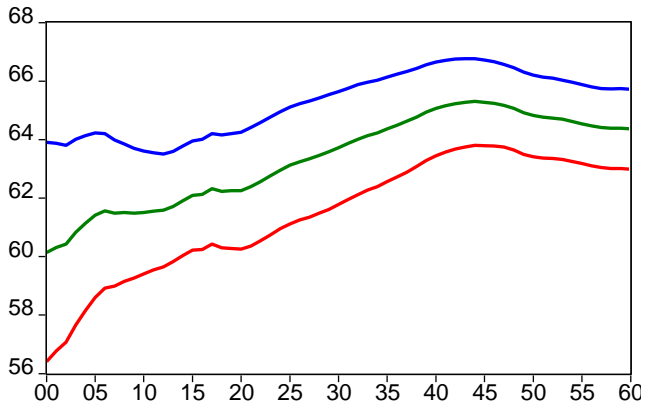

United Kingdom

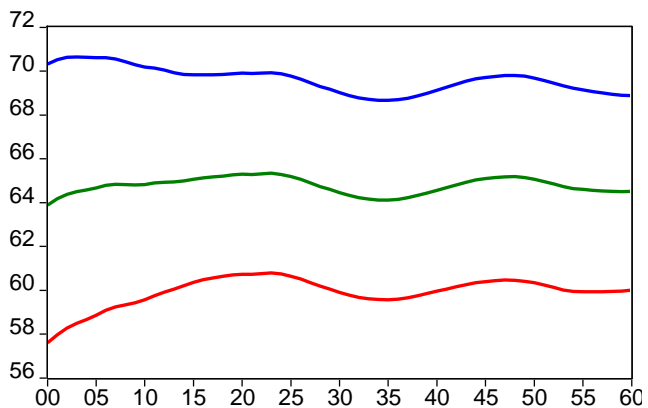

Hungary

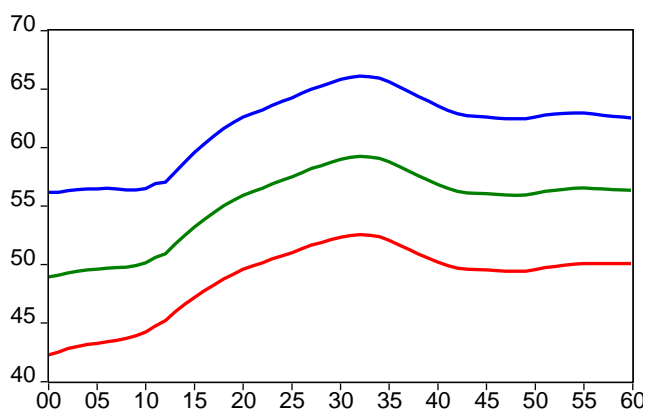

— Men _ Women _ Total 
Figure A2.2. Aggregate employment rates, by sex and total, per cent (contd.)

Iceland

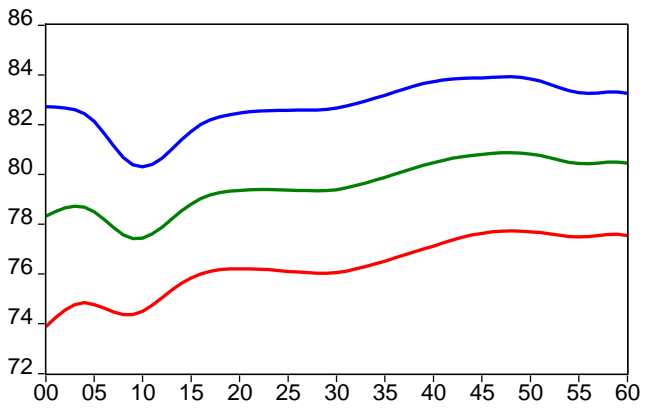

Israel

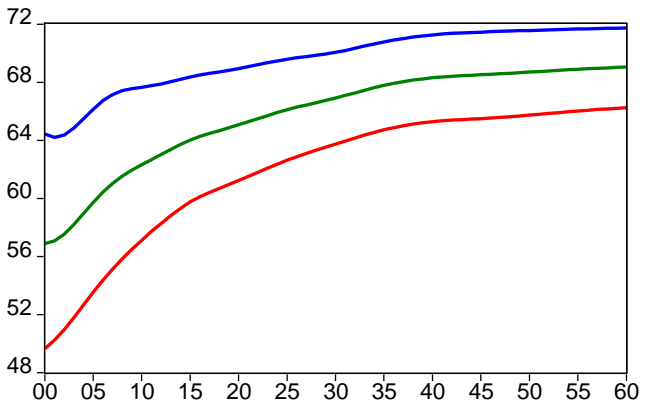

Japan

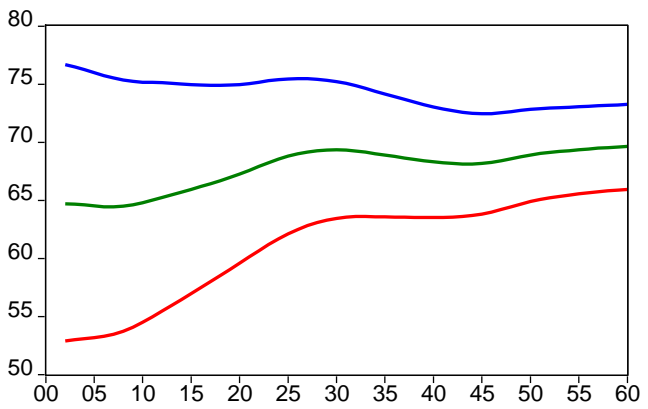

Luxembourg

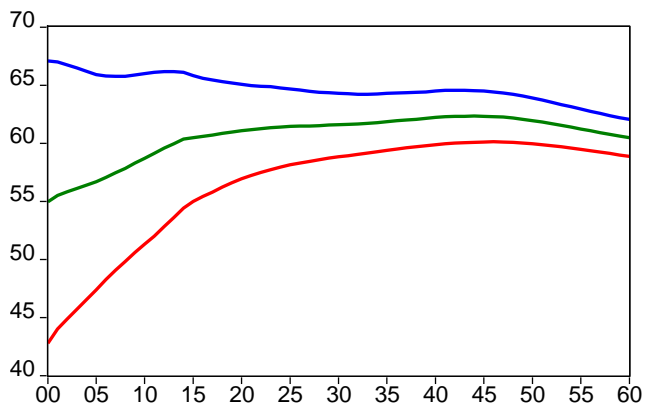

Ireland

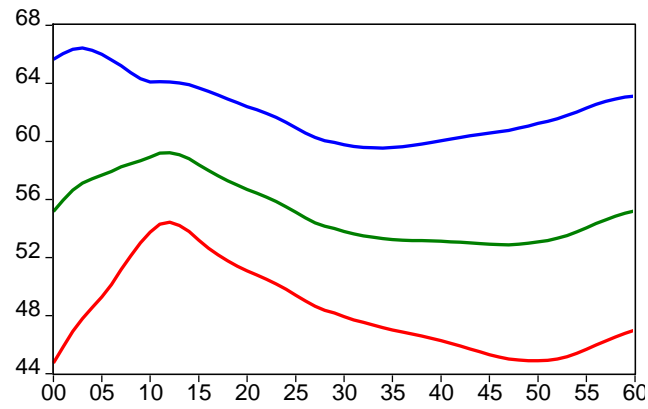

Italy

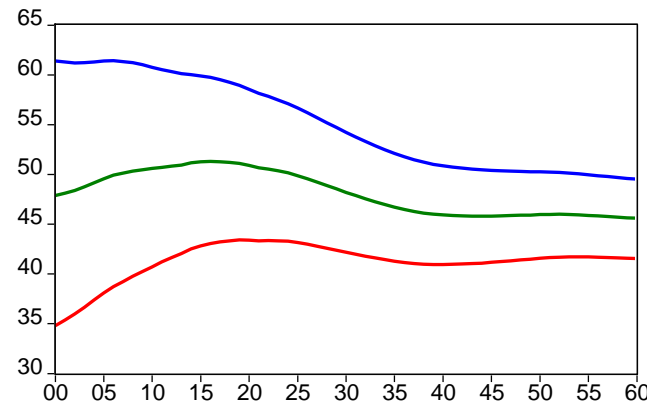

Korea

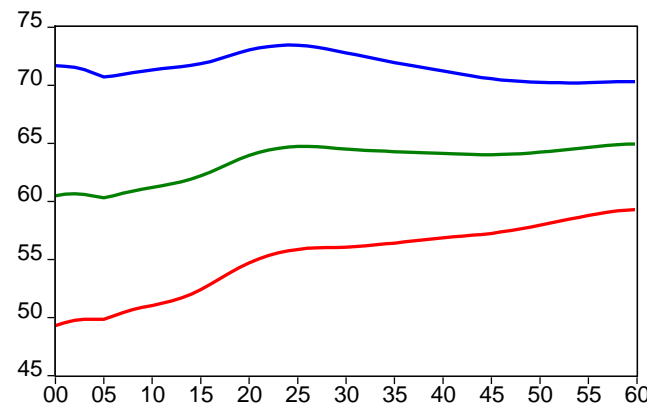

Mexico

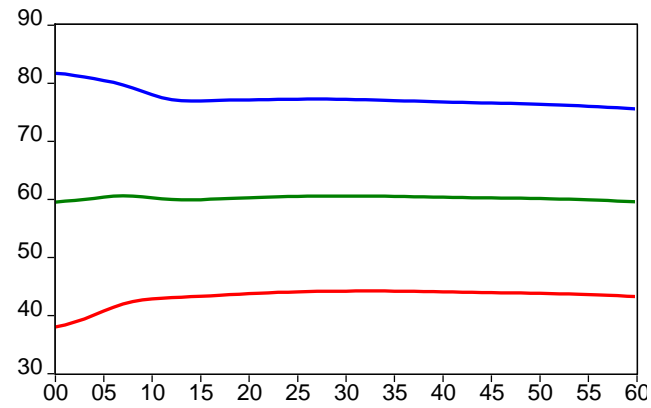

_ Men _- Women _ Total 
Figure A2.2. Aggregate employment rates, by sex and total, per cent (contd.) Netherlands

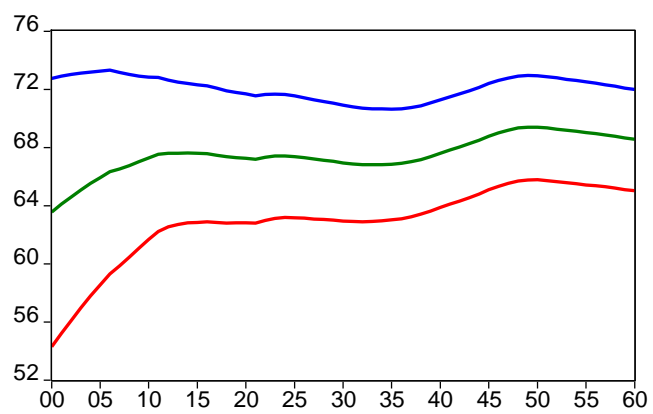

New Zealand

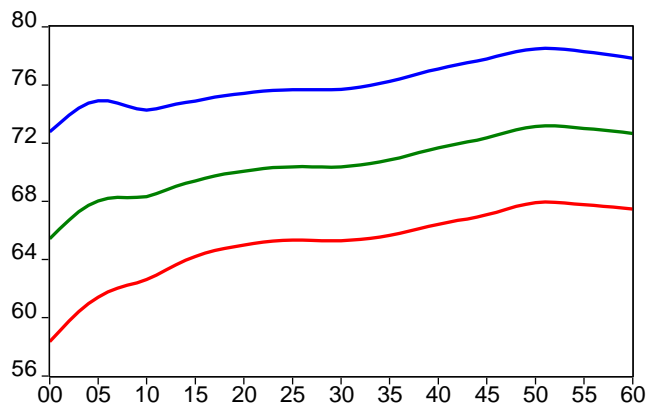

Portugal

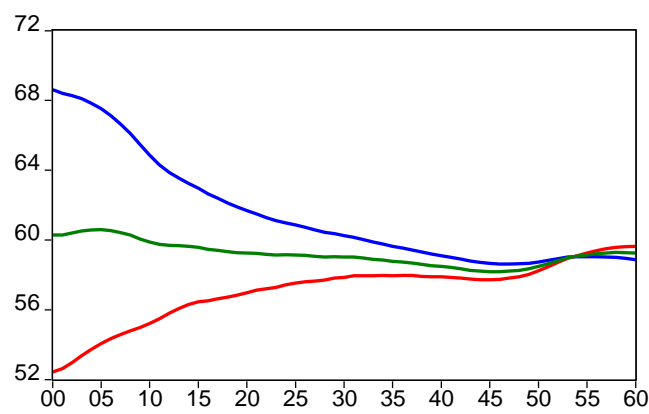

Slovenia

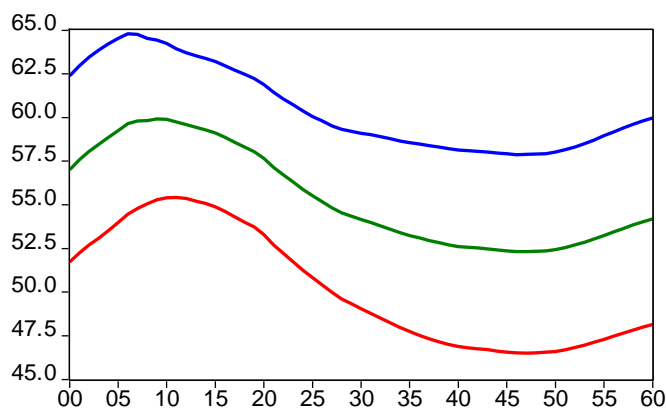

Norway

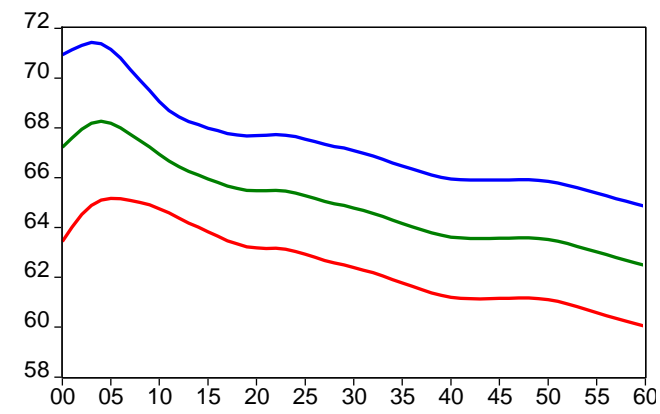

Poland

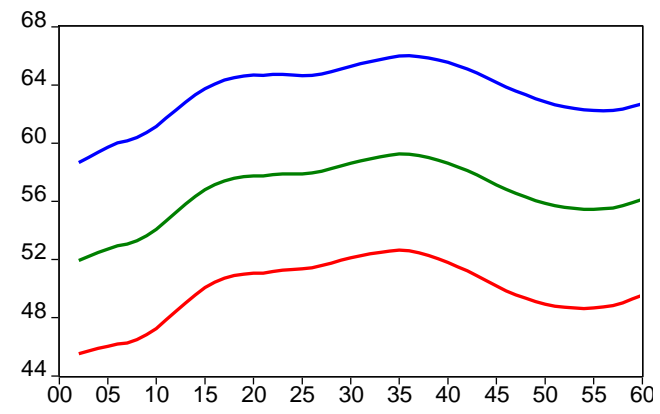

Slovak Republic

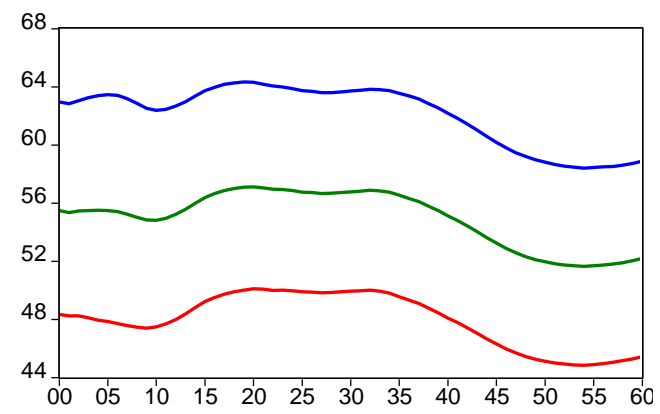

Sweden

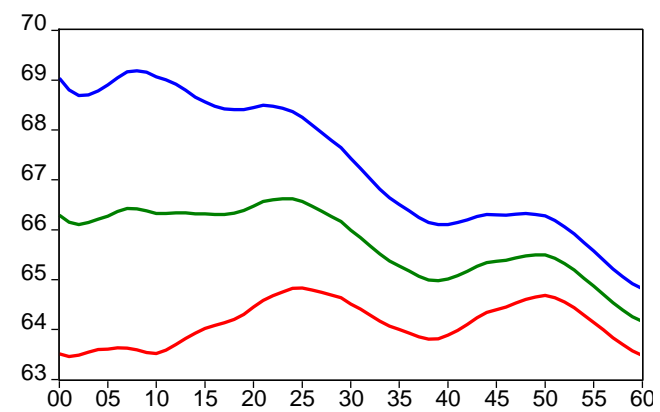

— Men _ Women _ Total 
Figure A2.2. Aggregate employment rates, by sex and total, per cent (contd.)

Turkey

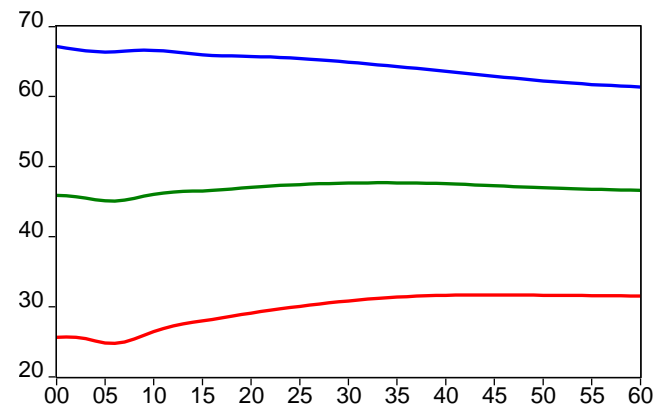

Costa Rica

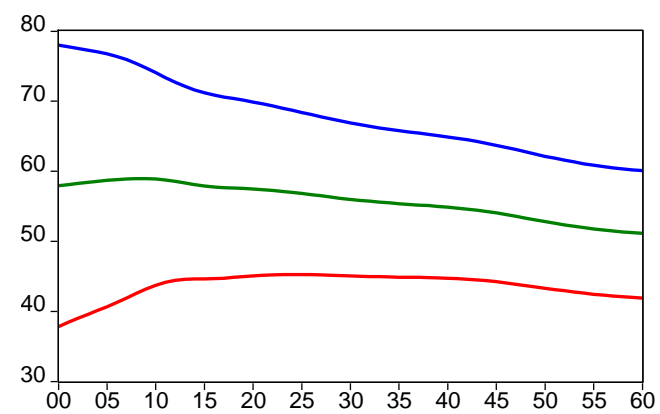

Lithuania

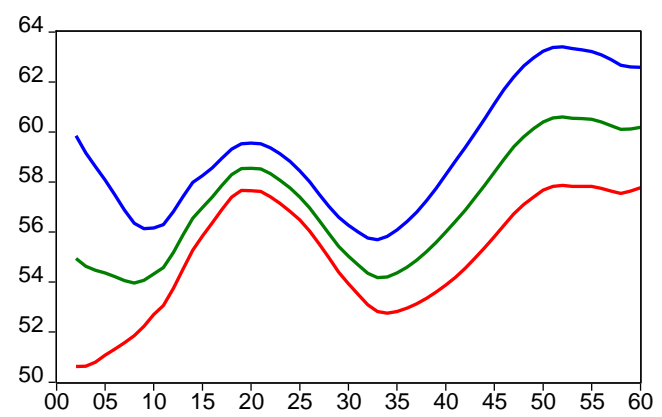

China

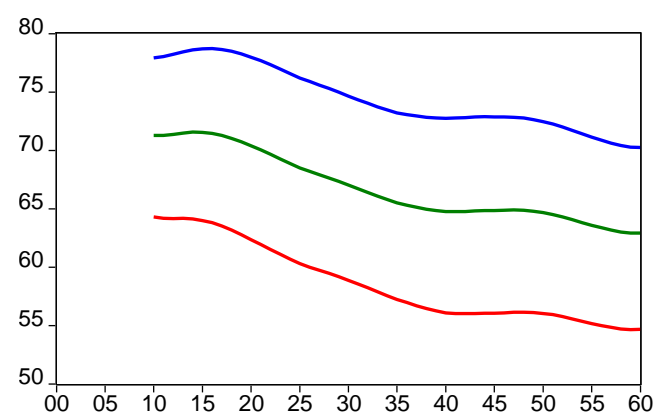

United States

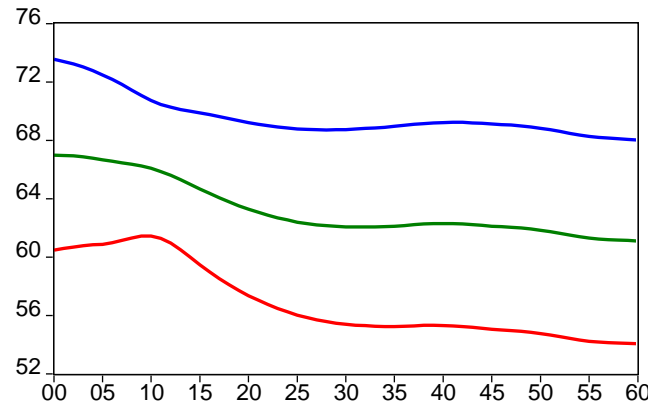

Latvia

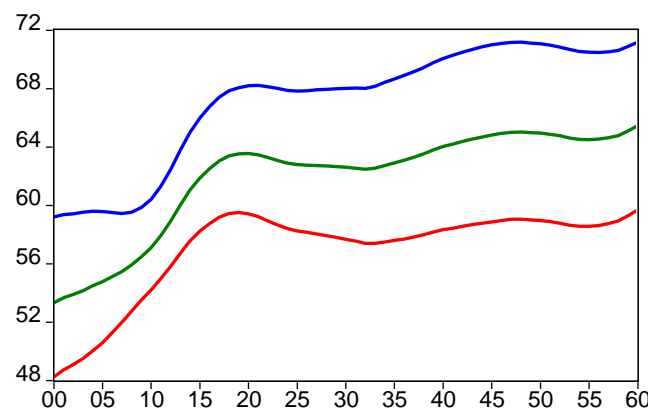

Brazil

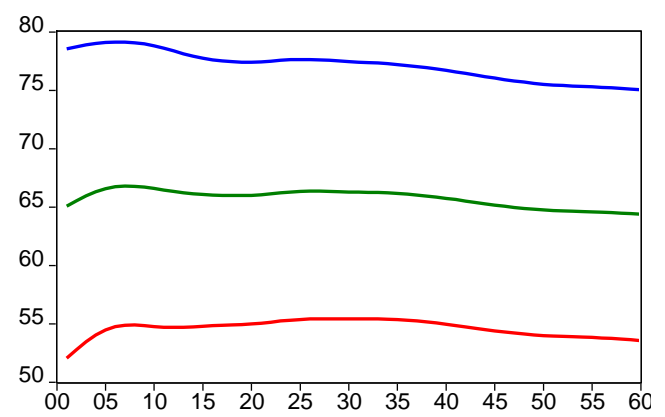

Colombia

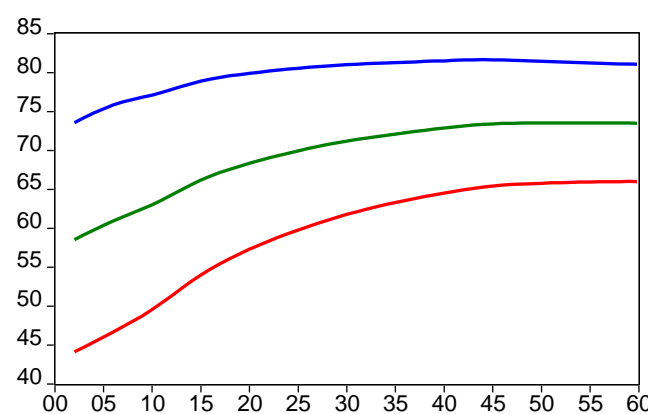

— Men _ Women _ Total 
Figure A2.2. Aggregate employment rates, by sex and total, per cent (contd.)

India

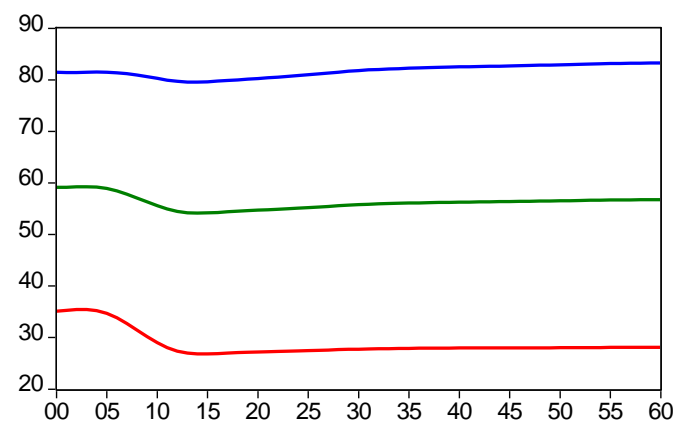

Russia

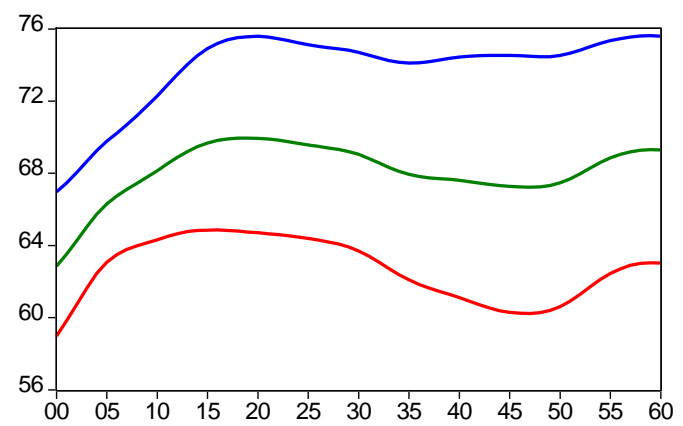

Argentina

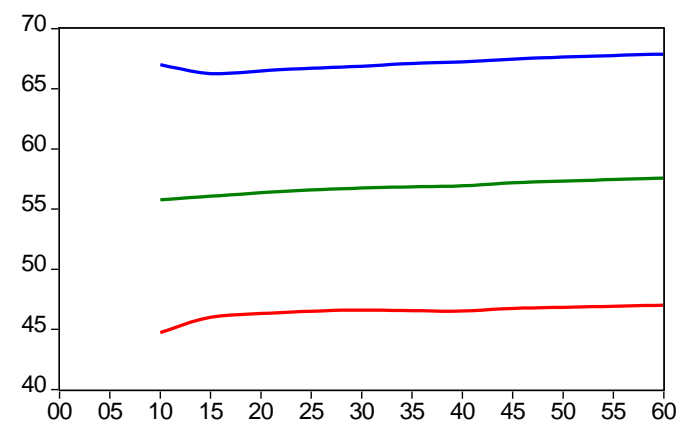

Indonesia

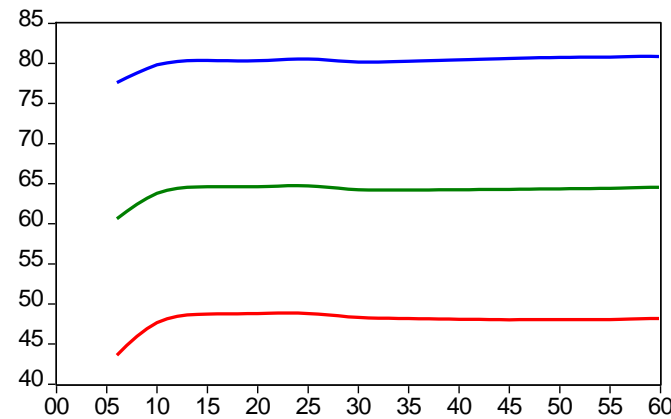

Saudi Arabia

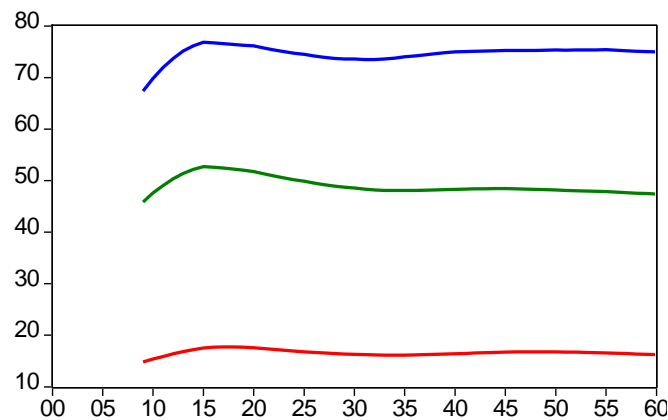

South Africa

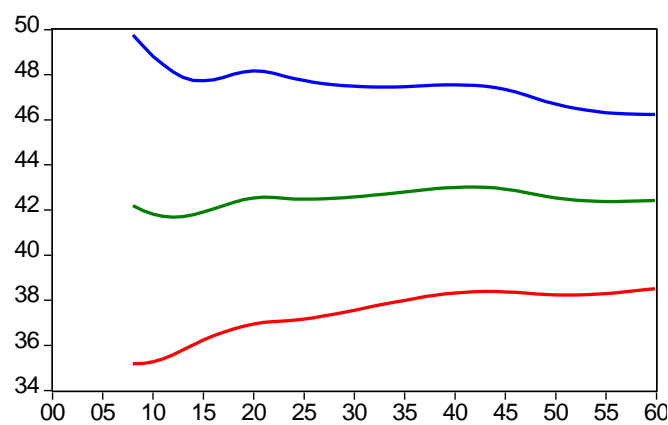

— Men — Women _ Total

Note: The aggregate projected employment rates take into account both cohort effects and projected changes in the age structure of the population, but assume no policy change. China, India, Indonesia, Argentina and Saudi Arabia are exceptions where only projected changes in the population age structure have an influence because age/sex-specific employment rates are constant over the future. 